\title{
HLA antibodies : detection and clinical relevance
}

Citation for published version (APA):

Billen, E. V. A. (2011). HLA antibodies : detection and clinical relevance. [Doctoral Thesis, Maastricht University]. Universitaire Pers Maastricht. https://doi.org/10.26481/dis.20110608eb

Document status and date:

Published: 01/01/2011

DOI:

10.26481/dis.20110608eb

Document Version:

Publisher's PDF, also known as Version of record

\section{Please check the document version of this publication:}

- A submitted manuscript is the version of the article upon submission and before peer-review. There can be important differences between the submitted version and the official published version of record.

People interested in the research are advised to contact the author for the final version of the publication, or visit the DOI to the publisher's website.

- The final author version and the galley proof are versions of the publication after peer review.

- The final published version features the final layout of the paper including the volume, issue and page numbers.

Link to publication

\footnotetext{
General rights rights.

- You may freely distribute the URL identifying the publication in the public portal. please follow below link for the End User Agreement:

www.umlib.nl/taverne-license

Take down policy

If you believe that this document breaches copyright please contact us at:

repository@maastrichtuniversity.nl

providing details and we will investigate your claim.
}

Copyright and moral rights for the publications made accessible in the public portal are retained by the authors and/or other copyright owners and it is a condition of accessing publications that users recognise and abide by the legal requirements associated with these

- Users may download and print one copy of any publication from the public portal for the purpose of private study or research.

- You may not further distribute the material or use it for any profit-making activity or commercial gain

If the publication is distributed under the terms of Article $25 \mathrm{fa}$ of the Dutch Copyright Act, indicated by the "Taverne" license above, 


\section{HLA ANTIBODIES}

\section{DETECTION AND CLINICAL RELEVANCE}


(C) Evy V.A. Billen, Maastricht

Layout: Tiny Wouters

Production: Datawyse | Universitaire Pers Maastricht

ISBN: 978-94-6159-055-8

The printing of this thesis was financially supported by NTV, Sanbio and One Lambda. 


\section{HLA ANTIBODIES}

\section{DETECTION AND CLINICAL RELEVANCE}

\section{PROEFSCHRIFT}

Ter verkrijging van de graad van doctor

aan de Universiteit Maastricht, op gezag van de Rector Magnificus, Prof. mr. G.P.M.F. Mols,

volgens het besluit van het College van Decanen, in het openbaar te verdedigen

op woensdag 8 juni 2011 om 12:00 uur

door

Evy V.A. Billen

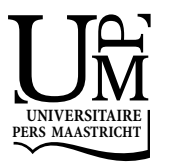




\section{Promotores}

Prof. dr. P.M. van den Berg-Loonen

Prof. dr. M.G.J. Tilanus

\section{Co-Promotor}

Dr. M.H.L. Christiaans

\section{Beoordelingscommissie}

Prof. dr. J.P. van Hooff (voorzitter)

Prof. dr. C.A. Bruggeman

Prof. dr. I.I.N. Doxiadis

Dr. M. Emonds

Prof. dr. L.W.E. van Heurn 
Aan mijn ouders 



\section{Contents}

$\begin{array}{lll}\text { Chapter } 1 & \text { Introduction } & 9\end{array}$

Chapter 2 Detection of HLA antibodies with special emphasis on the 33 Luminex Single antigen assay

Chapter 3 Clinical relevance of pretransplant donor-directed antibodies detected by Single antigen beads in highly sensitized renal transplant recipients

Chapter 4 Only HLA class II donor-specific antibodies appearing more than one year after renal transplantation are related to graft loss

Chapter 5 Donor-directed HLA antibodies before and after transplantectomy detected by the Luminex Single antigen assay

Chapter 6 HLA-DP antibodies before and after renal transplantation

Chapter $7 \quad$ Luminex donor-specific crossmatches 109

Chapter 8 Clinical relevance of Luminex donor-specific crossmatches: data from 165 renal transplants

Chapter 9 General discussion

Summary

Samenvatting

Abbreviations

Dankwoord

Curriculum Vitae 



\section{Chapter 1}

Introduction 



\section{The immune system}

The immune system is a complex cascade of cellular and protein interactions that protects the individual against pathogens. It consists of different types of cells, tissues and molecules that mediate the immune response. The first non-specific line of defence is provided by the innate immune system which includes the epithelial barrier, cells that phagocytize such as neutrophils and macrophages, dendritic cells that capture and present antigens, cells that release inflammatory mediators such as mast cells and natural killer cells $s^{1,2}$. The molecules that are involved in this early immune response are cytokines and plasma proteins such as complement factors and acutephase proteins ${ }^{3}$. The innate immune response also stimulates the second line of defence, the antigen-specific acquired or adaptive immune response ${ }^{4,5}$. Adaptive immune responses are initiated when antigen-receptors on lymphocytes recognize antigen. T-lymphocytes mediate cellular immunity and B-lymphocytes mediate humoral or antibody-mediated immunity. The adaptive immune system has an immunological memory, which implicates that the response to a recurrent infection by the same antigen can be more vigorously.

\section{Cellular immunity}

T-lymphocytes are triggered by antigens produced by intracellular microbes. The T-cell receptor (TCR) on T-lymphocytes recognizes MHC associated peptide antigens presented by antigen-presenting cells (APCs) ${ }^{6}$. Co-stimulatory signals are needed to establish stable TCR-APC contact. CD4 and CD8 co-receptors recognize the MHC, adhesion molecules strengthen the binding and co-stimulators recognize secondary signals provided by the APC. When these secondary signals are not present this will lead to a state of anergy or tolerance ${ }^{7}$. In response to antigen and co-stimulators, T-lymphocytes secrete cytokines such as IL2 which stimulate the T-cell to proliferate and differentiate into effector T-cells. CD4-positive $(+) \mathrm{T}$-cells differentiate into T-helper cells that activate phagocytic cells and stimulate B-lymphocytes ${ }^{8}$. CD8+ T-cells differentiate into cytotoxic T-cells that are able to kill infected cells ${ }^{9}$. At the same time, some T-lymphocytes become memory cells that remain inactive until re-exposure to the antigen ${ }^{10}$.

\section{Humoral immunity}

\section{B-lymphocytes and antibody production}

B-lymphocytes have membrane bound antibodies on their surface that act as B-cell receptors (BCR) for extracellular antigens ${ }^{11}$. The immature B-cell (B1) expresses IgM as $\mathrm{BCR}$ and produces natural IgM antibodies; the antibodies are poly-reactive and recognize carbohydrate antigens of bacterial origin and auto-antigens. In most cases, these natural antibodies have a relative low affinity. Mature but naive B-cells (B2) co- 
express $\operatorname{Ig} M$ and $\operatorname{IgD}$ antibodies as $\mathrm{BCR}$. These antibodies recognize and bind antigens of protein, carbohydrate or lipid origin. Similar as for the TCR, secondary signals are needed, the IgM and IgD receptors only recognize the antigen, the signal transduction to the B-cell is provided by two non-covalently attached proteins, Ig $\alpha$ and $\operatorname{Ig} \beta$. B-cells also have a receptor for a complement protein on their surface that provides the activation signal. Upon activation by antigen, they proliferate in a process called clonal expansion and differentiate into effector plasma cells. When the activating antigen is a protein, B-cells interact with T-helper cells through their CD86 co-stimulatory molecules that subsequently stimulate B-cell proliferation and differentiation ${ }^{12}$. Plasma cells actively secrete IgM and IgD antibodies. During differentiation, a process called heavy chain isotype or class switching takes place, which means that some B-cells start to produce antibodies of a different class that mediate other effector functions ${ }^{13}$. Repeated exposure to the same antigen promotes the affinity and amount of the antibodies produced. A fraction of B2-cells do not differentiate into antibody secreting plasma cells but become B-memory cells that use IgG, IgA or IgE as BCR and are able to respond rapidly when the antigen is encountered again ${ }^{14}$.

\section{Antibody structure}

Antibodies consist of four polypeptide chains, two heavy chains and two light chains that are held together by disulfide bonds. Each chain has a variable $\mathrm{N}$ terminal (V) and a constant $C$ terminal (C). The $V$ regions of the light and heavy chain form the two antigen-binding arms (Fab2) that attach antigen through three hypervariable complementarity-determining regions ${ }^{15}$. The $C$ regions of the heavy chain form the Fc region which specifies the immunoglobuline (Ig) class and subclass. There are five Ig isotypes or classes: IgA, IgD, IgE, IgG and IgM, four subclasses of IgG and two subclasses of IgA. These classes and subclasses differ in physical appearance and function $^{16}$. IgD, IgE and IgG are bivalent monomeric units, IgA is a tetravalent dimer and IgM is a decavalent pentamer. Each type of antibody can be produced as a free circulating molecule or as a membrane-bound $\mathrm{BCR}^{17}$.

\section{Antibody function}

$\operatorname{IgA}$ that is secreted into the gastrointestinal and respiratory tract neutralizes microbes and their toxins. IgD and IgM are the BCR of naieve B-lymphocytes. IgE defends the body against parasites and activates mast cells to provoke immediate hypersensitivity reactions. IgM, IgG1 and IgG3 can activate complement through the classical pathway, which initiates a cascade of events ultimately leading to the formation of a membraneattack complex that lyses infected cells. IgG neutralizes microbes and their toxins, it coats microbes to promote their ingestion by phagocytes in a process called opsonization, it also binds to infected cells which allows NK cells to kill them through antibody-dependent cellular cytotoxicity. Furthermore, IgG is involved in neonatal immunity and feedback inhibition of B-cell activation ${ }^{18}$. 


\section{Human Leukocyte Antigen (HLA) system}

The Human Leukocyte Antigen (HLA) complex is part of the Major Histocompatibility Complex (MHC) and was first described in the 1950's. It was demonstrated that blood transfusions and pregnancies can induce the production of antibodies that reacted with HLA antigens present on human leukocytes ${ }^{19-21}$. It is now known that these HLA molecules are involved in the recognition and presentation of self and foreign antigens ${ }^{22}$. In clinical transplantation, they play an important role in the allo-immune response leading to graft acceptance or graft rejection ${ }^{23}$. The HLA complex is located on the short arm of chromosome $6(6 \mathrm{p} 21)^{24}$ and represents the most polymorphic genes of the human genome. The HLA genes involved in the immune response are divided into HLA class I and class II genes based on structure, expression and function of the molecules they encode. The class III genes are not related to the class I and II genes structurally or functionally, they encode complement factors, heat shock proteins and tumor necrosis factor (Figure 1.1).

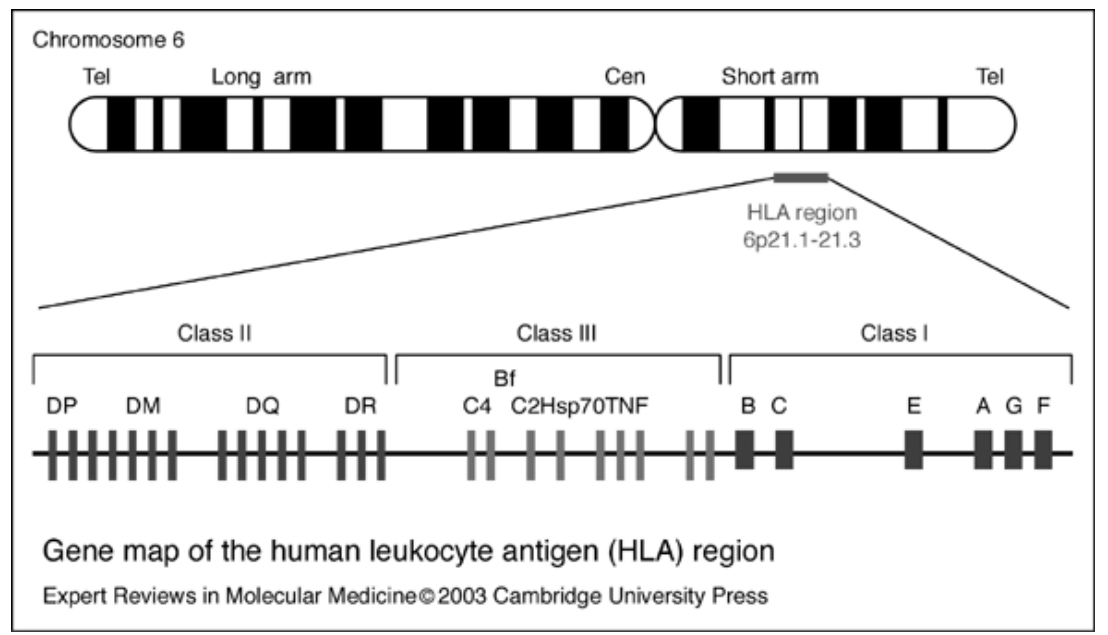

Figure 1.1 Localisation of the HLA complex on chromosome 6.

The HLA complex is located on the short arm of chromosome $6(6 \mathrm{p} 21)^{24}$ and represents the most polymorphic genes of the human genome. The HLA genes involved in the immune response are divided into HLA class I and class II genes based on structure, expression and function of the molecules they encode.

\section{HLA molecules}

HLA class I molecules are encoded by the HLA class I genes, HLA-A, -B and -C. They are expressed on all nucleated cells and on platelets. Class I molecules consist of two polypeptide chains, a membrane-anchored HLA chain and a non-covalently associated 
chain, $\beta_{2}$-microglobulin $\left(\beta_{2} m\right)$. $\beta_{2} m$ is encoded by a non-polymorphic gene located on chromosome 15 and it is required for the formation of a stable class I complex. The HLA chain is composed of three polymorphic extracellular domains, $\alpha 1, \alpha 2$ and $\alpha 3$, which form the peptide binding groove ${ }^{25}$ (Figure 1.2). HLA class I molecules present endogenously synthesized proteins, mostly of viral origin and self proteins, to cytotoxic CD8+ T-cells ${ }^{26}$. The latest WHO nomenclature update described 1001 HLA-A alleles, 1605 HLA-B alleles, 690 HLA-C alleles ${ }^{27}$, (http://www.ebi.ac.uk/imgt/hla/allele.html, release 3.0.0 April 2010).

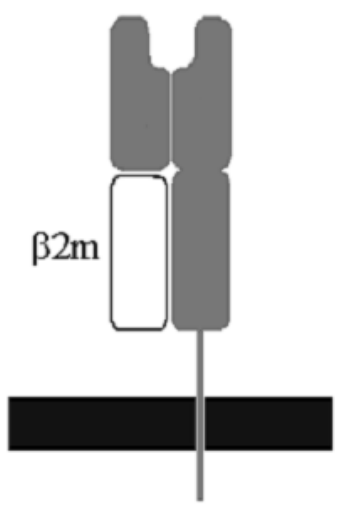

Figure 1.2 Class I molecule.

Class I molecules consist of two polypeptide chains, the membrane-anchored HLA chain and a non-covalently associated chain, $\beta 2-$ microglobulin $(\beta 2 \mathrm{~m})$. The HLA chain is composed of three polymorphic extracellular domains, $\alpha 1, \alpha 2$ and $\alpha 3$, which form the peptide binding groove.

HLA class II molecules are the products of the HLA class II genes, HLA-DR, -DQ and -DP. They are present on the cell surface of professional antigen-presenting cells, like B-lymphocytes, macrophages, dendritic cells and activated T- lymphocytes. They can be upregulated on endothelial cells and renal tubular cells in the presence of stressinduced cytokines. Class II molecules consist of two non-covalently bound transmembrane chains, the $\alpha$ - and $\beta$-chain. Both chains have two extracellular immunoglobulin-like domains, $\alpha 1$ and $\alpha 2$ for the $\alpha$-chain and $\beta 1$ and $\beta 2$ for the $\beta$-chain. The peptide binding groove is formed by the highly polymorphic $\alpha 1$ and $\beta 1$ domains $^{28}$ (Figure 1.3). HLA class II molecules present extracellular proteins to CD4+ T-helper cells.

The physiological function of the HLA molecule is to present self and foreign peptides to lymphocytes and therefore HLA molecules play an important role in the distinction between self and non-self and the proper functioning of the immune system. HLA molecules are highly polymorphic, this means that many different gene variants of 
each locus are present in the human population. This is illustrated by the number of alleles identified for each locus: 878 HLA-DR alleles, 35 HLA-DQA alleles, 108 HLA-DQB alleles, 28 HLA-DPA alleles and 138 HLA-DPB alleles ${ }^{27}$ (http://www.ebi.ac.uk/imgt/hla/ allele.html, release 3.0.0 April 2010). The most polymorphic residues of the HLA molecules are found in or around the peptide binding groove. This polymorphism provides diversity in peptide binding specificity and antigen presentation necessary to overcome infections caused by bacteria, viruses, fungi and parasites.

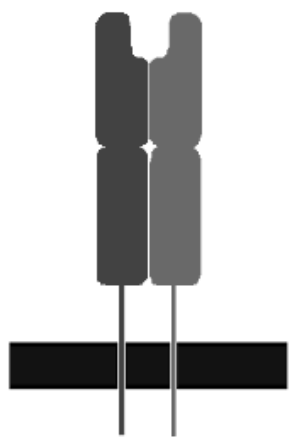

Figure 1.3 Class II molecule.

Class II molecules consist of two non-covalently bound transmembrane chains, the $\alpha$ - and $\beta$ chain. Both chains have two extracellular immunoglobulin-like domains, $\alpha 1$ and $\alpha 2$ for the $\alpha$ chain and $\beta 1$ and $\beta 2$ for the $\beta$-chain. The peptide binding groove is formed by the highly polymorphic $\alpha 1$ and $\beta 1$ domains.

\section{Typing for HLA}

HLA antigens have been defined by serological methods based on complementdependent cytotoxicity (CDC) since 50 years. A variant known as the $\mathrm{NIH}$ microlymphocytotoxitity test was developed and standardised by Terasaki. It has been widely used for HLA typing in clinical transplantation ${ }^{29}$. Serological typing demonstrates the expressed molecule on the cell surface. In the CDC typing assay lymphocytes and antisera of known HLA specificity are incubated. Rabbit complement is then added and activated by the binding of HLA specific antibodies to the surface HLA antigens. As a result, a membrane attack complex is formed that lyses the cell membrane which becomes permeable. When a dye is added thereafter, it penetrates the membrane of the lysed cells, which can now be discriminated from living cells. Although used for many years, the CDC assay has some distinct disadvantages such as labour intensiveness, requirement of viable cells and the lack of available monospecific alloantisera or monoclonal antibodies. 
In the 1980 's, molecular cloning made the identification of gene structures possible. Together with the introduction of the polymerase chain reaction (PCR), this lead to the development of a variety of DNA based typing methods that enable detection of the HLA polymorphism at the genetic level. Several molecular methods were developed to type the HLA genes. The most commonly used techniques are based on PCR: Sequence specific primers (SSP), Sequence specific oligonucleotide probes (SSOP) and Sequence based typing (SBT). In the PCR-SSP method, the target DNA is amplified with primers specific for alleles or groups of alleles. For the PCR-SSOP method, the HLA gene to be typed is amplified and hybridized with probes specific for alleles or allele groups. The SBT technique is based on direct DNA sequencing to determine the nucleotide sequence of the HLA alleles present. It detects all polymorphism in the sequenced part of the gene and therefore enables high resolution typing and identification of new alleles. A more detailed description of these techniques is given $\mathrm{in}^{30}$.

\section{HLA antibodies}

HLA antibodies do not occur naturally. They are produced after contact with foreign HLA antigens. Antibody formation is initiated by the uptake and processing of foreign antigen by antigen-presenting cells that present it to the CD4+ T cell. At the same time, antigen specific B2-cells recognize, bind, internalize and process these antigens through their BCR. Clonal expansion of B-cells is induced when a co-stimulatory signal is present. As a result B-cells will differentiate, secrete IgG and memory B-cells will be developed $^{7}$. The antigenic stimuli leading to HLA antibody formation in recipients are pregnancy $^{21}$, blood transfusion ${ }^{19,31}$ and previous transplants ${ }^{32}$. Recently it has become clear that they sometimes arise in response to HLA-unrelated immune stimulation ${ }^{33,34}$ and that their response is increased by stimuli such as infection ${ }^{35,36}$ or even vaccination $^{37}$.

In about 25 percent of pregnancies, women develop antibodies against paternal antigens present on the foetal cells that enter the maternal circulation ${ }^{38,39}$. The frequency of sensitization increases with the number of pregnancies ${ }^{38}$. The level of immunization may decrease over time, but can also increase and may acquire a wider spectrum after a new antigenic challenge such as blood transfusion or renal transplantation $^{40}$.

Before the introduction of erythropoietin, blood transfusions were frequently given to patients with end-stage renal disease. In the past, they were also given to reduce the allo-immune response to the prospective graft $^{41}$. Before the introduction of calcineurine inhibitors (CNI) as immunosuppressive agent, several studies showed that untransfused patients underwent more rejection episodes and presented with worse graft survival than transfused recipients ${ }^{42,43}$. Clinical studies showed that previously undetected historical anti-HLA antibodies from pregnancies may reappear after blood 
transfusion $^{44}$. Since the introduction of $\mathrm{CNI}$ however, the beneficial effect of pretransplant blood transfusions has become less clear and transfusions are also associated with primary sensitization ${ }^{45}$. Today in the Netherlands, after the results of a multicenter study demonstrated that donor-specific transfusions induce primary sensitization and have no beneficial effect on transplant outcome, donor-specific transfusions to induce tolerance and transfusions given with the intention to detect historical sensitization, are no longer in practice ${ }^{46}$.

The part of the HLA molecule that is recognized by the antibody is called epitope or determinant ${ }^{47}$. Epitopes or determinants can be "public" which means they are shared between HLA alleles, or "private" if they are specific for a certain allele ${ }^{48-50}$. HLA antigens have multiple epitopes that can be recognized by specific antibodies. Originally, epitopes were described on the basis of serological cross-reactivity, i.e. antibodies produced against one particular antigen may bind to other structurally similar antigens. Today, it has been shown that these epitopes correspond to distinct amino acid sequences in the HLA molecules. Epitopes may be recognized based on linear amino acid sequence or based on conformational shapes. Terasaki et al. have empirically identified 103 class I and 83 class II epitopes defined by polymorphic amino acid residues using extensive analyses of antibody reactivity patterns ${ }^{51-55}$. Duquesnoy's HLAMatchmaker-strategy of determining HLA epitopes is based on antibody-antigen complexes. An eplet, i.e. a conformational epitope has a so-called patch of highly energetic residues that determine the strength and specificity of the antibody binding ${ }^{56-61}$. Information about the HLA type of the antibody producer and the immunizing antigen permits the distinction between self and non-self amino acid residues. Each eplet has at least one non-self residue, on the molecular surface. Recently, the correlation between Terasaki's epitopes and HLAMatchmaker-defined eplets has been extensively studied and described ${ }^{62}$. About 90 percent of Terasaki's epitopes correspond to HLA Matchmaker-defined eplets.

\section{HLA and transplantation}

Renal transplantation remains the preferred treatment for suitable patients with endstage renal disease. Organ replacement is preferred over dialysis because it provides patients with a higher quality of life $^{63,64}$ and is associated with lower mortality rates $^{65,66}$. In 2009, 811 patients received a kidney from a living (417) or a deceased (394) donor in the Netherlands ${ }^{67}$.

The relevance of bloodgroup $A B O$ compatibility in renal transplantation had already been recognized by the early 1960's. Another system, the MHC, was discovered and shown to be important in renal transplantation. The first renal transplantation with long-term success (graft and patient survival >1 year) was performed in 1954 by 
Murray $^{68}$. The donor was the monozygotic twin brother of the recipient. By then, it was known that tissues were freely interchangeable between identical twins. Attempts to use unrelated or deceased donors were usually unsuccessful because the allografts were recognised as foreign by the recipient's immune system and were rejected. This situation stimulated the search for immunosuppressive therapy ${ }^{69-71}$. The introduction of immunosuppressive reagents made it possible to transplant patients with a donor other than a monozygotic twin ${ }^{72,73}$. However, rejection rates remained high and side effects of the immunosuppression such as nephrotoxicity, infections, metabolic disorders and cancer, were observed frequently. Further improvement in transplant outcome had to be found in immunological selection of the recipient-donor pairs.

In transplantation, the recognition of the donor's HLA molecules by the recipient's immune system generates a strong response that is a barrier to successful transplantation ${ }^{74,75}$. When a patient receives a renal transplant from a genetically different individual, his immune system comes into contact with foreign HLA antigens present on the donor cells. The subsequent immune response, allorecognition, may cause rejection of the transplant ${ }^{76}$. Presentation of the donor's HLA antigens can take place through two distinctive pathways: direct and indirect allorecognition. In the direct pathway, T-cells recognise intact allo-HLA on the surface of donor antigenpresenting cells. In the indirect pathway, donor-HLA is shed from the graft, which is then processed into allo-peptides presented by the recipients own antigen-presenting cells $^{77,78}$. These two pathways are not sufficient for full activation of the recipient's immune system. A co-stimulatory signal is needed for stabilisation of the cell-cell contact. When this secondary signal is absent this will lead to a state of anergy or tolerance. The effector mechanisms in transplant rejection and the co-stimulatory signals have been reviewed by Rocha et al. ${ }^{7}$.

\section{Transplant rejection}

Recognition of donor-HLA by T-cells and antibodies can lead to graft rejection ${ }^{79-81}$. Rejection is suspected when there is a decrease in renal function. Needle core biopsy is needed to confirm clinical rejection. Based on time of occurrence, not on mechanism, different types of rejection can be discriminated: hyperacute, acute and chronic rejection. Preformed HLA antibodies are deleterious to the renal graft ${ }^{82,83}$. Antibodies produced de novo after renal transplantation are a risk factor for acute and chronic rejection $^{84,85}$.

Preformed donor-specific HLA antibodies cause hyperacute rejection by binding to blood vessels and activating the complement system which initiates a cascade of events leading to coagulation of platelets and immediate circulation blockage and loss of graft function within minutes to hours after reperfusion. Hyperacute rejection is observed in up to $80 \%$ of the kidneys transplanted into recipients with preformed 
donor-specific HLA antibodies detected in the complement-dependent cytotoxicity crossmatch $^{82,86}$.

Acute rejection can occur at any time after transplantation, ranging from days to years. It is most commonly seen within the first three to six months after transplantation. For several decades, T-cells have been regarded to be the central regulatory and effector cells in acute rejection. Consequently, most current immunosuppressive therapies generally target T-cell function. Despite the use of these drugs, episodes of acute rejection can still occur. Recent evidence shows that circulating antibodies and complement deposition are involved in a substantial proportion of these remaining rejection episodes, particularly in those that involve total graft failure ${ }^{87-89}$. The binding of anti-donor antibodies to the endothelium of the graft activates complement, which triggers the recruitement of cellular infiltrates, neutrophils and macrophages in the capillaries. In 1991, transplant clinicians, pathologists, surgeons, immunologists and researchers first participated in a consensus meeting on renal allograft pathology in order to standardize the histological definition of different types of rejection, held in Banff, Canada. Originally, Banff type I acute rejection was defined as a manifestation of cell-mediated immunity, type III as strongly suggestive of an antibody-mediated process and Banff type II as a mixture of both cell- and antibody-mediated immunity. Based on the anatomical target of the immune reaction rejection was subclassified into two major categories: tubular/interstitial rejection and vascular rejection. This socalled Banff classification is regularly updated and redefined on the basis of new developments and evaluation studies, the last update took place in 2009, with special attention to diagnostic markers for antibody-mediated rejection such as circulating donor-specific antibody and C4d staining ${ }^{90,91}$. Antibody-mediated acute rejection, also known as humoral or acute vascular rejection, is often resistant to therapy with steroids or T-cell specific drugs ${ }^{92}$. Both cellular and antibody-mediated acute rejection episodes are more frequent in sensitized patients than in patients without circulating antibodies $^{93}$.

Chronic rejection or chronic allograft nephropathy, more than any other condition, limits the long-term success of renal transplantation. It occurs in a later stage after transplantation and is caused by a number of processes, particularly by repeated inflammation and injury from both immunological and non-immune-mediated reactions. The non-immunological causes for deteriorated graft function and graft loss like drug toxicity, ischemia and aging are extensively reviewed elsewhere ${ }^{94}$. Chronic rejection is histopathologically characterized by obliterative vasculopathy, infiltration of leukocytes and luminal occlusion of the arteries ${ }^{95}$. As mentioned earlier, the chronic immune injury is believed to be caused by indirect presentation of allogeneic peptides by recipient antigen-presenting cells. Many studies on the role of HLA antibody in chronic rejection have been published, albeit without consensus on the frequency. According to Terasaki, up to $60 \%$ of chronic rejections are supposed to be caused by 
donor-specific HLA antibodies ${ }^{96}$. Piazza et al. found that circulating donor-specific HLA antibodies correlate strongly with chronic rejection ${ }^{97}$. Lee et al. described that de novo anti-HLA antibodies are always present before the loss of a graft from chronic rejection ${ }^{98}$. Whether (donor-specific) antibodies actually cause chronic rejection or reflect a response to a damaged graft caused by other factors has yet to be determined.

\section{HLA matching}

Allogeneic donor-HLA can stimulate B cells to produce alloantibodies, which are involved in the humoral immune responses against grafts, therefore the degree of HLA matching between donor and recipient greatly influences transplant outcome ${ }^{99}$. Only grafts from monozygotic twins are successful without immunosuppression. Zero mismatched transplants have a superior outcome than grafts with one or more HLA mismatches (Figure 1.4) ${ }^{100-102}$.

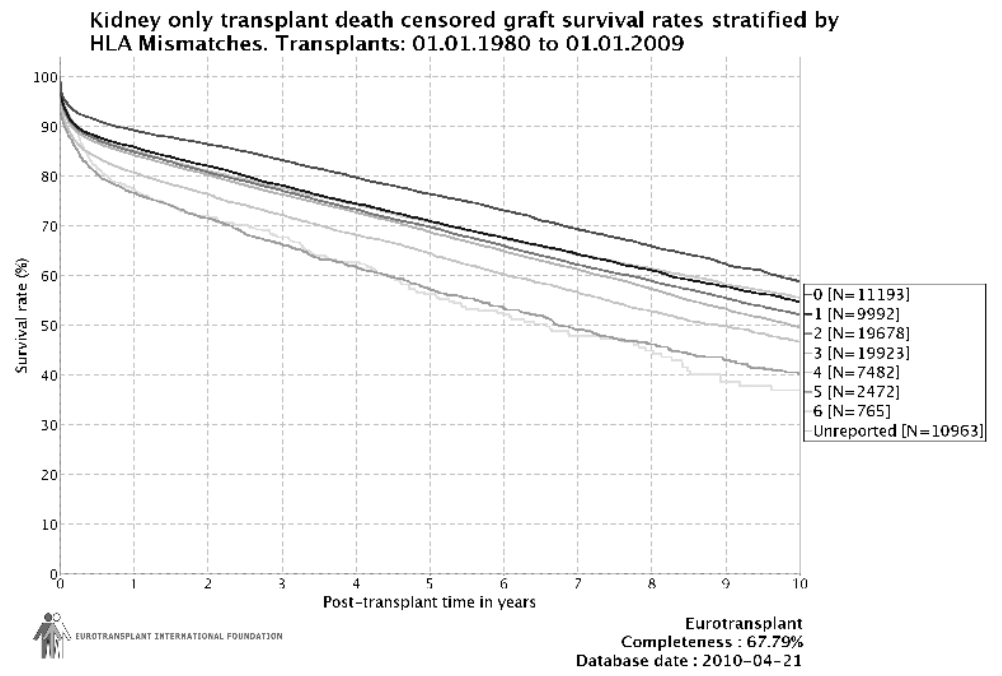

Figure 1.4 The influence of HLA matching on graft survival within eurotransplant.

Allogeneic donor-HLA can stimulate B cells to produce alloantibodies, which are involved in the humoral immune responses against grafts, therefore the degree of HLA matching between donor and recipient greatly influences transplant outcome ${ }^{99}$. Only grafts from monozygotic twins are successful without immunosuppression. Zero mismatched transplants have a superior outcome than grafts with one or more HLA mismatches

Due to the extreme polymorphism of the HLA system, it is not feasible to find an HLA identical donor for all renal transplant recipients. To increase the donorpool and therefore the chance of providing recipients with a suitable donor, Eurotransplant was founded, the first organ exchange organisation in the world. Since then many other 
organisations e.g. Scandiatransplant, France-transplant, UK transplant and UNOS have been founded. Today, 7 countries allocate their organs through Eurotransplant on the basis of several parameters that generate transplantation points, such as degree of HLA match, waiting time, cold ischemia time, and match prognostic index which means that sensitized patients and patients with rare HLA phenotypes receive extra points ${ }^{103}$.

The effect of HLA class I and II mismatches varies over time after transplantation. According to Thorogood et al., the effect of an HLA-DR mismatch is strongest in the first five months following transplantation and therefore is associated with increased risk of acute rejection and early graft loss, whereas HLA-A and HLA-B mismatches are associated with later graft loss ${ }^{104}$.

Traditionally, the degree of HLA compatibility between recipient and donor is determined by counting the number of mismatched HLA-A, -B and -DR antigens of the donor. Another way to asses compatibility is structurally based HLA matching. Based on this concept, Duquesnoy ${ }^{56,58,105,106}$ created HLA Matchmaker, a matching algorithm that views each HLA antigen as a string of short linear sequences (triplets) involving amino acid residues in antibody-accessible positions. These triplets are considered the key elements of epitopes that can induce the formation of specific antibodies. These epitopes have two distinct characteristics, namely antigenicity, its reactivity with antibody, and immunogenicity, its ability to induce an antibody response ${ }^{107}$. The immunogenicity of an epitope depends on the structural difference between the immunizing protein and the antibody responder's homologous proteins. It has been shown that the effect of HLA matching on transplant success varies depending on donor and recipient risk factors. In the USA especially, many clinicians even argue that current immunosuppressive regimens obviate the benefits of HLA matching, therefore HLA-A and $-B$ matching has been eliminated from the UNOS allocation algorithm. Many organizations still find a high correlation between the degree of matching and sensitization particularly after previous graft failure ${ }^{107}$. Therefore a poor HLA match decreases the chance of finding a second crossmatch-negative donor, prolonging waiting times for retransplantation ${ }^{108}$. In our center, minimal matching requirements are set at 1B and 1DR or 2 DR match between donor and recipient. For living donation, matching is less stringent, because of the superior quality of the donor kidney, and patients can be transplanted pre-emptive ${ }^{109-111}$. But even in the case of a living donor, well matched transplants have superior outcome.

\section{Crossmatching}

In 1969 the clinical relevance of preformed cytotoxic antibodies directed against donor lymphocytes was first demonstrated by Patel and Terasaki ${ }^{82}$. In their landmark study, using the complement-dependent cytotoxicity crossmatch (CDCXm) $80 \%$ of recipients transplanted with a positive CDCXm lost their graft due to hyperacute rejection, whereas less than $5 \%$ of recipients with a negative CDCXm had a bad outcome. Since 
then, the CDCXm, with and without DTT to abolish IgM antibodies, has been routinely used to detect preformed donor-specific antibodies and hyperacute rejection has become a rare event in renal transplantation. Within Eurotransplant, the CDCXm is the mandatory crossmatch assay, being the only one generally accepted to be clinically relevant. The fact that in Patel's study, $20 \%$ of the recipients with a positive CDCXm had an uneventful post-transplant course and $5 \%$ of recipienst with a negative CDCXm experienced early graft loss, suggests that the CDCXm is limited in specificity and sensitivity. In order to increase the sensitivity, variations of the standard CDCXm have been used, such as the addition of antiglobulin and wash steps, prolongation of incubation time and modification of incubation temperature. In 1983, the flow cytometry crossmatch (FCXm) was introduced as a more sensitive method for the detection of preformed donor-specific HLA antibodies in renal transplant recipients ${ }^{112}$. The main advantages of this method are increased sensitivity, differentiation between cell types and detection of non-complement-binding antibodies. Many groups reported a higher sensitivity in detecting clinically relevant antibodies, and therefore the FCXm was adopted as the standard crossmatch assay in many transplant centres in the UK and US. In our centre, FCXm was not found to be superior to the standard CDCXm with regard to clinical outcome ${ }^{113}$. In fact, transplantation with a mandatory negative FCXm would have excluded $28 \%$ of the recipients who are presently doing well after transplantation. T- and B-lymphocytes carry many different antigens on their surface, which can bind clinically irrelevant antibodies leading to false positive results. Solid-phase crossmatches that make use of soluble donor-HLA antigens coated to plates have also been investigated ${ }^{114-117}$. These crossmatches have never been used in clinical practice because of technical problems. The clinical relevance of crossmatching techniques with higher sensitivity than the standard CDC crossmatch is still subject of debate. In 2007, a bead-based solid-phase crossmatch was introduced. The technique and its clinical relevance are described in this thesis.

\section{Screening for HLA antibodies}

There is abundant evidence that preformed HLA antibodies have a deleterious effect on renal graft outcome as reflected by increased rejection rates and lower graft survival in sensitized recipients ${ }^{118}$. To prevent positive pretransplant crossmatches, all sera from recipients on the waiting list are tested for the presence and specificity of HLA antibodies. The specificities detected in the serum are then listed as nonacceptable mismatches (NAM). Anti-HLA antibodies are a product of the adaptive immune system which means that they can vary in quality and quantity over time. Therefore recipient serum is tested every three months and after every sensitizing event such as blood transfusion or previous transplant. The degree of sensitization is traditionally defined as percentage of panel reactive antibody (PRA). The traditional definition of PRA is based on the percentage of positive cells of the cell panel used for antibody detection. Patients with a PRA over $5 \%$ are called sensitized, those with a PRA 
that exceeds $85 \%$ highly sensitized. The PRA should ideally be an index of the chance to find a suitable donor with whom the recipient will have a negative crossmatch. Therefore, PRA is better based on the exact antibody specificities detected in the serum combined with the frequency of those antigens in the donor population. The PRA thus calculated is called the virtual PRA and its use is currently more promoted $^{119,120}$.

Most of the HLA antibodies detected in the serum of renal patients are complementbinding IgG (IgG1 and IgG3) antibodies. They have been proven clinically relevant and deleterious to the graft. However, IgG2 and IgG4 HLA antibodies are found in up to $50 \%$ of patients with previous failed grafts ${ }^{121}$. The clinical relevance of these noncomplement-binding antibodies is still unresolved, mainly due to the fact that they are not detected using standard antibody detection techniques ${ }^{122}$. IgM antibodies are usually irrelevant natural or auto-antibodies, but can also be directed against HLA. A recent study showed that $17 \%$ of retransplant candidates have IgM antibodies against HLA and that in $88 \%$ of cases these are directed against donor-HLA antigens ${ }^{123}$. The effect of the IgM antibodies is still a matter of debate, some authors believe they have a protective effect on the graft but a number of case reports show that they can negatively influence graft outcome ${ }^{124-128}$. A beneficial effect on graft survival has been reported for IgA antibodies ${ }^{123,129,130}$. IgA HLA antibodies are found in about $16 \%$ of eluates from explanted renal allografts ${ }^{131}$.

\section{Special allocation programs within Eurotransplant}

The Acceptable Mismatch program was introduced within Eurotransplant to increase the chance of finding a crossmatch-negative donor for highly sensitized recipients with a historical or current CDC-PRA $\geq 85 \%$. For these patients, the HLA antigens are defined towards which the recipient has not made antibodies. These antigens are then entered in the database as Acceptable Mismatches (AM) ${ }^{132-134}$. If an $A B O$ compatible donor becomes available, matching with the combined recipient's own and AM HLA, the graft is mandatory allocated to this patient. Patients enrolled in this program receive the highest priority within the allocation program. Recipients transplanted in the AM program have shorter waiting times and show graft survival that is identical to that of non-sensitized recipients ${ }^{135,136}$.

The Eurotransplant Senior Program (ESP) aims to achieve a more efficient use of kidneys from elderly donors and promotes their transplantation in elderly recipients. ABO compatible kidneys obtained from donors over 65 years of age are allocated to recipients older than 65 years, regardless of HLA matching. Risk factors such as delayed graft function (DGF) and acute rejection (AR) are reduced by only including nonimmunized recipients undergoing their first transplant. Cold ischemia time (CIT) is reduced by preferably allocating these kidneys locally. In this program, waiting time, 
DGF and CIT are reduced. Graft survival is identical and AR rates are only 5 to $10 \%$ higher than kidneys that are allocated with matching requirements ${ }^{137-139}$. Recently, a new research program was introduced, the Eurotransplant Senior DR-compatible Program (ESDP), which aims to allocate older donor kidneys on the basis of the ESP principle in combination with DR-compatibility to further reduce the need for rejection treatment and the accompanying risk of infectious complications. This approach will be validated in a study where paired kidneys will be allocated through ESP and ESPD to recipients receiving a standardized immunosuppressive regimen.

Cross-over transplantation is a variant of living donation for donor-recipients pairs that are $A B O$ and/or antibody (positive crossmatch) incompatible. The donor of the first couple donates his or her kidney to the recipient of the second couple and vice versa $^{140}$.

\section{Aim of thesis}

In the last 40 years, our understanding of sensitization in renal patients, the clinical relevance of HLA antibodies and the available antibody detection techniques have evolved considerably. Recently, the new bead-based antibody detection technology has significantly increased the sensitivity and specificity of HLA antibody detection. Therefore, interpretation has become an important factor in discriminating clinically relevant from non-clinically relevant antibodies detected by this technology.

The aim of this thesis is to study the use of the Luminex Single antigen and Luminex crossmatch assays on antibody profiles of renal transplant patients and to compare their profiles to the ones obtained with standard antibody detection techniques. Results are correlated to clinical outcome. Chapter 1 introduces relevance of HLA and HLA antibodies in renal transplantation by giving an overview of what is known from the literature up to now. In Chapter 2, the different techniques for antibody detection that have been used over the years are described, in particular the Luminex technology. Antibody detection by LSA is compared to the standard CDC assay by testing a large panel of well-known CDC typing sera. In Chapter 3, the clinical relevance of preformed DSA detected by LSA only is studied in a group of highly sensitized recipients transplanted in the AM-program. All recipients were transplanted on the basis of negative CDC crossmatches, their sera had been tested for HLA antibodies by CDC and were now retested with LSA. Chapter 4 describes the appearance, persistence, specificity and effect on graft survival of DSA produced after transplantation. Multiple serum samples of a consecutive cohort of recipients without pre-transplant DSA, at least one year of renal function and a long follow-up period, were tested with LSA. In Chapter 5 DSA appearance in post-transplant sera of 56 recipients who underwent transplantectomy at different time points after 
transplantation was monitored. All recipients were DSA negative before transplantation. Production of DSA, time of appearance and antibody class were analyzed and correlated with matching grade and donor- and patient characteristics. The incidence of HLA-DP antibodies in renal patients before and after transplantation is analyzed in Chapter 6. The epitope-specificity of the donor and the correlation between development of DSA and non-DSA were examined by comparing the HLA-DP types of patient and donor. Chapter 7 reports on the Luminex crossmatch. Pre- and post-transplant sera of 18 patients transplanted between 1997 and 1999 with a negative CDC crossmatch were tested with a new crossmatch technique, the results of which were compared to flow cytometric results obtained for the same donorrecipient combinations and to LSA antibody screening results. In Chapter $\mathbf{8}$, the clinical significance of the Luminex crossmatch is evaluated over a 4-year period in a group of renal transplant recipients, all transplanted on the basis of a negative CDC crossmatch. Luminex crossmatches with the sera of 165 patients drawn at the time of transplantation, were performed and correlated to acute rejection and graft survival. 


\section{References}

1. Whiteside TL, Stanson J, Shurin MR, Ferrone S. Antigen-processing machinery in human dendritic cells: up-regulation by maturation and down-regulation by tumor cells. J Immunol 2004;173:1526-34.

2. Miller JS. The biology of natural killer cells in cancer, infection, and pregnancy. Exp Hematol 2001;29: 1157-68.

3. Walport MJ. Complement. First of two parts. N Engl J Med 2001;344:1058-66.

4. Medzhitov R, Janeway CA Jr. Innate immunity: impact on the adaptive immune response.Innate immunity. N Engl J Med 2000;343:338-44.

6. Garcia KC, Teyton L, Wilson IA. Structural basis of T cell recognition. Annu Rev Immunol 1999;17: 369-97.

7. Rocha PN, Plumb TJ, Crowley SD, Coffman TM. Effector mechanisms in transplant rejection. Immunol Rev 2003;196:51-64.

8. Hahn S, Gehri R, Erb P. Mechanism and biological significance of CD4-mediated cytotoxicity. Immunol Rev 1995;146:57-79.

9. Mosmann TR, Li L, Sad S. Functions of CD8 T-cell subsets secreting different cytokine patterns. Semin Immunol 1997;9:87-92.

10. Dutton RW, Bradley LM, Swain SL.. T cell memory. Annu Rev Immunol 1998;16:201-23.

11. Novotny J, Bruccoleri R, Newell J, Murphy D, Haber E, Karplus M. Molecular anatomy of the antibody binding site. J Biol Chem 1983;258:14433-7.

12. Seliger B, Marincola FM, Ferrone S, Abken H. The complex role of B7 molecules in tumor immunology. Trends Mol Med 2008;14:550-9.

13. Davis MM, Kim SK, Hood L. Immunoglobulin class switching: developmentally regulated DNA rearrangements during differentiation. Cell 1980;22:1-2.

14. Slifka MK, Ahmed R. Long-lived plasma cells: a mechanism for maintaining persistent antibody production. Curr Opin Immunol 1998;10:252-8.

15. Edelman GM. Antibody structure and molecular immunology. Science 1973;180:830-40.

16. Porter RR. Structural studies of immunoglobulins. Science 1973;180:713-6.

17. Wall R, Kuehl M. Biosynthesis and regulation of immunoglobulins. Annu Rev Immunol 1983;1:393-422.

18. Mix E, Goertsches R, Zett UK. Immunoglobulins--basic considerations. J Neurol 2006;253 Suppl 5: v9-17.

19. Dausset J. Leuco-agglutinins IV; leuco-agglutinins and blood transfusion. Vox Sanguinis 1954;4:190-8.

20. Payne R. Leukocyte agglutinins in human sera: correlation between blood transfusions and their development. Arch Intern Med 1957;99:587-606.

21. Rood van JJ, Eernisse JG, Leeuwen van A. Leucocyte antibodies in sera from pregnant women. Nature 1958;181:1735-6.

22. Bodmer WF, Bodmer JG. Evolution and function of the HLA system. Brit Med Bull 1978;34:309-16.

23. McCluskey J, Peh CA. The human leucocyte antigens and clinical medicine: an overview. Rev Immunogenet 1999;1:3-20.

24. Breuning $\mathrm{MH}$, van den Berg-Loonen Em, Bernini LF, Bijlsma JB, van Loghem E, Meera Khan $P$, Nijenhuis LE. Localization of HLA on the short arm of chromosome 6. Hum Genet 1977;37:131-9.

25. Bjorkman PJ, Parham P. Structure, function and diversity of class I major histocompatibility complex molecules. Ann Rev Biochem 1990;59:253-88.

26. Bjorkman PJ, Saper MA, Samraoui B, Bennett WS, Strominger JL, Wiley DC. Structure of the human class I histocompatibility antigen, HLA-A2. Nature 1987;329:506-12.

27. Robinson J, Waller MJ, PArham P, de Groot N, Bontrop R, Kennedy L, Stark P, Marsh SG. IMGT/HLA and IMGT/MHC: sequence databases for the study of the major histocompatibility complex. Nucl Acids Res 2003;31:311-4.

28. Brown JH, Jardetzky TS, Gorga JC, Stern JL, Urban RG, Strominger JL, Wiley DC. Three-dimensional structure of the human class II histocompatibility antigen HLA-DR1. Nature 1993;364:33-9.

29. Terasaki PI, McClelland JD. Microdroplet assay of human serum cytotoxins. Nature 1964;204: 998-1000.

30. Bidwell JL, Navarrete C. Histocompatibility Testing. Histocompatibility Testing. 2000, London: Imperial College Press. 481. 
31. Scornik JC, Ireland JE, Howard RJ, Fennell RS, Pfaff WW. Role of regular and leukocyte-free blood transfusions in the generation of broad sensitization. Transplantation 1984;38:594-5.

32. Thick M, Verbi V, Kennedy L, Welsh K. Sensitization following kidney graft failure and blood transfusion. Transplantation 1984;37:525-6.

33. Alberú J, Morales-Buenrastro LE, de Leo C, Vargas-Rojas MI, Marino-Vazquez LA, Crispin JC. A nonallogeneic stimulus triggers the production of de novo HLA antibodies in healthy adults. Transplant Immunol 2007; 18:166-71.

34. Morales-Buenrostro LE, Terasaki PI, Marino-Vazquez LA, Lee JH, El-Awar, Alberu JN. "Natural" human leukocyte antigen antibodies found in nonalloimmunized healthy males. Transplantation 2008;86: 1111-5.

35. Locke JE, Zachary AA, Warren DS, Segev DL, Houp JA, Montgomery RA, Leffell MS. Proinflammatory events are associated with significant increases in breadth and strength of HLA-specific antibody. Am J Transplant 2009;9:2136-9.

36. Candon S, Thervet E, Lebon P, Suberbielle C, Zuber J, Lima C, Charron D, Legendre C, Chatenoud L. Humoral and cellular immune responses after influenza vaccination in kidney transplant recipients. Am J Transplant 2009;9:2346-54.

37. Danziger-Isakov L, cherkassky L, Siegel H, McManamon M, Kramer K, Budev M, Sawinski D, Augustinne JJ, Hricik DE, Fairchild R, Hugers PS, Poggio ED. Effects of influenza immunization on humoral and cellular alloreactivity in humans. Transplantation 2010;89:838-44.

38. Rebibou J-M, Chabod J, Alcalay D, Coussediere MC, Deteix P, Touchard G, Dupont J, Thevenin C, Chalopin J, Thiberghien P. Flow cytometric evaluation of pregnancy-induced anti-HLA immunization and blood transfusion-induced reactivation. Transplantation 2002;74:537-40.

39. Bouma GJ, van Cauwenberg P, van Bree SP, Castelli-Visser RM, Witvliet MD, van der Meer-Prins EM, van Rood JJ, Class FH. Pregnancy can induce priming of cytotoxic T lymphocytes specific for paternal HLA antigens that is associated with antibody formation. Transplantation 1996;62:672-8.

40. Masson D, Bayle F, Vichier C, Zaoui P, Bensa JC. Anti-HLA Class I Reiimunization After One HLA SemiIdentical Blood Transfusion in Non-Naive Patients on a Waiting List for a First Renal Allograft. Transplant Proc 1998;30:2854.

41. Opelz G, Rood van JJ. Mechanisms responsible for the blood transfusion effect. Transplant Proc 1983; 15:1520-1.

42. Hooff van JP, Kalff MW, Poelgeest van $A E$, Blood transfusions and kidney transplantation. Transplantation 1976;22:306-7.

43. Opelz G, Sengar DP, Mickey MR, Terasaki PI. Effect of blood transfusions on subsequent kidney transplants. Transplant Proc 1973;5:253-9.

44. Bayle F, Masson D, Zaoui P, Vialtel P, Janbon B, Bensa JC, Cordonnier DJ. Beneficial effect of one HLA haplo- or semi-identical transfusion versus three untyped blood units on alloimmuniztion and acute rejection episodes in first renal allograft recipients. Transplantation 1995;59:719-23.

45. Marti H-P, Henschkowski J, Lauw G, Vogt B, Suler C, Opelz G, Frey PJ. Effect of donor-specific transfusions on the outcome of renal allografts in the cyclosporine era. Transpl Int 2006;19:19-26.

46. Aalten J, Bemelman FJ, van den Berg-Loonen EM, Claas FH, Christiaans MH, de Fijter JW, Hepkema BG, Hene RJ, van der Heide JJ, van Hooff JP, Lardy NM, Lems SP, Otten HG, Weimar W, Allebes WA, Hoitsma AJ. Pre-kidney-transplant blood transfusions do not improve transplantation outcome: a Dutch national study. Nephrol Dial Transplant 2009;24:2559-66.

47. Lee PC, Lee PH, Shaw CK, Takemoto SK, Gjertson DW, Sialew PA, Terasaki PI. HLA epitopes for kidney allocation. Transplant Proc 1998;30:3496-7.

48. Rodey GE, Fuller TC. Public epitopes and the antigenic structure of the HLA molecules. Crit Rev Immunol 1987; 7:229-67.

49. McKenna RM, Lee KR, Gough JC, Jeffery JR, Grimm PC, Rush DN, Nickerson P. Matching for private or public HLA epitopes reduces acute rejection episodes and improves two-year renal allograft function. Transplantation 1998;66:38-43.

50. Piazza A, Poggi E, Ozzella G, Borrelli L, Monaco PI, Scornajenghi A, Tisone G, Adorno D. Public epitope specificity of HLA class I antibodies induced by a failed kidney transplant: alloantibody characterization by flow cytometric techniques. Transplantation 2006;81:1298-305.

51. El-Awar N, Lee JH, Tarsitani C, Terasaki PI. HLA class I epitopes: recognition of binding sites by mAbs or eluted alloantibody confirmed with single recombinant antigens. Hum Immunol 2007;68: 170-80. 
52. El-Awar NR, Akaza T, Terasaki PI, Nguyen A. Human leukocyte antigen class I epitopes: update to 103 total epitopes, including the $C$ locus. Transplantation 2007;84:532-40.

53. El-Awar N, Terasaki PI, Nguyen A, Sasaki N, Morales-Buenrostro LE, Saji H, Maruya E, Poli F., Epitopes of human leukocyte antigen class I antibodies found in sera of normal healthy males and cord blood. Hum Immunol 2009;70: 844-53.

54. Mao Q, Terasaki PI, Cai J, El-Awar N, Rebellato L. Analysis of HLA class I specific antibodies in patients with failed allografts. Transplantation 2007;83:54-61.

55. Sasaki N, Idica A, Terasaki PI. Mimetic human leukocyte antigen epitopes: shown by monoclonal antibodies and extra antibodies produced on transplantation. Transplantation 2008;86:912-8.

56. Duquesnoy R. A structurally based approach to determine HLA compatibility at the humoral immune level. Hum Immunol 2006;67:847-62.

57. Duquesnoy RJ, Mulder A, Askar M, Fernandez-Vina M, Claas FH. HLAMatchmaker-based analysis of human monoclonal antibody reactivity demonstrates the importance of an additional contact site for specific recognition of triplet-defined epitopes. Hum Immunol 2005;66:749-61.

58. Duquesnoy RJ, Marrari M. HLA matchmaker: a molecularly based algorithm for histocompatibility determination. II. Verification of the algorithm and determination of the relative immunogenicity of amino acid triplet-defined epitopes. Hum Immunol 2002;63:353-63.

59. Giebel S, Locatelli F, Lamparelli T, Velardi A, Davies S, Frumento G, Maccario R, Bonetti F, Wojnar J, Martinetti M, Frassoni F, Giorgiani G, Bacigalupo A, Holowiecki J. Survival advantage with KIR ligand incompatibility in hematopoietic stem cell transplantation from unrelated donors. Blood 2003;102: 814-9.

60. Adeyi OA, Girnita AL, Howe J, Marrari M, Awadalla Y, Askar M, Martell J, Zeevi A, Shapiro R, Nalesnik $M$, Randhawa $P$, Demetris AJ, Duquesnoy RJ. Serum analysis after transplant nephrectomy reveals restricted antibody specificity patterns against structurally defined HLA class I mismatches. Transplant Immunol 2005;14: 53-62.

61. Duquesnoy RJ, Marrari M. HLAMatchmaker-based definition of structural human leukocyte antigen epitopes detected by alloantibodies. Curr Opin Organ Transplant 2009;14:403-9.

62. Duquesnoy RJ, Marrari M. Correlations between Terasaki's HLA class I epitopes and HLAMatchmakerdefined eplets on HLA-A, -B and -C antigens. Tissue Antigens 2009;74:117-33.

63. Waiser J, Budde K, Schreiber M, Peibst O, Koch U, Böhler T, Höffken B, Hauser I, Neumayer HH. The quality of life in end stage renal disease care. Transpl Int 1998;11 Suppl 1:S42-5.

64. Evans RW, Manninen DL, Garrison LP Jr, Hart LG, Blagg CR, Gutman RA, Hull AR, Lowrie EG. The quality of life of patients with end-stage renal disease. N Engl J Med 1985;312:553-9.

65. Schnuelle $\mathrm{P}$, Lorenz D, Trede M, Van Der Woude FJ. Impact of renal cadaveric transplantation on survival in end-stage renal failure: evidence for reduced mortality risk compared with hemodialysis during long-term follow-up. J Am Soc Nephrol 1998;9: 2135-41.

66. Wolfe RA, Ashby VB, Milford EL, Ojo AO, Ettenger RE, Agodoa LY, Held PJ, Port FK. Comparison of mortality in all patients on dialysis, patients on dialysis awaiting transplantation, and recipients of a first cadaveric transplant. N Engl J Med 1999;341:1725-30.

67. Eurotransplant, Transplants in 2008, by transplant country. Eurotransplant Annual Report $2008 ; 34$.

68. Merrill JP, Murray JE, Harrison JH, Guild WR. Successful homotransplantation of the human kidney between identical twins. J Am Med Assoc 1956;160:277-82.

69. Starzl TE, Barker C. The origin of clinical organ transplantation revisited. JAMA 2009;301:2041-3.

70. Barry JM, Murray JE. The first human renal transplants. J Urol 2006;176:888-90.

71. Murray JE, Merrill JP, Harrison JH. Renal homotransplantation in identical twins. 1955. J Am Soc Nephrol 2001;12:201-4.

72. Schwartz R, Dameshek W. The effects of 6-mercaptopurine on homograft reactions. J Clin Invest 1960; 39:952-8.

73. Starzl TE, Marchioro TL, Holmes JH, Hermann G, Brittain RS, Stonington OH, Talmage DW, Waddell WR. Renal Homografts in Patients with Major Donor-Recipient Blood Group Incompatibilities. Surgery 1964;55:195-200.

74. Kim IK, Bedi DS, Denecke C, Ge X, Tullius SG. Impact of innate and adaptive immunity on rejection and tolerance. Transplantation 2008;86: 889-94.

75. LaRosa DF, Rahman AH, Turka LA. The innate immune system in allograft rejection and tolerance. J Immunol 2007;178:7503-9. 
76. Afzali B, Lechler RI, Hernandez-Fuentes MP. Allorecognition and the alloresponse: clinical implications. Tissue Antigens 2007;69:545-56.

77. Sayegh $\mathrm{MH}$. Why do we reject a graft? Role of indirect allorecognition in graft rejection. Kidney Int 1999;56:1967-79.

78. Waanders MM, Heidt S, Koekkoek KM, Zoet YM, Doxiadis II, Amir A, Heemskerk MH, Mulder A, Brand A, Roelen DL, Claas FH. Monitoring of indirect allorecognition: wishful thinking or solid data? Tissue Antigens 2008;71:1-15.

79. Whitelegg A, Barber LD. The structural basis of T-cell allorecognition. Tissue Antigens 2004;63:101-8.

80. Halloran PF. T Cell-mediated Rejection of Kidney Transplants: A Personal Viewpoint. Am J Transplant 2010;10:1-9.

81. Vongwiwatana A, Tasanarong A, Hidalgo LG, Halloran PF. The role of B cells and alloantibody in the host response to human organ allografts. Immunol Rev 2003;196:197-218.

82. Patel R, Terasaki PI. Significance of the positive crossmatch test in kidney transplantation. N Engl J Med 1969;280:735-9.

83. Cecka JM, Zhang Q, Reed EF. Preformed cytotoxic antibodies in potential allograft recipients: recent data. Hum Immunol 2005;66:343-9.

84. Terasaki P, Lachmann N, Cai J. Chapter 39. Summary of the Effect of de novo HLA antibodies on chronic kidney graft failure, in Clinical Transplants, Terasaki PI, Editor, 2006, Los Angeles:455-62.

85. McKenna RM, Takemoto SK, Terasaki PI. Anti-HLA antibodies after solid organ transplantation. Transplantation 2000;69:319-26.

86. Kissmeyer-Nielsen F, Olsen S, Petersen VP, Fjeldborg O. Hyperacute rejection of kidney allografts, associated with pre-existing humoral antibodies against donor cells. The Lancet 1966;288:662-5.

87. Crespo M, Pascual M, Tolkoff-Rubin N, Mauiyyedi S, Collins AB, Fitzpatrick D, Farrell ML, Williams WW, Delmonico FL, Cosimi AB, Colvin RB, Saidman SL. Acute humoral rejection in renal allograft recipients: I. Incidence, serology and clinical characteristics. Transplantation 2001;71:652-8.

88. Mauiyyedi S, Crespo M, Collins AB, Schneeberger EE, Pascual MA, Saidman SL, Tolkoff-Rubin NE, Williams WW, Delmonico FL, Cosimi AB, Colvin RB. Acute humoral rejection in kidney transplantation: II. Morphology, immunopathology, and pathologic classification. J Am Soc Nephrol 2002;13:779-87.

89. Mauiyyedi S, Colvin RB. Humoral rejection in kidney transplantation: new concepts in diagnosis and treatment. Curr Opin Nephrol Hypertens 2002;11:609-18.

90. Sis B, Mengel M, Haas M, Colvin RB, Halloran PF, Racusen LC, Solez K, Baldwin WM 3rd, Bracamonte ER, Broecker V, Cosio F, Demetris AJ, Drachenberg C, Einecke G, Gloor J, Glotz D, Kraus E, Legendre C, Liapis H, Mannon RB, Nankivell BJ, Nickeleit V, Papadimitriou JC, Randhawa P, Regele H, Renaudin K, Rodriguez ER, Seron D, Seshan S, Suthanthiran M, Wasowska BA, Zachary A, Zeevi A. Banff '09 Meeting Report: Antibody Mediated Graft Deterioration and Implementation of Banff Working Groups. Am J Transplant 2010;9:1-8.

91. Solez K, Colvin RB, Racusen LC, Haas M, Sis B, Mengel M, Halloran PF, Baldwin W, Banfi G, Collins AB, Cosio F, David DS, Drachenberg C, Einecke G, Fogo AB, Gibson IW, Glotz D, Iskandar SS, Kraus E, Lerut E, Mannon RB, Mihatsch M, Nankivell BJ, Nickeleit V, Papadimitriou JC, Randhawa P, Regele H, Renaudin K, Roberts I, Seron D, Smith RN, Valente M. Banff 07 classification of renal allograft pathology: updates and future directions. Am J Transplant 2008;8:753-60.

92. Baldwin WM, Valujskikh A, Fairchild RL. Antibody-Mediated Rejection: Emergence of Animal Models to Answer Clinical Questions. Am J Transplant 2010;10:108.

93. Terasaki PI, Mizutani K. Antibody mediated rejection: update 2006. Clin J Am Soc Nephrol 2006;1: 400-3.

94. Pratschke J, Weiss S, Neuhaus $P$, Pascher A. Review of nonimmunological causes for deteriorated graft function and graft loss after transplantation. Transpl Int 2008;21: 512-22.

95. Fletcher JT, Nankivell BJ, Alexander SI. Chronic allograft nephropathy. Pediatr Nephrol 2009;24: 1465-71.

96. Terasaki PI, Cai J. Human leukocyte antigen antibodies and chronic rejection: from association to causation. Transplantation 2008;86:377-83.

97. Piazza A, Poggi E, Borrelli L, Servetti S, Monaco PI, Buonomo O, Valeri M, Torlone N, Adorno D, Casciani CU. Impact of donor-specific antibodies on chronic rejection occurrence and graft loss in renal transplantation: posttransplant analysis using flow cytometric techniques. Transplantation 2001;71: 1106-12. 
98. Lee PC, Terasaki PI, Takemoto SK, Lee PH, Hung CJ, Chen YL, Tsai A, Lei HY. All chronic rejection failures of kidney transplants were preceded by the development of HLA antibodies. Transplantation 2002;74: 1192-4.

99. Takemoto S, Port FK, Claas FH, Duquesnoy RJ. HLA matching for kidney transplantation. Hum Immunol 2004;65:1489-505.

100. Opelz G, Döhler B. Effect of human leukocyte antigen compatibility on kidney graft survival: comparative analysis of two decades. Transplantation 2007;84:137-43.

101. Opelz G, Wujciak T, Döhler B. Is HLA matching worth the effort? Transplant Proc 1999;1:717-20.

102. Opelz G, Wujciak T, Mytilineos J, Scherer S. Revisiting HLA matching for kidney transplantation. Transplant Proc 1993;25:173-5.

103. Claas FH, Doxiadis II. Human leukocyte antigen antibody detection and kidney allocation within Eurotransplant. Hum Immunol 2009;70:636-9.

104. Thorogood J, Persijn GG, Schreuder GM, D'Amaro J, Zantvoort FA, van Houwelingen JC, van Rood JJ. The effect of HLA matching on kidney graft survival in separate posttransplantation intervals. Transplantation 1990;50:146-50.

105. Duquesnoy RJ. HLA matchmaker: a molecularly based algorithm for histocompatibility determination. I. Description of the algorithm. Hum Immunol 2002;63:339-52.

106. Duquesnoy RJ, Askar M. HLA matchmaker: a molecularly based algorithm for histocompatibility determination. V. Eplet matching for HLA-DR, HLA-DQ, and HLA-DP. Hum Immunol 2007;68:12-25.

107. Dankers MK, Witvliet MD, Roelen DL, de Lange P, Korfage N, Persijn GG, Duquesnoy R, Doxiadis II, Claas FH. The number of amino acid triplet differences between patient and donor is predictive for the antibody reactivity against mismatched human leukocyte antigens. Transplantation 2004;77:1236-9.

108. Meier-Kriesche HU, Scornik JC, Susskind B, Rehman S, Schold JD. A lifetime versus a graft life approach redefines the importance of HLA matching in kidney transplant patients. Transplantation 2009;88: 23-9.

109. Terasaki PI, Cecka JM, Gjertson DW, Takemoto S. High survival rates of kidney transplants from spousal and living unrelated donors. N Engl J Med 1995;333: 333-6.

110. Opelz G. Impact of HLA compatibility on survival of kidney transplants from unrelated live donors. Transplantation 1998;64:1473-5.

111. Opelz G. HLA compatability and kidney grafts from unrelated live donors. Transplant Proc 1998;30: 704-5.

112. Garovoy MR. Flow cytometry crossmatch testing in renal transplantation. Transpl Immunol 1988;5:1.

113. Christiaans $M H$, Overhof $R$, ten Haaft $A$, Nieman F, van Hooff JP, van den Berg-Loonen EM. No advantage of flow cytometry crossmatch over complement-dependent cytotoxicity in immunologically well-documented renal allograft recipients. Transplantation 1996;62:1341-7.

114. Buelow R, Chiang TR, Monteiro F, Cornejo MC, Ellingson L, Claas F, Gaber O, Gelder F, Kotb M, Orosz C. Soluble HLA antigens and Elisa - a new technology for crossmatch testing. Transplantation 1995;60: 1594-9.

115. Pelletier RP, Adams PW, Hennessy PK, Orosz CG. Comparison of crossmatch results obtained by ELISA, flow cytometry, and conventional methodologies. Hum Immunol 1999;60:855-61.

116. Hennessy PK. ELISA vs flow cytometry for pre-transplant donor reactive crossmatches. Hum Immunol 2001;62(suppl 1):136.

117. Book BK, Agarwal A, Milgrom AB, Bearden CM, Sidner RA, Higgins NG, Pescovitz MD. New crossmatch technique eliminates interference by humanized and chimeric monoclonal antibodies. Transpl Proc 2005;37:640-2.

118. Terasaki PI. Humoral theory of transplantation. Am J Transplant 2003;3:665-73.

119. Amico P, Hönger G, Steiger J, Schaub S. Utility of the virtual crossmatch in solid organ transplantation. Curr Opin Organ Transplant 2009;14:656-61.

120. Cecka JM. Calculated PRA (CPRA): the new measure of sensitization for transplant candidates. Am J Transplant 2010;10:26-9.

121. Arnold ML, Zacher T, Dechant M, Kalden JR, Doxiadis II, Spriewald BM. Detection and specification of noncomplement binding anti-HLA alloantibodies. Hum Immunol 2004;65:1288-96.

122. Karuppan SS, Ohlman S, Möller E. The occurrence of cytotoxic and non-complement-fixing antibodies in the crossmatch serum of patients with early acute rejection episodes. Transplantation 1992;54: 839-43. 
123. Arnold ML, Dechant M, Doxiadis II, Spriewald BM. Prevalence and specificity of immunoglobulin $G$ and immunoglobulin A non-complement-binding anti-HLA alloantibodies in retransplant candidates. Tissue Antigens 2008;72:60-6.

124. McCalmon RT Jr, Tardif GN, Sheehan MA, Fitting K, Kortz W, Kam I. IgM antibodies in renal transplantation. Clin Transplant 1997;11:558-64.

125. Suzuki M, Ishida $H$, Komatsu T, Kennoki T, Ishizuka T, Tanabe K. Kidney transplantation in a recipient with anti-HLA antibody IgM positive. Transpl Immunol 2009;21:150-4.

126. Spees E, McCalmon R. Successful kidney transplantation with a positive IgM crossmatch. Transplant Proc 1990;22:1887-8.

127. Tardif GN, McCalmon RT Jr. Successful renal transplantation in the presence of donor specific HLA IgM antibodies. Transplant Proc 1995;27:664-5.

128. Khan N, Robson AJ, Worthington JE, Martin S. The detection and definition of IgM alloantibodies in the presence of IgM autoantibodies using flowPRA beads. Hum Immunol 2003;64: 593-9.

129. Koka P, Chia D, Terasaki PI, Chan H, Chia J, Ozawa M, Lim E. The role of IgA anti-HLA class I antibodies in kidney transplant survival. Transplantation 1993;56:207-11.

130. Susskind BM, Kerman RH, Browne BJ, Hartwell BA, Davis BG, Katz SM, Van Buren CT, Kahan BD. The impact of elevated serum IgA and race on primary recipient renal allograft survival. Transplantation 1996;61:205-11.

131. Heinemann FM, Roth I, Rebmann V, Arnold ML, Witzke O, Wilde B, Spriewald BM, Grosse-Wilde H. Immunoglobulin isotype-specific characterization of anti-human leukocyte antigen antibodies eluted from explanted renal allografts. Hum Immunol 2007;68:500-6.

132. van Rood JJ, Lagaaij EL, Doxiadis I, Roelen D, Persijn G, Claas F. Permissible mismatches, acceptable mismatches, and tolerance: new trends in decision making, in Clinical Transplants, T.a. Cecka, Editor. 1993, Los Angeles, California: 285-292.

133. Duquesnoy RJ, Witvliet M, Doxiadis II, de Fijter H, Claas FH. HLAMatchmaker-based strategy to identify acceptable HLA class I mismatches for highly sensitized kidney transplant candidates. Transpl Int 2004; $17: 22-30$.

134. Goodman RS, Taylor CJ, O'Rourke CM, Lynch A, Bradley JA, Key T. Utility of HLAMatchmaker and singleantigen HLA-antibody detection beads for identification of acceptable mismatches in highly sensitized patients awaiting kidney transplantation. Transplantation 2006;81:1331-6.

135. Claas FH, Witvliet MD, Duquesnoy RJ, Persijn GG, Doxiadis II. The acceptable mismatch program as a fast tool for highly sensitized patients awaiting a cadaveric kidney transplantation: short waiting time and excellent graft outcome. Transplantation 2004;78:190-3.

136. Claas FH, Rahmel A, Doxiadis II. Enhanced kidney allocation to highly sensitized patients by the acceptable mismatch program. Transplantation 2009;88:447-52.

137. Frei U, Noeldeke J, Machold-Fabrizii V, Arbogast H, Margreiter R, Fricke L, Voiculescu A, Kliem V, Ebel H, Albert U, Lopau K, Schnuelle P, Nonnast-Daniel B, Pietruck F, Offermann R, Persijn G, Bernasconi C. Prospective age-matching in elderly kidney transplant recipients - A 5-year analysis of the Eurotransplant senior program. Am J Transplant 2007;7:1-8.

138. Smits JM, Persijn GG, van Houwelingen HC, Claas FH, Frei U. Evaluation of the Eurotransplant senior program. The results of the first year. Am J Transplant 2002;2:664-70.

139. de Fijter JW, Mallat MJ, Doxiadis II, Ringers J, Rosendaal FR, Claas FH, Paul LC. Increased immunogenicity and cause of graft loss of old donor kidneys. J Am Soc Nephrol 2001;12:1538-46.

140. de Klerk M, Keizer KM, Claas FH, Witvliet M, Haase-Kromwijk BJ, Weimar W. The Dutch national living donor kidney exchange program. Am J Transplant 2005;5:2302-5. 



\section{Chapter 2}

Detection of HLA antibodies with special emphasis on the Luminex Single antigen assay 



\section{Complement-dependent cytotoxicity test}

For over 40 years the complement-dependent cytotoxicity assay (CDC) has been the standard HLA antibody detection assay. Patient serum is incubated with cells of a selected HLA-typed panel to allow the formation of immune complexes. Subsequently rabbit complement is added, that binds to the immune complexes. The formation of a membrane-attack complex is induced, that lyses the cell membrane. Lysed cells are stained using a fluorescent dye. Positive and negative reactions are discriminated using an inverted microscope ${ }^{1,2}$. The reaction pattern shows the specificity of the antibodies present in the serum, using the best correlation of positive reactions with the HLA antigens of the panel cells. The results are expressed as a panel reactive antibody (PRA) value, defined as the percentage of cells in the panel to which the serum reacts. The composition of the cell panel is crucial, it has to take into account cross-reactivity and linkage disequilibrium of the HLA system. The size of the panel is usually 50-60 selected cells with HLA types that include most common and some rare alleles. The distribution of alleles in the cell panel should reflect the frequencies of these alleles in the local patient and donor population.

The detection and assignment of class I antibodies is generally trouble free in patients with low PRA values, in contrast to the assignment in highly sensitized recipients. Class II antibodies are far more difficult to detect, because the class II antigens are expressed on B-lymphocytes, which represent only 10 to $15 \%$ of the peripheral blood cells. Modifications in cell concentration and incubation time partly surpass this shortcoming ${ }^{3}$. The fact that B-lymphocytes present with both class I and II HLA antigens on their surface is another reason for the more complicated detection of class II antibodies ${ }^{4-6}$.

The CDC assay detects complement-binding IgG and IgM antibodies. Most HLA antibodies are IgG, while IgM antibodies are usually but not exclusively autoantibodies. The clinical role of IgM HLA antibodies is doubtful, therefore sera are pretreated with dithiothreitol (DTT) to abolish the IgM antibodies in the serum. DTT disrupts the sulphide-bonds of the IgM molecules, thereby degrading the antibodies ${ }^{7,8}$. Modifications to increase sensitivity and allow identification of non complementbinding IgG and low titered antibodies have been proposed. Extended incubation times, that permit binding of low-avidity antibodies, wash steps that remove lowaffinity antibodies and inhibitory factors and addition of anti-human globulin (AHG), that allows detection of low-level or non-complement-binding antibodies, are examples of these modifications ${ }^{9-11}$.

Technical problems of the CDC assay include labour intensiveness, need of viable panel cells and the interference of certain agents present in the test-serum as ATG for example $^{12}$. Nevertheless extensive experience exists with this technique. The major 
advantage of the assay is that it reflects more than any other test the situation in vivo, the HLA antigens used as antibody-target are unaltered and have not been manipulated. And most importantly, the clinical relevance of CDC-detected antibodies has been clearly established ${ }^{13,14}$.

Many of the problems involved using cell-based assays, such as need for viable cells, presence of auto-antibodies and difficulty to distinguish class I from class II antibodies, were resolved when solid-phase antibody detection assays became available. The assays are more sensitive, require only small amounts of serum and reading is objective and can be automated ${ }^{15,16}$. The tests use soluble or recombinant HLA molecules adhered to trays (ELISA) or microspheres as antibody target ${ }^{17}$. The latter bead-based assays are run on a flow cytometer (FlowPRA) ${ }^{18}$ or are multiplexed on a Luminex platform (LABScreen) ${ }^{19}$. They are more sensitive in detecting low-titer antibody than the ELISA assay ${ }^{20}$.

\section{Enzyme-linked immuno-sorbent assay}

The first solid-phase assay for clinical use was introduced in $1993^{17}$. The ELISA assay uses soluble or recombinant HLA molecules, adhered to plastic plates as antibody target. The HLA molecules are immuno-precipitated from platelets or Epstein-Barr virus (EBV) transformed B-lymphocyte cell lines. When serum is added to the plate, only HLA antibodies will bind. Enzyme-conjugated antibody to human IgG is added to detect bound IgG antibody. If HLA antibodies are present in the serum, the resulting optical density values will reflect this. Two types of assays are commercially available. One consisting of wells containing a pool of class I or class II antigens that gives a negative or positive result. In the second one HLA molecules of one individual are present per well, thus allowing PRA value determination as well as determination of HLA specificity. Class I and II antibodies are easily distinguished and isotype-detection is limited to one immunoglobulin class, usually $\operatorname{lgG}^{17,21,22}$. By changing the isotype of the secondary anti-human antibody in the assay, one can detect other isotypes, for instance $\operatorname{lgM}^{23}$. The assay is more sensitive than $C D C$, it detects complement-binding antibodies and non-complement-binding antibodies simultaneously.

A possible drawback of the method is that the HLA molecules on the plates, are manipulated before being bound to the artificial surface, thus the natural conformation of the molecule may be altered, which can result in false-positive and false-negative reactions of the test. 


\section{Bead-based assays}

The need to measure and quantify multiple analytes at the same time lead to the development of particle or bead-based flow cytometric assays. Small cell-sized polysterene or latex microbeads were already used to calibrate first commercial flow cytometers in the early 1980's. Shortly thereafter latex, polysterene, polyacrylamide or glass microspheres were being used as the solid support for a variety of molecular reactions that were analyzed by a flow cytometer. The first beads used to quantify soluble analytes were FITC labelled latex beads or fluorescent beads. Conventional flow cytometers with the appropriate lasers for the fluorochromes could aquire the microbead emission data ${ }^{24}$. In the late 1990 's, the Luminex corporation developed the FlowMetrix system. This system consisted of 64 beads impregnated with a distinct proportion of red and orange fluorescent dyes. The unique properties of these beads were their size, stability, uniformity and their capacity to absorb and retain fluorescent dye. Different assays that make use of these beads were developed, for instance an assay to quantify multiple cytokines simultaneously at the protein level. Data acquisition for these assays was done on a conventional flow cytometer connected to a digital signal processor. The microbeads were excited at $488 \mathrm{~nm}$ by an argon laser. The orange and red fluorescence of the internal dyes of the beads is detected by the FL2 and FL3 detectors of the flow cytometer. The green reporter dye, which is a measure for the amount of analyte bound to the surface of each bead is detected on the FL1 detector. The dyes emit light at 580 and $660 \mathrm{~nm}$, the reporter dye emits light at $519 \mathrm{~nm}$. A disadvantage of this system was the need to compensate for the spectral overlap between the FL1 and FL2/FL3 detectors ${ }^{25}$. To resolve this problem, the Luminex 100 flow analyzer (Luminex ${ }^{\circ}$, Austin,Tx) and XMAP microbeads were developed. This system provided a high signal-to-noise ratio for detection of low-level fluorescence. The Luminex XMAP technology was designed to measure soluble analytes. The system is based on flow cytometry and can simultaneously analyze up to 100 analytes in a single test sample. Luminex xMAP microspheres or beads are highly uniform, polystyrene particles, 5.6 micron in size, that are internally dyed with varying amounts of red and infrared fluorochromes. In this way, 100 microspheres were created with a unique spectral signature determined by their red/infrared mixture (Figure 2.1). The surface of the beads allows simple chemical coupling of capture reagents such as cytokines, DNA probes, antibodies and antigens. The Luminex flow analyzer is equipped with a digital signal processor and two lasers. The $532 \mathrm{~nm}$ YAG laser excites the R-phycoerythrin (PE) reporter molecule, which is a measure for the amount of analyte bound to the bead, upon excitation it emits light at $578 \mathrm{~nm}$. The $635 \mathrm{~nm}$ red diode laser excites the two classification dyes imbedded in the beads, upon excitation by the laser they emit light at 658 and $712 \mathrm{~nm}$ (Figure 2.2). In this system, there is no overlap between the beads and the reporter molecules. Automated sample acquisition is made possible by the X-Y platform for reading 96-well microtiter plates $^{26-28}$. X-map beads to develop in-house assays as well as an array of commercial 
assays became available. The different commercial assays to detect HLA antibodies are described below.

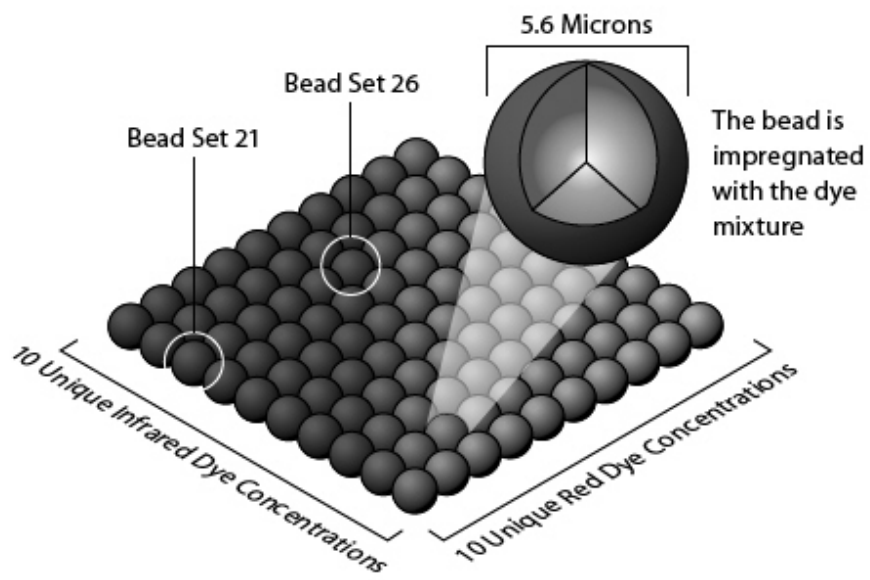

\section{Figure 2.1 Luminex xMAP microspheres.}

Luminex xMAP microspheres are highly uniform, polystyrene particles, 5.6 micron in size, internally dyed with varying amounts of red and infrared fluorochromes. This way, 100 microspheres were created with a unique spectral signature determined by their red/infrared mixture.

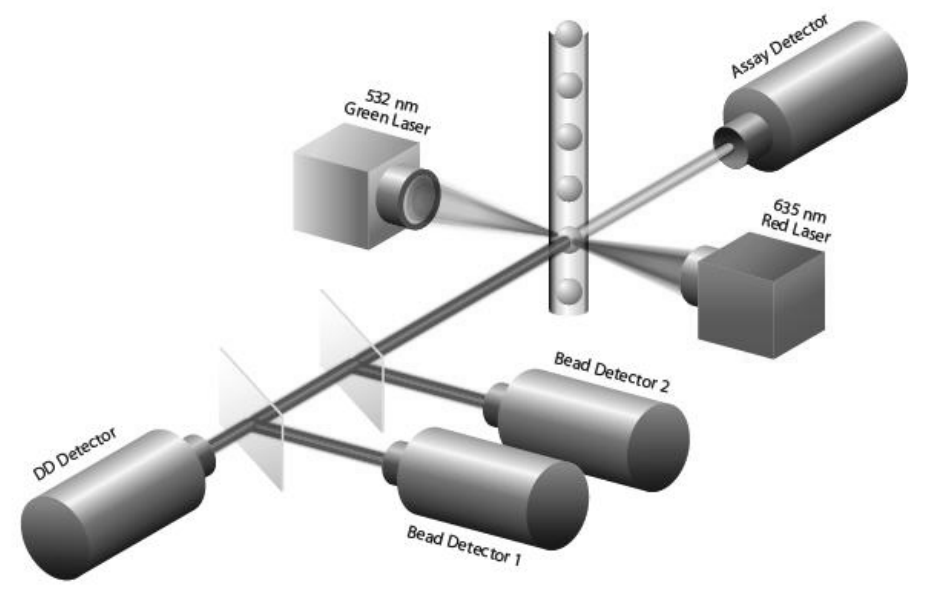

Figure 2.2 The Luminex flow analyzer.

The Luminex flow analyzer has two lasers. The $635 \mathrm{~nm}$ red diode laser excites two classification dyes imbedded in the beads, they emit light at 658 and $712 \mathrm{~nm}$. The $532 \mathrm{~nm}$ green YAG laser excites the R-phycoerythrin (PE) reporter molecule, which is a measure for the amount of analyte bound to the bead, upon excitation it emits light at $578 \mathrm{~nm}$. 


\section{FlowPRA}

In the late 1990's the bead-based flow cytometric assays (FlowPRA) (OnelambdaC, Canoga Park, CA) were introduced, one to determine the PRA value of the test serum and another to define the antibody specificity ${ }^{29,30}$. For these assays, HLA antigens are purified from EBV transformed cell lines by cell lysis and affinity chromatography with monomorphic monoclonal antibodies specific for class I and II HLA antigens. They are directly linked to uniform latex beads. In the FlowPRA screening assay, a pool of 30 class I antigens are bound to non-fluorescent beads and a second pool of 30 class II antigens to fluorescent beads. The specific class I and class II assays consist of 4 groups of 8 microbeads with different fluorescent properties, each coated with purified HLA antigens from individual cell lines which allow analysis of the antibody specificities. The FlowPRA specific assay is performed by incubating serum with beads to allow HLA-specific antibodies to adhere to the molecules on the bead's surface. After washing, FITC-conjugated $\mathrm{F}(\mathrm{ab}) 2$ fragments of goat anti-human IgG are added, which bind to the IgG HLA antibodies. Upon excitation of the beads, the fluorescence is analysed using a flow cytometer. Each of the eight beads has a unique PE fluorescence that emits light at $580 \mathrm{~nm}$ and is measured by the FL2 detector. The fluorescent signal of the FITC is emitted at $519 \mathrm{~nm}$ and is detected on the FL1 detector. Positive bead reactions show a FL1 channel shift on the FL1 versus FL2 dot blot when compared to the negative control serum and the control bead. A detailed description of the assay is given by Pei et al. ${ }^{30}$.

For patients with high PRA, it is difficult to determine the exact specificities present in the serum with these assays, because one single reaction may be caused by multiple HLA molecules present in the beads. As described by Pei et al., the search for so called Single antigens that can be used for antibody testing has been ongoing since 1979. Monoclonal antibodies and an E. Coli expression system have been used with limited success until 2002, when a new mammalian cell expression system of HLA-transfected cells was developed using recombinant DNA technology. HLA antigens purified from these transfectants by cell lysis and affinity chromotography were then coated onto FlowPRA beads. The Single antigen panel allows the identification of formerly masked specificities in patients with broad sensitisation ${ }^{31}$.

An important limitation of the commercially available FlowPRA assays is that only 4 groups of 8 (maximum 11) beads can be separated due to the spectral overlap between PE (beads, FL2) and FITC (FL1), As mentioned before this problem was overcome by the development of the Luminex XMAP technology.

\section{LABScreen assays}

The LABScreen assays (Onelambda ${ }^{\circledR}$, Canoga Park, CA) use beads coated with purified HLA molecules as target for antibody detection. By using the Luminex multi-analyte 
sytem, up to one hundred beads are combined in a single test sample. The LABScan 100 flow analyser is used for data acquisition and analysis. There are 3 variants of the test presently available: the Mixed, the PRA and the Single antigen assay. The Mixed assay consists of beads with a large number of class I or class II HLA molecules bound to their surface which detect the presence of HLA antibodies and provides a negative or positive test result. The PRA test determines the specificity of the HLA antibodies using beads coated with the fenotype equivalent of one cell, thus two HLA molecules present for each locus. In the Single antigen assay the beads are coated with single recombinant antigens from transfected human cell lines, which allow accurate definition of the HLA antibody specificities present in the serum. To date, the Single antigen panel contains all of the most frequently observed HLA alleles, 98 class I alleles (31 A, $51 \mathrm{~B}$ and $16 \mathrm{CW}$ ) and 65 class II (34 DR, $14 \mathrm{DQ}$ and $17 \mathrm{DP}$ ) are included (http://www.onelambda.com).

All assays are performed in a 96-well plate, which allows simultaneous testing of 95 patient sera and one negative control serum. Patient sera, stored frozen at $-30^{\circ} \mathrm{C}$, are centifugated at $10.000 \mathrm{~g}$ for 10 minutes prior to testing. Five $\mu \mathrm{l}$ of the appropriate beadmixture are vortexed and incubated with $20 \mu \mathrm{l}$ of patient serum for 30 minutes to allow the binding of HLA antibody to the HLA molecule on the bead. After three washes with $200 \mu \mathrm{l}$ of diluted wash buffer to remove unbound antibody, the beads are incubated for $30 \mathrm{~min}$ with $100 \mu \mathrm{l}$ of antihuman-IgG-conjugated phyco-erythrine (anti-IgG-PE), diluted 1:100 with wash buffer. After another two washes to remove unbound anti-IgG-PE, $80 \mu \mathrm{l}$ of phosphate-buffer solution is added (Figure 2.3). Incubations are performed on a gently rotating platform in the dark at room temperature. All beadmixtures contain a positive control bead coated with IgG and a negative control bead without HLA molecules. A negative control serum is run with every assay, it is used to establish the background value for each bead in the mixture. The LABScan 100 flow analyser (Luminex ${ }^{\mathcal{C}}$, Austin, TX) and HLA-Visual software (One Lambda ${ }^{\odot}$ ) are used for data acquisition and analysis.

The Luminex 100 analyzer is a flow cytometer with an excitation system that comprises two solid-state lasers that illuminate the beads as they flow through it in a single file. The red classification laser exites both the internal red and infrared dyes of the bead, allowing classification of the microbead. The green reporter laser excites the fluorescence of the PE molecules bound to the HLA antibodies on each of the beads. The fluorescent signal of the PE label, which is a measure for the amount of antibody bound to the bead, is expressed as median fluorescence intensity (MFI) value per bead. The results of the analysis of each sample are incorporated in data-files (CSV). CSV files contain data on the number of events for each bead and the MFI value for each event. These files are then interpreted by the HLA-Visual software that generates graphs of the results per serum. On the X-axis all beads and the HLA molecules on their surface are listed. On the Y-axis, the MFI per bead can be read. 


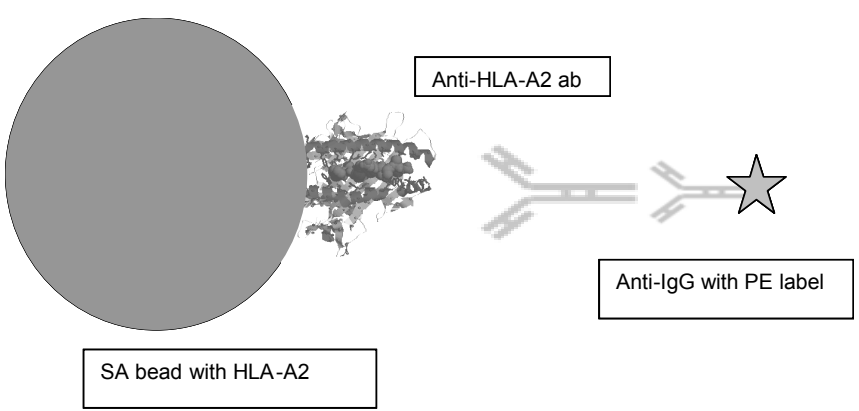

Figure 2.3 LABScreen Single antigen assay.

Single antigen beads are incubated with patient serum to allow the binding of HLA antibody to the HLA molecule on the bead. After three washes to remove unbound antibody, the anti-human-IgG antibody labelled with fluorescent phyco-erythrine (PE) label is added. Unbound secondary antibody is removed by washing.

A serum's reactivity can be assessed by the fluorescent signal for each HLA coated bead (MFI) after correction for non-specific binding to the negative control bead. All data are then normalized to the results obtained with the negative control serum. For the Mixed assay, the normalized MFI value equals the MFI value of the class I or class II coated beads minus the MFI value of the negative control bead. For the PRA and Single antigen assay, the normalized MFI value for each bead equals the MFI value of the bead divided by the MFI value of the negative control bead. The value obtained is then divided by the normalized MFI value for each bead obtained with the negative control serum, which equals the MFI value of the bead with the negative serum divided by the MFI value of the negative control bead when tested with the negative serum. This normalized background ratio is then used to assign the strength of each bead reaction and to divide the beads in groups with strength $8,6,4,2$ or 0 . Which of these scores is assigned as positive or negative is defined by the user.

The LABScan 100 flow analyzer has to be calibrated before every use with calibration and control beads. For all assays, the bead count for each kind of bead should be over 50. The MFI value of the negative control bead should be lower than 500 or 1500 for high-background sera and less than half of the MFI value of the positive control bead. The MFI of the positive control bead should be over 500 and at least twice the $\mathrm{MFI}$ value of the negative control bead.

\section{Benefits, limitations and modification of bead-based assays}

The Luminex technology is shown to be more sensitive in detecting HLA antibodies than CDC and ELISA assays ${ }^{32-34}$. Because bead-based assays make use of total IgG as 
secondary antibody, they do not discriminate between complement-binding and noncomplement-binding antibodies. Because the clinical relevance of non-complementbinding antibodies is still unclear, several modifications of the assays have been tested to solely detect complement-binding antibodies. Wahrmann et al. adapted the FlowPRA assay by using human serum as the source of complement $C 4 d$, which binds to the beads in the presence of complement-binding antibodies. A FITC-labeled anti-C4d antibody was used for detection ${ }^{35}$. Smith et al. also modified the Single antigen assay, they used human serum as the source of complement again but used a mouse anti-human C4d monoclonal antibody and a PE- donkey anti-mouse IgG for detection of complement-binding antibodies ${ }^{36}$. Several other investigators replaced the total IgG with the individual isotypes, i.e. IgG1,2,3 or $4^{37,38}$.

The major advantage of the Single antigen assay is that it allows accurate evaluation of sera containing complex mixtures of antibodies. Class I and class II antibodies are clearly discriminated. Furthermore, antibodies directed against HLA-DRB3,4,5, HLA-DQ and HLA-DP are discriminated from reactivity against HLA-DR. Beads containing different HLA-C, HLA-DQA, -DPA, -DPB alleles are available, as well as beads for detection of antibodies against MHC class I chain-related (MICA) molecules ${ }^{39-41}$. Even antibodies directed against some allelic specificities can now be detected ${ }^{42-45}$. Using the Single antigen assay, it has become clear that many sera with multiple specificities reacted with epitopes shared by several HLA molecules ${ }^{46-49}$. Based on the specificities found using these assays, a so-called virtual PRA can be calculated. This virtual PRA value is based on the antigen frequencies in the local donor population to which the recipient has antibodies ${ }^{50,51}$. The virtual PRA predicts the chance to find a positive crossmatch and results in a so-called "virtual" crossmatch ${ }^{52-56}$. The strength of the antibody detected can be measured by converting MFI values in molecular equivalent fluorescent (MESF) values using specific calibration beads ${ }^{57}$.

When bead-based assays were first introduced and their results compared to those of cell-based assays, some discrepancies were encountered. Bray et al. ${ }^{58}$ describe a serum with a positive FCXm but negative FlowPRA screening. They hypothesized that this discrepancy was caused by an epitope that is recognized by antibody on the intact cell membrane, but not on bead-bound protein. According to them this could be due to separation of the HLA from the $\beta 2 \mathrm{~m}$ chain which could lead to an altered class I morphology; either alteration of epitopes during bead preparation or altered conformation of the protein once adhered to the bead. Gebel et al. ${ }^{59}$ describe a similar case, they assume the discrepancy to be due to allelic variation or lesser density of HLA antigens expressed on beads than on living cells. Bray also describes a serum with a negative FC-Xm but a positive FlowPRA screening, which might be caused by antibody binding to epitopes that are inaccessible on the cell membrane but become accessible on the bead ${ }^{58}$. Recently, it was shown that $\operatorname{lgM}$ antibodies present in recipient serum can sterically hinder IgG antibody detection because they are 
pentamers and thus larger than IgG antibodies. This inhibition can be removed by either hypotonic dialysis or DTT treatment of the sera ${ }^{60-62}$.

\section{Comparison of LSA and CDC assays}

The cut-off point for positivity of the Luminex Single antigen assay has to be defined by the user and therefore may differ considerably between laboratories. To clarify how the results of the assay compare to those of the CDC assay, we decided to test a number of well-known HLA sera in both techniques. The sera used for this validation were CDC HLA typing sera that have been used in our lab as well as in many others all over the world for over 20 years. Both CDC specificity and reaction strength of each serum were well-defined. The main strong specificity as well as occasional extra reacting weak specificities are given in Table 2.1.

A total of 103 well-known HLA typing sera were used, 73 for class I and 26 for class II. They were tested with the LSA class I and II test respectively. The normalized MFI values obtained were divided in 5 areas: values less than 2000 (score 0), 2000-4000 (score 2), 4000-8000 (score 3), 8000-12000 (score 4) and values over 12000 (score 5). For each serum the main CDC specificity and the extra specificities if present, were categorized according to their MFI value in one of these areas.

For the HLA class I typing sera, all main specificities were detected to have a score 3 or higher, most of them score 4 and 5. None were found with an MFI value below 4000 . For the weaker extra specificities $98 \%$ reacted with score 3 or higher (132/135), 2\% of the reactions were found in the score 2 area, none had values under $2000 \mathrm{MFI}$. Altogether $99 \%$ of all class I CDC specificities had an MFI value of 4000 or more in the LSA assay.

For the HLA class II typing sera, $94 \%$ of the main specificities were found to have a score 3, 4 or 5, 6\% were found with MFI values between 2000-4000. From the extra reactions $88 \%$ reacted with score 3 or higher. Thus in total, $92 \%$ of all class II CDC specificities showed an MFI value of 4000 or more when tested with LSA. The results for all sera are summarized in Table 2.2. 
Table 2.1A Main and extra CDC specificities of 73 HLA class I typing sera.

\begin{tabular}{|c|c|c|c|c|c|}
\hline Serum & CDC specificities & & Serum & CDC specificities & \\
\hline ID & Main & Extra & ID & Main & Extra \\
\hline ms 135 & $A 1,36$ & & ms 187 & B55,42 & $B 7,54,56,67$ \\
\hline ms 145 & $A 1,36,80$ & & ms 003 & $\mathrm{~B} 27$ & $B 7,42,47,61,67$ \\
\hline ms 023 & $A 25,26,34,66$ & B7 & ms 045 & B27,47 & B13 \\
\hline ms 124 & $A 25,26,66$ & $A 11,34$ B7, 60, 61 & ms 050 & B27,47 & $\mathrm{B} 44,5,53,17,59$ \\
\hline ms 133 & $A 25,26,34,66,11$ & $A 25,26,34,66,11$ & ms 025 & B35, 50,70 & $\mathrm{B} 53,56,62,75$ \\
\hline ms 084 & $A 26,66$ & $A 25,34$ & ms 093 & B35,50,56,62,75 & $B 55,70,76,77,8$ \\
\hline ms 166 & A25 & & ms 152 & $\mathrm{~B} 13,60,61,81$ & B47,48 \\
\hline ms 027 & A11 & & ms 160 & $\mathrm{~B} 48,60,61,81$ & $\mathrm{~B} 13,47$ \\
\hline ms 066 & $A 11,66$ & $A 26,34$ & ms 042 & B51 & $\mathrm{B} 52,53 \mathrm{~A} 1$ \\
\hline ms 070 & $A 29,30,31,33$ & $\mathrm{~B} 60$ & ms 071 & $B 49,51,52,63,77,78$ & $\mathrm{~B} 53,57,58$ \\
\hline ms 125 & $A 29$ & & ms 162 & B51 & $\mathrm{B} 52,53,77,78$ \\
\hline ms 062 & $A 2,203,28$ & & ms 172 & B51,52 & $\mathrm{B} 49,53,63,77$ \\
\hline ms 092 & $A 2,203$ & A28 & ms 033 & B35,51,52,53,75,77,78 & $\mathrm{B} 18,49,62,63$ \\
\hline ms 096 & $A 2,203$ & A28 & ms 037 & B35,51,52,53,78 & $\mathrm{B} 18,49,75,77$ \\
\hline ms 105 & $A 2,203,28$ & B57,58 & ms 103 & B35, $51,52,53,78$ & B70 \\
\hline ms 110 & $\mathrm{~A} 28$ & $\mathrm{~A} 2$ & ms 137 & B35, 51,53 & \\
\hline ms 142 & $\mathrm{~A} 28$ & $\mathrm{~A} 2$ & ms 059 & $B 7,27,42,55,56,67,81$ & B54 \\
\hline ms 142 & $\mathrm{~A} 28$ & & ms 076 & $B 7,42,48,60,67,73,81$ & $\mathrm{~B} 27,22,61$ \\
\hline ms 188 & $\mathrm{~A} 3$ & & ms 079 & $\mathrm{~B} 7,42,67,81$ & $\mathrm{~B} 13,22,61,73$ \\
\hline ms 195 & $\mathrm{~A} 3$ & $B 7,27$ & ms 085 & $B 7,27,81$ & $\mathrm{~B} 13,47,73$ \\
\hline ms 009 & $A 23,24$ & A32 B51 & ms 104 & $B 7,27,42,48,60,67,73,81$ & $\mathrm{~B} 55,56,41,61$ \\
\hline ms 109 & A23,24 2403 & & ms 120 & $\mathrm{~B} 7,81$ & $B 42,67,73$ \\
\hline \multirow[t]{2}{*}{ ms 119} & $\mathrm{~A} 23,24,2403$ & & ms 044 & B73 & \\
\hline & & & ms 112 & B73 & \\
\hline ms 017 & B44,45 & $\mathrm{B} 13,49,52,57$ & ms 146 & B73 Cw7 & \\
\hline ms 127 & B44, 45 & & ms 018 & B8 & B60 \\
\hline ms 134 & $B 44,57,58,49$ & & ms 069 & B8 & \\
\hline ms 158 & B44, 45 & $\mathrm{~B} 13,60,61,41$ & ms 089 & B8 & B14 \\
\hline ms 144 & B44 & & ms 108 & $\mathrm{~B} 8,14$ & B59 \\
\hline ms 072 & B13 & & ms 030 & Bw6 (not B46) & \\
\hline ms 173 & B13 & & & & \\
\hline ms 026 & $\mathrm{~B} 62,75,76,77$ & B63 & ms 156 & Cw9,10 B46 & $\mathrm{B} 62,63,75$ \\
\hline ms 002 & $\mathrm{~B} 57,58,63,59$ & B49 A24 & $\mathrm{ms} 080$ & Cw4 & \\
\hline ms 032 & $\mathrm{~B} 57,58$ & B63 & ms 150 & Cw5,8 & \\
\hline ms 091 & $\mathrm{~B} 57,58,63$ & & ms 040 & Cw6,NM(18) & Cw4 \\
\hline ms 078 & B18 & & & & \\
\hline ms 010 & B49 & B50,51,52,53,57,58,63 & & & \\
\hline ms 167 & $\mathrm{~B} 49,50,52,53$ & $\mathrm{~B} 62,63,77$ & & & \\
\hline ms 115 & $\mathrm{~B} 55,42,67$ & $\mathrm{~B} 56,7 \mathrm{~A} 2$ & & & \\
\hline ms 176 & B54,55,56,42,67 & $\mathrm{B} 7,81$ & & & \\
\hline
\end{tabular}


Table 2.1B Main and accompanying weak extra CDC specificities of 26 HLA class II typing sera.

\begin{tabular}{|c|c|c|c|c|c|}
\hline \multirow{2}{*}{$\begin{array}{l}\text { Serum } \\
\text { ID } \\
\end{array}$} & \multicolumn{2}{|c|}{ CDC specificities } & \multirow{2}{*}{$\begin{array}{l}\text { Serum } \\
\text { ID }\end{array}$} & \multicolumn{2}{|c|}{ CDC specificities } \\
\hline & Main & Extra & & Main & Extra \\
\hline msd 046 & DR1 & & msd 014 & $\mathrm{DQ} 5,6$ & \\
\hline msd 102 & DR1 & & msd 021 & $\mathrm{DQ} 5,6$ & \\
\hline msd 002 & DR15 & DR16 & msd 029 & $\mathrm{DQ} 5,6$ & \\
\hline msd 075 & DR16 & DR15 & msd 068 & $\mathrm{DQ} 5,6$ & \\
\hline msd 003 & DR17,18 & & msd 020 & DQ2 & DR7 \\
\hline msd 060 & DR4 & & msd 023 & DQ7,8,9 & DR4 \\
\hline msd 097 & DR4 & & msd 085 & $\mathrm{DQ7}, 8,9$ & DQ4 DR13 \\
\hline msd 050 & DR11 & DR12,13 & msd 065 & $\mathrm{DQ7}, 8,9,2,4$ & \\
\hline msd 057 & DR11,13,8 & & & & \\
\hline msd 018 & DR11,14,4 & DR12,13,3 & & & \\
\hline msd 024 & DR11,13 & DR12,14,3 & & & \\
\hline msd 095 & DR12,13,9 & DR14,3,7 & & & \\
\hline msd 004 & DR15,51 & & & & \\
\hline msd 030 & DR51 & & & & \\
\hline msd 051 & DR53 & & & & \\
\hline msd 077 & DR53,7 & & & & \\
\hline msd 001 & DR7 & & & & \\
\hline msd 096 & DR11,8 & & & & \\
\hline
\end{tabular}

Table 2.2A Classification of main and weak extra class I CDC specificities according to their MFI value in the LSA class I assay.

\begin{tabular}{lccccc}
\hline CDC specificities & \multicolumn{5}{c}{ Single antigen Score (MFI) } \\
& 5 & 4 & 3 & 2 & 0 \\
& $>12000$ & $12000-8000$ & $8000-4000$ & $4000-2000$ & $<2000$ \\
\hline Main $(n=184)$ & $98(53 \%)$ & $72(39 \%)$ & $141(44 \%)$ & 0 & 0 \\
Extra $(n=135)$ & $31(23 \%)$ & $69(51 \%)$ & $32(24 \%)$ & $3(2 \%)$ & 0 \\
Total $(n=319)$ & $129(41 \%)$ & $141(44 \%)$ & $46(14 \%)$ & $3(1 \%)$ & 0 \\
\hline
\end{tabular}

Table 2.2B Classification of main and weak extra class II CDC specificities according to their MFI value in the LSA class II assay.

\begin{tabular}{lccccc}
\hline CDC specificities & \multicolumn{5}{c}{ Single antigen Score (MFI) } \\
& 5 & 4 & 3 & 2 & 0 \\
& $>12000$ & $12000-8000$ & $8000-4000$ & $4000-2000$ & $<2000$ \\
\hline Main $(n=49)$ & $28(57 \%)$ & $16(33 \%)$ & $2(4 \%)$ & $3(6 \%)$ & 0 \\
Extra $(n=17)$ & $3(18 \%)$ & $5(29 \%)$ & $7(41 \%)$ & $2(12 \%)$ & 0 \\
Total $(n=66)$ & $31(47 \%)$ & $21(32 \%)$ & $9(14 \%)$ & $5(7 \%)$ & 0 \\
\hline
\end{tabular}

The median MFI values for main and extra class I specificities was 12.382 (5.786$17.931)$ and 9.449 (2.553-15.478) respectively. For the main and weak extra class II specificities, the median values were 11.037 (2.914-17.659) and 7.797 (2.369-16.559) (Table 2.3). 
Table 2.3A MFI values of main and weak extra class I CDC specificities in the LSA class I assay.

\begin{tabular}{lcc}
\hline CDC specificities & median MFI & range of MFI values \\
\hline Main & 12382 & $5786-17931$ \\
Extra & 9449 & $2553-15478$ \\
Total & 11249 & $2553-17931$ \\
\hline
\end{tabular}

Table 2.3B MFI values of main and weak extra class II CDC specificities in the LSA class II assay.

\begin{tabular}{lcc}
\hline CDC specificities & median MFI & range of MFI values \\
\hline Main & 11037 & $2914-17659$ \\
Extra & 7797 & $2369-16559$ \\
Total & 10069 & $2369-17659$ \\
\hline
\end{tabular}

The increased sensitivity of the LSA obviously results in a much larger number of specific HLA antibodies than those detected in CDC. The numbers of these additional specificities demonstrated in the sera using LSA are given in Table 2.4. The majority of the antibodies are most likely non-complement binding antibodies, they are mainly found in the score 3 area. Some of them are directed against less common HLA alleles, which means that they might have been missed by the CDC test. On average 11 additional LSA specificities per serum were found for class I, while only one was detected for class II.

Table 2.4 Number of HLA specificities only detected by the LSA.

\begin{tabular}{lcccc}
\hline & & \multicolumn{3}{c}{ Single Antigen Score (MFI) } \\
& & 5 & 4 & 3 \\
\hline Class I & (73 sera) & $>12000$ & $12000-8000$ & $8000-4000$ \\
Class II & (26 sera) & 45 & 237 & 505 \\
\hline
\end{tabular}

Together with the transplantation clinicians we decided that in our centre, the cut-off point for positivity of the LSA would be $4000 \mathrm{MFI}$ for clinical transplant purposes, based on the results obtained with the typing sera. This means that a number of CDC undetected, non-complement binding antibodies are excluded for a given patient but we feel confident that with this cut-off point all specificities detected by CDC are covered and listed as not acceptable antigens for a transplant recipient. 


\section{References}

1. Terasaki PI, McClelland JD. Microdroplet assay of human serum cytotoxins. Nature 1964;204: 998-1000.

2. Amos DB, Bashir H, Boyle W, MacQueen M, Tiilikainen A. A simple micro cytotoxicity test. Transplantation 1969;7:220-3.

3. Rood van JJ, Leeuwen van A, Ploem JS. Simultaneous detection of two cell populations by two-colour fluorescence and application to the recognition of B-cell determinants. Nature 1976;262:795-7.

4. Rebibou JM, Bittencourt MC, Ducloux D et al. Anti-class II antibodies in kidney transplant patients. Transplant Proc 2000;32:2748-9.

5. Schonemann C, Groth J, Leverenz S, May G. HLA Class I and Class II Antibodies; monitoring before and after kidney transplantation and their clinical relevance. Transplantation 1998;65:1519-23.

6. Bas le-Bernardet $\mathrm{S}$, Hourmant $\mathrm{M}$, Valentin $\mathrm{N}$ et al. Identification of the antibodies involved in B-cell crossmatch positivity in renal transplantation. Transplantation 2003;75:477-82.

7. Taylor CJ, Chapman JR, Ting A, Morris PJ. Characterization of lymphocytotoxic antibodies causing a positive crossmatch in renal transplantation. Transplantation 1989;48:953-8.

8. Hoor ten GM, Coopmans M, Allebes WA. Specificity and Ig class of preformed alloantibodies causing a positive crossmatch in renal transplantations: the implications for graft survival. Transplantation 1993; 56:298-304.

9. Johnson $\mathrm{AH}$, Rossen RD, Butler WT. Detection of alloantibodies using a sensitive antiglobulin microcytotoxicity test: identification of low levels of pre-formed antibodies in accelerated allograft rejection. Tissue Antigens 1972;2:215-26.

10. Fuller TC, Phelan D, Gebel HM, Rodey GE. Antigenic specificity of antibody reactive in the antiglobulinaugmented lymphocytotoxicity test. Transplantation 1982;34:24-9.

11. Zachary AA, Klingman L, Thorne N, Smerglia AR, Teresi GA. Variations of the lymphocytotoxicity test. Transplantation 1995;60:498-503.

12. Book BK, Agarwal A, Milgrom $A B$ et al. New crossmatch technique eliminates interference by humanized and chimeric monoclonal antibodies. Transpl Proc 2005;37:640-2.

13. Kissmeyer-Nielsen F, Olsen S, Petersen VP, Fjeldborg O. Hyperacute rejection of kidney allografts, associated with pre-existing humoral antibodies against donor cells. The Lancet 1966;288:662-5.

14. Patel R, Terasaki PI. Significance of the positive crossmatch test in kidney transplantation. N Engl J Med 1969;280:735-9.

15. Christiaans MHL, Nieman F, Hooff van JP, Berg van den-Loonen EM. Detection of HLA class I and II antibodies by ELISA and complement-dependent cytotoxicity before and after transplantation. Transplantation 2000;69:917-27.

16. Mansour I, Messaed C, Azoury M, Klayme S, Naaman R. Panel-reactive antibodies using complementdependent cytotoxicity, flow cytometry, and ELISA in patients awaiting renal transplantation or transplanted patients: a comparative study. Transplant Proc 2001;33:2844-7.

17. Kao K-J, Scornik JC, Small SJ. Enzyme-linked immunoassay for anti-HLA antibodies - an alternative to panel studies by lymphocytotoxicity. Transplantation 1993;55:192-6.

18. Moses LA, Stroncek DF, Cipolone KM, Marincola FM. Detection of HLA antibodies by using flow cytometry and latex beads coated with HLA antigens. Transfusion 2000;40:861-6.

19. El-Awar N, Lee J,Terasaki PI. HLA Antibody identification with single antigen beads compared to conventional methods. Hum Immunol 2005;66:989-97.

20. Gebel HM, Bray RA. Sensitization and sensitivity - defining the unsensitized patient. Tranplantation 2000;69:1370-4.

21. Zachary AA, Delaney NL, Lucas DP, Leffell MS. Characterization of HLA class I specific antibodies by ELISA using solubilized antigen targets: I. Evaluation of the GTI QuikID assay and analysis of antibody patterns. Hum Immunol 2001;62:228-35.

22. Zachary AA, Ratner LE, Graziani JA, Lucas DP, Delaney NL, Leffell MS. Characterization of HLA class I specific antibodies by ELISA using solubilized antigen targets: II. Clinical relevance. Hum Immunol 2001; 62:236-46.

23. Arnold M-L, Zacher T, Dechant M, Kalden JR, Doxiadis IIM, Spriewald BM. Detection and specification of noncomplement binding anti-HLA alloantibodies. Hum Immunol 2004:65:1288-96. 
24. Vignali DA. Multiplexed particle-based flow cytometric assays. J Immunol Methods 2000;243:243-55.

25. Kettman JR, Davies T, Chandler D, Oliver KG, Fulton RJ. Classification and properties of 64 multiplexed microsphere sets. Cytometry 1998;33:234-43.

26. Earley MC, Vogt RF, Jr., Shapiro HM et al. Report from a workshop on multianalyte microsphere assays. Cytometry 2002;50:239-42.

27. Kellar KL, lannone MA. Multiplexed microsphere-based flow cytometric assays. Exp Hematol 2002;30: 1227-37.

28. Dunbar SA. Applications of Luminex xMAP technology for rapid, high-throughput multiplexed nucleic acid detection. Clin Chim Acta 2006;363:71-82.

29. Pei R, Wang G, Tarsitani C et al. Simultaneous HLA class I and class II antibodies screening with flow cytometry. Hum Immunol 1998;59:313-22.

30. Pei R, Lee JH, Chen T, Rojo S, Terasaki PI. Flow cytometric detection of HLA antibodies using a spectrum of microbeads. Hum Immunol 1999;60:1293-302.

31. Pei R, Lee J-H, Shih N-J, Chen M, Terasaki PI. Single human leukocyte antigen flow cytometry beads for accurate identification of human leukocyte antigen antibody specificities. Transplantation 2003;75: 43-9.

32. Saidman SL. Histocompatibility testing for highly sensitized transplant candidates. Transpl Proc 2007; 39:673-5.

33. Leffell MS, Zachary AA. Antiallograft antibodies: relevance, detection, and monitoring. Curr Opin Organ Transplant 2010;15:2-7.

34. Zeevi A, Girnita A, Duquesnoy R. HLA antibody analysis: sensitivity, specificity, and clinical significance in solid organ transplantation. Immunol Res 2006;36:255-64.

35. Wahrmann $M$, Exner $M$, Haidbauer B et al. \{C4d\}flow PRA screening - a specific assay for selective detection of complement-activating anti-HLA alloantibodies. Hum Immunol 2005;66:526-34.

36. Smith JD, Hamour IM, Banner NR, Rose ML. C4d fixing, Luminex binding antibodies - a new tool for prediction of graft failure after heart transplantation. Am J Transplant 2007;7:2809-15.

37. Heinemann FM, Roth I, Rebmann V et al. Immunoglobulin isotype-specific characterization of antihuman leukocyte antigen antibodies eluted from explanted renal allografts. Hum Immunol 2007;68: 500-6.

38. Arnold ML, Dechant M, Doxiadis, II, Spriewald BM. Prevalence and specificity of immunoglobulin G and immunoglobulin A non-complement-binding anti-HLA alloantibodies in retransplant candidates. Tissue Antigens 2008;72:60-6.

39. Barabanova Y, Ramon DS, Tambur AR. Antibodies against HLA-DQ alpha-chain and their role in organ transplantation. Hum Immunol 2009;70:410-2.

40. Mizutani K, Terasaki P, Rosen A et al. Serial ten-year follow-up of HLA and MICA antibody production prior to kidney graft failure. Am J Transplant 2005;5:2265-72.

41. Mizutani K, Terasaki P, Bignon JD et al. Association of kidney transplant failure and antibodies against MICA. Hum Immunol 2006;67:683-91.

42. Bray RA, Wilmoth-Hosey L, Chapman P, Holcomb JE, Gebel HM. Identification of allele-specific HLA class II alloantibodies: paradigm or paradox. Hum Immunol 2004;65 suppl 1:S39.

43. Bray RA, Gebel HM. Allele-specific HLA alloantibodies and implications for organ allocation. Hum Immunol 2005;66:S10.

44. Middleton D, Martin J, Magee B, Cole M. Interpretation of One Lambda flow bead screening and identification results: the role of DRB3. Hum Immunol 2006;67:S47.

45. Collins D, Yu M, Henel G, Schmitz J. Post transplant development of a DQA $1 * 0501$ dependent alloantibody. Hum Immunol 2007;68:S128.

46. Cai J ,Terasaki PI. Post-transplantation antibody monitoring and HLA antibody epitope identification. Curr Opin Immunol 2008;20:602-6.

47. El-Awar N, Lee J-H, Tarsitani C, Terasaki PI. HLA class I epitopes: recognition of binding sites by mAbs or eluted alloantibody confirmed with single recombinant antigens. Hum Immunol 2007;68:170-80.

48. Duquesnoy RJ ,Marrari M. Correlations between Terasaki's HLA class I epitopes and HLAMatchmakerdefined eplets on HLA-A, -B and -C antigens. Tissue Antigens 2009;74:117-33.

49. Marrari M, Duquesnoy RJ. Why can sensitization by an HLA-DR2 mismatch lead to antibodies that react also with HLA-DR1? Hum Immunol 2009;70:403-9. 
50. Cecka JM. Calculated PRA (CPRA): the new measure of sensitization for transplant candidates. Am J Transplant 2010;10:26-9.

51. Taylor CJ, Kosmoliaptsis V, Summers DM, Bradley JA. Back to the future: application of contemporary technology to long-standing questions about the clinical relevance of human leukocyte antigenspecific alloantibodies in renal transplantation. Hum Immunol 2009;70:563-8.

52. Bielmann D, Hönger G, Lutz D, Mihatsch MJ, Steiger J, Schaub S. Pretransplant risk assessment in renal allograft recipients using virtual crossmatching. Am J Transplant 2007;7:626-32.

53. Zachary AA, Sholander JT, Houp JA, Leffell MS. Using real data for a virtual crossmatch. Hum Immunol 2009;70:574-9.

54. Bingaman AW, Murphey CL, Palma-Vargas J, Wright F. A virtual crossmatch protocol significantly increases access of highly sensitized patients to deceased donor kidney transplantation. Transplantation 2008;86:1864-8.

55. Ho EK, Vasilescu ER, Colovai Al, Stokes MB, Hallar M, Markowitz GS, D'Agati VD, Cohen DJ, Ratner LE, Suciu-Foca N. Sensitivity, specificity and clinical relevance of different cross-matching assays in deceased-donor renal transplantation. Transpl Immunol 2008;20:61-7.

56. Amico P, Honger G, Steiger J, Schaub S. Utility of the virtual crossmatch in solid organ transplantation. Curr Opin Organ Transplant 2009;14:656-61.

57. Mizutani K, Terasaki P, Hamdani E, Esquenazi V, Rosen A, Miller J, Ozawa M. The importance of antiHLA-specific antibody strength in monitoring kidney transplant patients. Am J Transplant 2007;7:102731.

58. Bray RA, Nickerson PW, Kerman RH, Gebel HM. Evolution of HLA antibody detection. Immunologic Rev 2004;29:41-53.

59. Gebel HM, Harris SB, Zibari G, Bray RA. Conundrums with flowPRA (TM) beads. Clin Transplant 2002; 16:24-9.

60. Zachary AA, Lucas DP, Detrick B, Leffell MS. Naturally occurring interference in Luminex assays for HLAspecific antibodies: characteristics and resolution. Hum Immunol 2009;70:496-501.

61. Kosmoliaptsis V, Bradley JA, Peacock S, Chaudhry AN, Taylor CJ. Detection of immunoglobulin G human leukocyte antigen-specific alloantibodies in renal transplant patients using single-antigen-beads is compromised by the presence of immunoglobulin $\mathrm{M}$ human leukocyte antigen-specific alloantibodies. Transplantation 2009;87:813-20.

62. Kosmoliaptsis V, O'Rourke C, Bradley JA, Taylor CJ. Improved Luminex-based human leukocyte antigenspecific antibody screening using dithiothreitol-treated sera. Hum Immunol 2010;71:45-9. 



\section{Chapter 3}

Clinical relevance of pretransplant donor-directed antibodies detected by Single antigen beads in highly sensitized renal transplant patients

EM van den Berg-Loonen, EVA Billen, CEM Voorter, ELW van Heurn, FHJ Claas, JP van Hooff, MHL Christiaans 


\section{Abstract}

\section{Background}

Highly sensitized (HS) patients (>85\% panel-reactive antibodies) have a lower chance of receiving a donor kidney. Within Eurotransplant the Acceptable Mismatch (AM) program was developed to increase the chances of $\mathrm{HS}$ patients to receive a crossmatch negative donor kidney. The standard crossmatch in the AM program is based on complement-dependent cytotoxicity.

\section{Methods}

In this study we wanted to determine the clinical relevance of human leukocyte antigen donor-directed antibodies (DDA) detected by the Single antigen (SA) bead technique, in the pretransplant sera of HS patients transplanted in our center through the Eurotransplant AM program.

\section{Results}

From 34 AM patients, 27 were transplanted with 1 to 5 mismatches and 7 received a 0 - mismatched graft. From the mismatched patients, retrospectively, 13 proved to possess pretransplant DDA by SA whereas 14 did not. No antibodies were found in the 0-mismatched group. Comparison of the DDA+ and DDA- patients in the human leukocyte antigen-mismatched donor/recipient combinations revealed a trend to an earlier and higher number of rejection episodes in DDA+ patients $(P=0.08)$. No detrimental effect of DDA on graft survival was observed.

\section{Conclusions}

This single-centre study showed that in the AM program DDA detected by SA and not by less- sensitive methods, may be related to acute rejection episodes but is not detrimental to long-term graft outcome. These findings question the increasing use of more-sensitive screening techniques for the allocation of organs. 


\section{Introduction}

Patients with a sensitization of $85 \%$ or more panel reactive antibodies (PRA) are generally considered to be highly sensitized (HS). They have a lower chance of receiving a donor-kidney offer than other patients on the waiting list. The sensitization is caused by pregnancies, blood-transfusions, or previous transplants.

There are two strategies to facilitate transplantation in HS patients. One is increasing the chance of finding a crossmatch-negative donor, for example, by determination of acceptable human leukocyte antigen (HLA) mismatches, and the other removal of HLA antibodies by desensitization, for example, with intravenous immunoglobulinbased protocols. Within Eurotransplant (ET) the Acceptable Mismatch (AM) program consists of a special HS waiting list that allows patients with a current or historical sensitization of $85 \%$ or more PRA to enter ${ }^{1,2}$. Acceptable mismatches are defined as those mismatches against which the recipient has never made antibodies and are considered to be acceptable as mismatch on the potential donor organ. A blood group compatible deceased donor that becomes available and is HLA-A,-B,-DR matched with the recipient's antigens, including the AM antigens, is first offered to the HS patient waiting list. The standard crossmatch performed in the AM program is the complement-dependent cytotoxicity (CDC) crossmatch. Patients transplanted in the program have a 1-year graft survival similar to that of nonsensitized patients within $\mathrm{ET}^{3}$.

Screening techniques of higher sensitivity than $C D C$ and enzyme-linked immunosorbent assay (ELISA), such as the Single antigen (SA) bead assay have been introduced recently, ${ }^{4,5}$. In this assay, color-coded microspheres coated with single HLA antigens are used to identify HLA class I and II antibodies in patient sera. The test detects both complement-binding and non-complement-binding HLA antibodies using anti-human IgG as secondary antibody. More and more laboratories rely on the detection of specificities demonstrated by these types of assays, and use the information obtained for allocation of donor organs. The clinical relevance, however, has not been studied systematically, nor has it been proven.

In this study we wanted to determine the presence or absence of HLA donor-directed antibodies (DDAs) by the SA Luminex bead technique in the pretransplant sera in a cohort of highly immunized patients that entered the ET AM program and were transplanted in our center. These patients were transplanted on the basis of a negative CDC crossmatch. Their post-transplant course was studied to evaluate the clinical relevance of the DDA specificities detected. 


\section{Materials and Methods}

\section{Patients and donor}

Thirty-four patients with PRA greater than $85 \%$ from the Maastricht Transplant Center entered the ET AM program and were transplanted between 1989 and 2006. Acceptable mismatches were determined by means of crossmatches with selected donors or by extensive screening protocols. Since 2001, also the HLA matchmaker algorithm has been used in the determination of acceptable mismatches ${ }^{6}$. From 34 patients seven were transplanted with a 0-mismatched donor, the remaining 27 with 1 to 5 mismatches. There were 12 first and 15 retransplants.

Organ donors were offered through the ET organ exchange organization, and typed or retyped by the Maastricht laboratory. All relevant crossmatches with current and historical patient sera were performed in the recipient center. All grafts were from heart-beating donors, except two from non-heart-beating donors.

\section{Immunosuppression}

The immunosuppressive regimen was calcineurin inhibitor-based triple drug therapy for all recipients. Calcineurin inhibitor was cyclosporine (CsA;n=14) until 1994 and tacrolimus (TAC; $n=20$ ) thereafter. Additional immunosuppression was prednisone in all, azathioprine in 8, mycophenolate mofetil in 15, sirolimus in 2 and FK778 in 2 recipients. None of the patients received induction therapy with antilymphocyte globuline or IL2-receptor antagonist. CsA levels were determined in whole blood by enzyme monoclonal immuno test (Dade Behring, Newark, DE) or high performance liquid chromotography-MS/MS. In the first 3 months after transplantation, target CsA trough levels were 0.10 to $0.15 \mathrm{mg} / \mathrm{l}$, afterwards decreasing to 0.05 to $0.10 \mathrm{mg} / \mathrm{l}$. TAC trough levels were measured in whole blood by Imx (Abbott, Abbott Park, IL) or high performance liquid chromotography-MS/MS; target levels were 15 to $20 \mathrm{ng} / \mathrm{ml}$ for weeks $1+2$ and 10 to $15 \mathrm{ng} / \mathrm{ml}$ for weeks $3+4$, thereafter tapering to 5 to $7 \mathrm{ng} / \mathrm{ml}$.

\section{Clinical outcome parameters}

A biopsy was taken during surgery 1 hour after reperfusion for every transplant. Rejection was defined as any rejection treatment within 3 months after grafting. All rejection episodes were proven by needle core biopsy. No fresh frozen material for C4d staining was available because of the retrospective design of the study. Rejection treatment consisted of three doses of methylprednisolone (0.5-1.0 g/dose) or a 10-day course of antithymocyte globulin for vascular rejections. Graft failure was defined as failure of graft, but also included death with functioning graft. 


\section{Center policy of tissue typing}

During the study period all patients were typed for HLA-A, -B, -DR and -DQ. Typings were initially performed by serology; from 1994, class II was DNA typed by polymerase chain reaction-sequence-specific primers and from 2004 class I as well. Recently, all recipient and donor typings have been repeated with molecular techniques (SSO Luminex) to ascertain the exact number of mismatches. HLA antigens were considered unacceptable for a patient, if antibodies against the specificity had ever been demonstrated, either at the time of transplantation or in the past. Mismatches from previous transplants were excluded, as were the paternally inherited antigens of children in female patients. CDC crossmatches of peak and current patient sera had to be negative with and without DTT in order for the transplant to be performed.

\section{Screening for human leukocyte antigen antibodies}

All recipient sera had been screened before transplantation for the presence of class I and class II antibodies. The routine antibody detection technique during the whole period, 1989 to 2006, was CDC. Both class I and class II DR antibodies were determined using the two-color fluorescence technique on unseparated PBLs. Reading was performed with automated Leitz inverted fluorescence microscopes. In 2002 a generic ELISA test (LAT-M, One Lambda, Inc., Canoga Park, CA) as well as ELISA identification test (Quick-ID, GTI Diagnostics, Brookfield, WI and LAT-M, One Lambda) for class II DR-antibodies was added to our screening strategy. The generic test was used as a prescreening test, the identification tests for better definition of class II DR antibodies.

For all recipients, acceptable mismatches were defined by performing CDC crossmatches with selected panel cells, differing for only one antigen with the patient, or by determining the negative antigens in relevant sera by extensive $C D C$, and since 2002, also by Elisa screening. For this study all historical relevant sera and the current serum have now been retested with class I and II SA Luminex beads (One Lambda) according to the manufacturer's protocol.

\section{Statistical analysis}

All statistical analyses were performed by using Statistical Package for the Social Sciences software (SPSS, Cary, NC; version 12.0.1 for Windows). Groups were compared by non- parametric tests. Kaplan-Meier survival analysis was performed to analyze differences in rejection-free survival and graft survival (log-rank statistic). 


\section{Results}

\section{Mismatches and antibodies}

From 34 recipients, 27 were transplanted with 1 to 5 AM mismatches, the remaining 7 received a 0 -mismatched graft. Their pretransplant characteristics are given in Table 3.1. The relevant sera of all patients in the study were retested by Luminex class I and II SA bead assay. Patients who received a 0-mismatched graft never showed the presence of donor-directed HLA antibodies in their relevant pretransplant serum. From the 27 mismatched patients, 13 presented with DDA in the relevant pretransplant serum and 14 had no detectable antibodies. The positive patients showed a class I or II antibody in 11 and 2 patients, respectively. The two groups of mismatched patients were compared; the 0-mismatched patients were excluded from the analysis. The number of mismatches, the actual mismatched antigens, the DDAs found, and PRA values for peak and current serum are given in Table 3.2.

Table 3.1 Pretransplant recipient characteristics $(n=27)$.

\begin{tabular}{lcc}
\hline & $\begin{array}{c}\text { DDA+ group } \\
(\mathrm{n}=13)\end{array}$ & $\begin{array}{c}\text { DDA- group } \\
(\mathrm{n}=14)\end{array}$ \\
\hline Median recipient age, yrs (range) & $51(30-69)$ & $51,5(29-65)$ \\
Gender, male/female & $5 / 8$ & $5 / 9$ \\
Female recipients with pregnancies & 7 & 7 \\
Transplant number, 1/2/3/4 & $7 / 5 / 1 / 0$ & $5 / 6 / 2 / 1$ \\
Median donorage, yrs (range) & $45(23-63)$ & $43,5(7-63)$ \\
Donor type, HB/non-HB & $13 / 0$ & $12 / 2$ \\
\hline
\end{tabular}

${ }^{a}$ DDA positivity was based on reactivity of the peak pretransplant serum

\section{Rejection and Graft Survival}

In total 8 of 27 patients were treated for an acute rejection. For the peak sera, more rejections were seen in the DDA+ than in the DDA- group (six vs. two). The rejections in the DDA+ group occurred earlier after transplantation (days 5-21) than in the DDA-group (days 35-44). In three patients the rejection was treated with antithymocyte globulin; two were on TAC and one on CSA, two were DDA+ and one was DDA- (Table 3.2). However, rejection-free survival was $83 \%$ for the DDA- and $54 \%$ for the DDA+ group. The difference in actuarial rejection-free survival did not reach statistical significance (Kaplan-Meier survival analysis; log-rank statistic: 3.1, 1df, $P=0.08$; Figure 3.1). For the current sera three patients were shown to have lost their DDA, one patient from the DDA- group was shown to possess DDA at the time of transplant. Analysis of the current pretransplant sera in both groups showed comparable rejection-free survival (DDA+vs. DDA-, $\mathrm{P}=0.14$ ). 


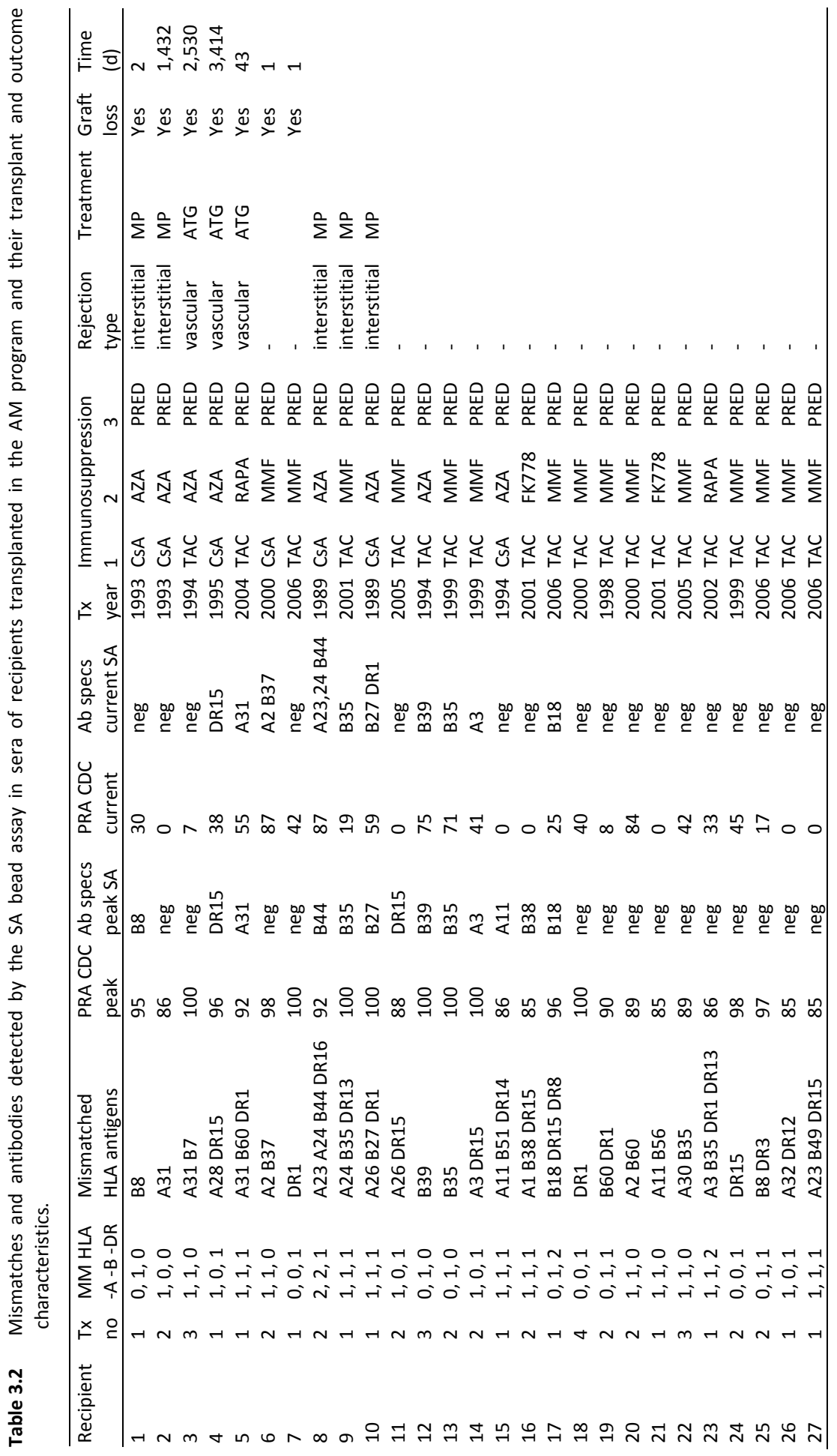




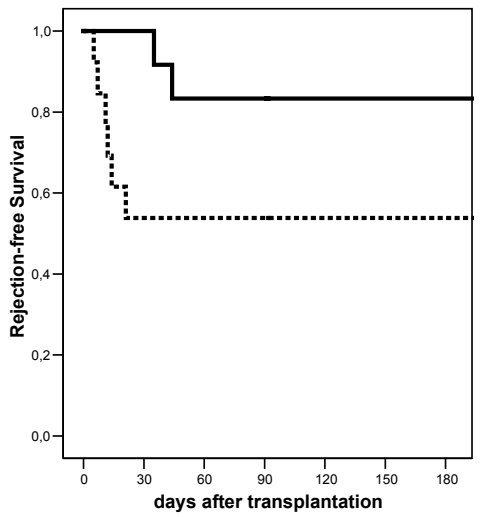

Figure 3.1 Rejection-free survival according to DDA positivity by SA of 27 highly sensitized patients transplanted in the Acceptable Mismatch program. Kaplan-Meier curve of acute rejection-free survival for DDA- (solid line) and DDA+ (dotted line) patients. $\mathrm{P}=0.08$

Graft failure occurred in 4 of 27 patients in the early post-transplant period (up to day 45). There were no histological signs of rejection in any of them. Two primary non-function failures were in the DDA- group. Both patients received a graft from an older donor, one had persistent hypotension. The other two failures were in the DDA+group. By Kaplan Meier survival analysis, it was found that graft survival up to 8 years did not differ significantly between the DDA groups (log-rank statistic: 0.27 , $1 \mathrm{df}, \mathrm{P}=0.60$; Figure 3.2). Graft survival was not different when the analysis was performed for current serum $(P=0.75)$.

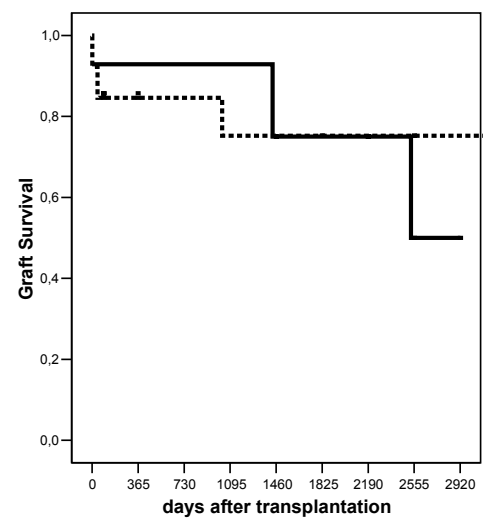

Figure 3.2 Graft survival according to DDA positivity by SA of 27 highly sensitized patients transplanted in the Acceptable Mismatch program. Kaplan-Meier curve of graft survival for DDA- (solid line) and DDA+ (dotted line) patients. $P=0.60$ 


\section{Discussion}

From 34 HS patients from the Maastricht Transplant Center transplanted in the ET AM program, 27 were transplanted with 1 to 5 mismatches, whereas seven received a 0 -mismatched organ. From the mismatched patients 13 proved to possess pretransplant DDA when tested retrospectively with the SA Luminex beads, whereas 14 did not. No antibodies were found in the $0 \mathrm{~mm}$ group. Comparison of the two mismatched groups revealed a trend to an earlier and higher number of rejection episodes in the DDA+ group; however, DDA positivity did not have a detrimental effect on graft survival. The difference in rejection rate did not reach statistical significance with the limited size of the patient groups. The results were similar when the current pretransplant serum was used for DDA definition.

The SA Luminex bead assay is a very sensitive and specific screening method for HLA class I and II antibodies. The antibodies detected are both complement-binding and non complement-binding. One can not differentiate between these antibodies, because the secondary antibody in the test is anti-human total IgG. The clinical impact of cytotoxic complement-binding DDA is well known. The DDA detected here were mainly class I, only 2 of 13 patients showed class II antibody. Rejection episodes showed the same distribution; five in class I-positive and one in class II-positive patients. The antibody specificities detected were against antigens common in the Dutch population. In this study we were not able to prove a clear clinical impact of the DDA detected by the SA Luminex test. Although there might be an effect on the occurrence of rejection episodes, it is obvious that the DDA detected are not detrimental to long-term graft outcome. This poses questions to the clinical relevance of antibodies detected by Luminex bead- based screening tests but not in CDC.

In this single-center study, the AM program without induction therapy results in longterm graft survival, which is identical to the results obtained by the Dutch transplant registry for deceased heart-beating donors. Donor-directed antibodies detected by SA Luminex beads and not by less- sensitive methods, might be related to acute rejection episodes but seemed not to be detrimental to long-term graft outcome. These findings question the ongoing use of more and more sensitive techniques in allocation of organs. Although this single-center study comprises only a relatively small number of patients and confirmation of the findings in a larger patient group is necessary, these findings are important in view of the fact that presently a lot of effort and money is spent on desensitization protocols to remove DDA, detected in these sensitive assays, in patients before transplantation. 


\section{References}

1. Claas FHJ, Waal de LP, Beelen J et al. Transplantation of highly sensitized patients on the basis of acceptable HLA-A and B mismatches. Clin Transplant 1989:1-6.

2. Claas FH, Meester de J, Witvliet MD et al. Acceptable HLA mismatches for highly immunized patients. Rev Immunogenet 1999;1:351-8.

3. Meester De J, Doxiadis IIN, Persijn GG, Claas FHJ. Renal transplantation of highly sensitised patients via prioritised renal allocation programs. Nephron 2002;92:111-9.

4. Pei R, Lee J-H, Shih N-J, Chen M, Terasaki PI. Single human leukocyte antigen flow cytometry beads for accurate identification of human leukocyte antigen antibody specificities. Transplantation 2003;75: 43-9.

5. El-Awar N, Lee J, Terasaki PI. HLA Antibody identification with single antigen beads compared to conventional methods. Hum Immunol 2005;66:989-97.

6. Duquesnoy RJ, Witvliet M, Doxiadis IIN, Fijter de H, Claas FHJ. HLAMatchmaker-based strategy to identify acceptable HLA class I mismatches for highly sensitized kidney transplant candidates. Transpl Int 2004;17:22-30. 


\section{Chapter 4}

HLA class II donor-specific antibodies persisting or appearing more than one year after renal transplantation are related to graft loss

MHL Christiaans, EVA Billen, PI Terasaki, M Ozawa, MGJ Tilanus, ELW van Heurn, EM van den Berg-Loonen 


\section{Abstract}

Prevalence, time of appearance, and HLA class of DSA were studied in 140 consecutive renal transplant patients. Pre-transplant DSA-negative recipients with at least one year renal function and a follow-up time of up to 14 years was monitored for the production of DSA in 1107 sera by the Single antigen assay. Presence of DSA was shown in 224 sera of 35 recipients (class $1 / I I / I+I I$ in 11/20/4). In 17 patients transient DSA were found, present for a short period of time and not reappearing during follow-up (class $1 / 11 / 1+I I$ in $9 / 7 / 1$ ). Median fluorescence intensity values (MFI) differed considerably for persistent and transient DSA (median 12.000 versus 3.000). In multivariate analysis class II DSA persisting or appearing after the first year posttransplant was the only independent risk factor for graft failure (OR=3.2). For transient DSA patients both class I and II positivity showed a comparable risk of graft failure as DSA-negative recipients. Thus, class II DSA positivity was predictive of graft failure if present after the first year post-transplant. The presence of transient DSA did not affect graft failure. Persistent DSA was shown to have 4 times higher MFI values, nevertheless many DSA positive patients had grafts with stable function. 


\section{Introduction}

Despite the improvement of current immunosuppressive regimens, HLA antibodies continue to be a risk factor for kidney transplant failure. Until recently it has been difficult to study the development of HLA antibodies in recipients because the methods available for their detection were insensitive and cumbersome. However the new detection technologies provide the possibility to define more specific their significance in patients before and after transplantation.

The presence of pre-transplant cytotoxic donor-specific HLA antibodies (DSA) is a major cause of graft loss ${ }^{1,2}$. The development of DSA after renal transplantation is associated with acute and chronic rejection, and a decline in graft survival ${ }^{3-6}$. The results from a collaborative prospective international study showed that patients with HLA antibodies had graft failure at a significantly higher rate than patients without graft failure ${ }^{7}$. Many authors have described similar results ${ }^{8,9,10}$ and HLA antibodies therefore are considered to be a major cause of kidney allograft failure. This has led many laboratories to post-transplant HLA antibody testing of their recipients, in order to predict graft failure ${ }^{11,12}$. In many of the studies described, the patient population included recipients with pre-transplant DSA or was restricted to recipients who rejected their graft ${ }^{12,13}$. The number of serum samples tested per patient was limited, the methods used were of intermediate sensitivity (ELISA), and clinical follow-up time was short.

The present paper is a detailed analysis of the frequency and features of HLA DSA, particularly whether and when the presence of post-transplant anti-HLA class I and/or II DSA leads to graft failure. This study differs from most other studies in that it includes a cohort of consecutive renal transplant recipients, some of whom have lost their graft but most still have functioning transplants. The presence of DSA is monitored from the moment of transplantation up to 15 years thereafter. All patients were proven DSA negative before transplantation, had at least 1 year of renal function and an average of 8 serum samples was tested per patient. Sera were collected before and after transplantation up to graft failure and DSA were determined with the Luminex Single antigen assay. The time of appearance, persistence, specificity, and antibody class of DSA were analyzed, as well as their effect on graft survival.

\section{Materials and Methods}

\section{Patients}

The patients included in the study were 140 consecutive kidney transplant recipients with at least one year of renal function. All were DSA negative before transplantation 
as assessed by the Luminex Single antigen assay. They were transplanted at the University hospital of Maastricht from January 1995 until January 1999 and clinical follow-up was continued through January 2010. Hundred-twenty were first transplants and 20 were re-transplants. Patient, donor and transplant characteristics are listed in Table 4.1. Serum samples were collected at the time of transplantation and at regular intervals thereafter. Multiple serum samples were available for the recipients included in the study: a sample immediate pre-transplant, at month 3 , month 6 , year 1 , and preferably one for every year thereafter up to July 2009, graft failure or death. As not every patient had a yearly follow-up in the transplant center, the serum samples could not be obtained every year for all patients in the study. Two patients were lost to follow-up at three and four years. A total of 1107 sera were tested for the presence of DSA. Testing of at least 5 sera per patient was mandatory, 4 in the first year including the pre-transplant sample and at least 1 serum thereafter. On average, eight serum samples per patient were examined. Collection, storage and use of tissue and patient data have been performed in agreement with the Code for "Proper Secondary Use of Human Tissue", put forward by "The Federation of Dutch medical scientific societies" (www. Federa.org), therefore no IRB approval is needed.

Table 4.1 Patient, donor and transplant characteristics $(n=140)$.

\begin{tabular}{ll}
\hline Parameter & \\
\hline Recipient age, years* & $51(16-76)$ \\
Male gender & $96 / 44$ \\
Donor type (HB/DCD/L) & $83 / 35 / 22$ \\
Donor age, years* & $47(4-70)$ \\
HLA-A mismatch 0/1/2 & $41 / 68 / 31$ \\
HLA-B mismatch 0/1/2 & $41 / 68 / 31$ \\
HLA-DR mismatch 0/1/2 & $53 / 80 / 7$ \\
HLA-DQ mismatch 0/1/2 & $85 / 55 / 0$ \\
Pre-transplant CDC PRA & 132 \\
& $0-5 \%$ \\
Serum creatinine level at year 1** & $85 \%$ \\
First transplants/ re-transplant & 158.02 \\
Acute rejection yes/no & $120 / 20$ \\
Delayed graft function yes/no & $47 / 93$ \\
Cold ischemia time, hours** & $53 / 87$ \\
\hline
\end{tabular}

Data are given as numbers or in case of * as median (range), ${ }^{* *}$ mean

\section{Immunosuppression}

The immunosuppressive regimen at the time of transplantation was prednisone (PRED) in combination with a calcineurine inhibitor (CNI) in all recipients: cyclosporine (CSA) in 60 , and tacrolimus (TAC) in 80 recipients. In addition to CSA and PRED, azathioprine (AZA) was added in 15 recipients. Additional immunosuppression to TAC and PRED, was AZA in 5 recipients and mycophenolate mofetil (MMF) in 26 recipients. None of 
the recipients received induction therapy at the time of transplantation. CSA levels were determined in whole blood by Enzyme Monoclonal Immuno Test (EMIT, Dade Behring, Newark, DE, USA) or HPLC-MS/MS. In the first 3 months after transplantation, target CSA trough-levels for CSA+PRED treated recipients were $0.15-0.20 \mathrm{mg} / \mathrm{l}$ and for CSA+PRED+AZA treated recipients $0.10-0.15 \mathrm{mg} / \mathrm{l}$. TAC trough-levels were measured in whole blood by Imx (Abbott) or HPLC-MS/MS, target levels were 15-20 ng/ml for week $1+2$ and $10-15 \mathrm{ng} / \mathrm{ml}$ for week $3+4$, thereafter tapering to $5-7 \mathrm{ng} / \mathrm{ml}$. The immunosuppressive regimen one year after transplantation was CNI-based in all but one recipient who received $M M F$ in combination with PRED. Fifty-two recipients received CSA, 8 recipients were on CSA monotherapy, 28 on CSA+PRED, 15 on $C S A+P R E D+A Z A(14) / M M F(1), 1$ received $C S A+A Z A$. Eighty-seven recipients received TAC, 48 recipients were on TAC monotherapy, 27 on TAC+PRED, 3 on TAC+PRED+AZA, 2 on TAC+PRED+MMF, and 7 on TAC+MMF. The immunosuppressive regimen was solely based on pre-transplant immunological status (PRA and HLA match) and posttransplant clinical course (acute rejections) and not on HLA antibody screening posttransplant.

\section{Clinical outcome parameters}

Acute rejection was defined as any rejection treatment within 3 months after grafting. Rejection episodes were proven by needle core biopsy. Rejection treatment consisted of three doses of methylprednisolone $(0.5-1.0 \mathrm{~g} /$ dose). For steroid-resistant rejections, second line therapy consisted of anti-thymocyte globulin (ATG). Delayed graft function (DGF) was defined as the need for renal replacement therapy in the first week after transplantation. Graft failure was defined as return to dialysis and was censored for recipient death with functioning graft.

\section{Center policy of tissue typing}

All patients and donors were typed at the time of transplant for HLA class I (HLA-A and -B) by serology and for HLA class II (HLA-DR and -DQ) by molecular methods (PCR-SSP). Donor typing for CW and DP was not performed and DSA against these specificities were not included. All transplants were performed under the auspices of Eurotransplant and were $\mathrm{ABO}$ compatible. Crossmatches before transplantation were the standard NIH crossmatch with and without dithiothreitol (DTT), and the two-color fluorescence crossmatch. Crossmatch-sera used were the pre-transplant serum drawn at the time of transplantation and all relevant positive historical samples (peak sera). A negative class I CDC crossmatch was mandatory for transplantation. Pre-transplant CDC-screening was performed with and without DTT and included a selected 60-cell panel, in which most common HLA specificities were included. Reading was performed using a Leitz Patimed automated microscope and positivity was defined as at least $10 \%$ of cell death in the patient serum over the negative controls. Of the 140 recipients in this cohort, 132 were non-immunized (CDC-PRA 0-5\%) and 8 were immunized (CDC- 
PRA 6-85\%). HLA class I and II antigens were considered unacceptable for a patient, if antibodies against the specificity had ever been demonstrated either at the time of transplantation or in the past. Mismatches from previous transplants were excluded, as were the paternally inherited antigens of children in female patients. Nontransfused male recipients and female recipients not immunized by pregnancy received at least one leukocyte-poor blood transfusion before transplantation according to the local transfusion protocol at that time ${ }^{14}$.

\section{Single antigen Bead Assay}

Patient sera were screened for HLA antibody at the Terasaki Foundation Laboratory using the HLA class I and class II Single antigen assay (LABScreen beads: LS1A04 and LS2A01, One Lambda Inc, Canoga Park, CA). The beads detect HLA-A, -B, CW, -DR, -DQ and -DP antibodies. All assays were performed according to the manufacturer's protocol. Briefly, $20 \mu \mathrm{l}$ of test serum was added to $5 \mu \mathrm{l}$ of SA beads, incubated in the dark for 30 minutes at room temperature (RT), and then washed with the provided wash buffer. One hundred $\mu$ of goat anti-human IgG antibody conjugated with R-phycoerythrin(PE) was added to the beads, incubated for 30 minutes in the dark at RT, then washed and read on the LABScan 100 flow cytometer (One Lambda Inc., Canoga Park, CA). With every assay a negative control serum (One Lambda Inc, Canoga Park, CA) was run to determine the background due to non-specific binding. All beads with normalized median fluorescence intensity value (i.e. raw MFI value of the test bead - MFI value of the negative control bead) $>2000$ were considered positive. This cut-off point was established based on the results from a previous study ${ }^{15}$.

\section{Statistical analysis}

All statistical analyses were performed using Statistical Package for the Social Sciences software (SPSS, Cary, NC). Graft survival was analyzed with the proportional hazards regression analysis (Cox regression) using stepwise forward selection and backward elimination techniques for a basic model including suspected patient, donor, transplant and clinical risk factors: "age of recipient (years)", "gender recipient (male vs. female)", "type of CNI at the time of transplantation (TAC vs. CSA)", "type of CNI at year 1 after transplantation (TAC vs. CSA)", "PRED at year 1 after transplantation (yes vs. no)" "CDC PRA\% current serum (non-immunized $<6 \%$ vs. immunized $\geq 6 \%$ )", "serum creatinine $\mu \mathrm{mol} / \mathrm{l}$ at year 1 grouped into quartiles $(<110 \mu \mathrm{mol} / \mathrm{l}$ vs. $110-140 \mu \mathrm{mol} / \mathrm{l}$ vs. $140-180 \mu \mathrm{mol} / \mathrm{l}$ vs. $>180 \mu \mathrm{mol} / \mathrm{l})$ ", "age of donor (years)", "donor type (living vs. heartbeating vs. donation after cardiac death)", "transplant number (first transplant vs. re-transplantation)", "mismatch HLA-A, -B, -DR, -DQ (0 vs. $\geq 1$ )", "cold ischemia time (hours)", "Acute rejection (no vs. yes)", "Delayed graft function (immediate graft function vs. delayed graft function". Results of DSA testing and interaction factors were then entered into the model that included the statistically significant risk factors from the basic model. Non-parametric tests (Pearson chi-square, 
Kruskall-Wallis) were performed when indicated, a P-value $<0.05$ was considered to be statistically significant.

\section{Results}

\section{DSA prevalence}

A total of 1107 sera of 140 renal transplant recipients (all pre-transplant DSA negative) with at least one year graft function were retrospectively tested for DSA using the Luminex Single antigen assay. The number of sera per patient was 5 to 17 (median 8). Median time of follow-up post-transplant was 11.4 years (range 1.1-14.7). During the follow-up period, 38 recipients lost their graft, 29 died with a functioning graft, and 73 continued to function. After transplantation DSA were shown in 35 out of the 140 recipients (25\%). DSA were HLA class I in 11 recipients (5 A, $6 \mathrm{~B}$ ) and class II in 20 (2 $D R, 13 D Q, 5 D R+D Q)$. Four recipients had both class I and II (2 A+B+DQ, $1 A+D Q, 1$ $A+D R$ ) (Table 4.2). DSA were detected in 83 out of 224 samples of the 35 positive recipients (mean per patient 6.4 ), none were shown at any time after transplantation in 883 samples of 105 negative recipients (mean per patient 8.4).

\section{Time of DSA detection}

DSA were detected early -in the first year after transplantation-, or late -after the first year post-transplant (Table 4.2). Early DSA were shown in 23 recipients (ID 1-23), in 16 for the first time at month 3 (70\%), in three at month $6(13 \%)$ and in four at year 1 post-transplant (17\%). Nine had class I, 12 class II, and two both I and II. Late DSA was shown in 12 recipients (ID 24-35) between year 2 and 10; two class I, 8 class II and two both I and II.

From the early DSA group $(n=23)$ six patients showed DSA positivity throughout the follow-up period (ID1-6), in four the antibodies disappeared and reappeared several years later (ID7-10). The remaining 13 patients presented with DSA in one or two sera and stayed negative thereafter (ID11-23). In the late DSA group 8 of 12 recipients had antibodies present throughout the follow-up period (ID 24-31), the remaining four showed antibody presence only in one or two sera and were negative thereafter (ID32-35).

The DSA specificities in the positive patients were consistent. With the exception of ID1, all patients maintained the locus specificities in all positive sera tested, as shown in Table 4.2. Only ID1, who presented with anti-DQ7 in all DSA-positive sera, showed the additional presence of $A 24$ and B35 in one sample (month 6). 
68 Chapter 4

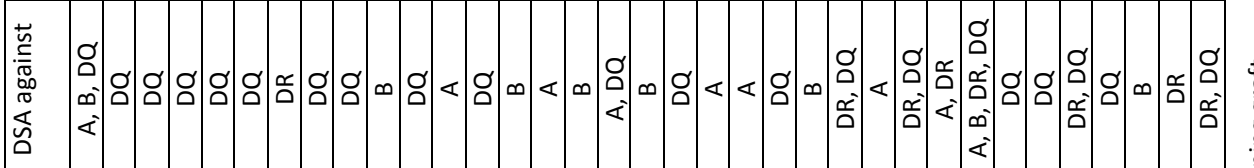

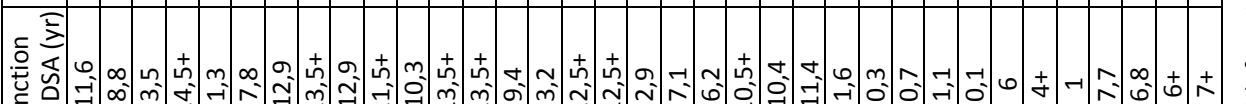
至

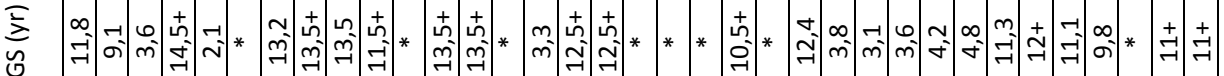

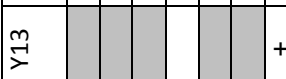

\begin{tabular}{|l|l|l|l|l|l|l}
\multirow{3}{*}{} & & & & & & + \\
\hline
\end{tabular}

$\stackrel{-1}{-}$

옥 $\quad$ (

이 +

$\stackrel{\infty}{>}$

乏

$\stackrel{0}{>}+++$

in

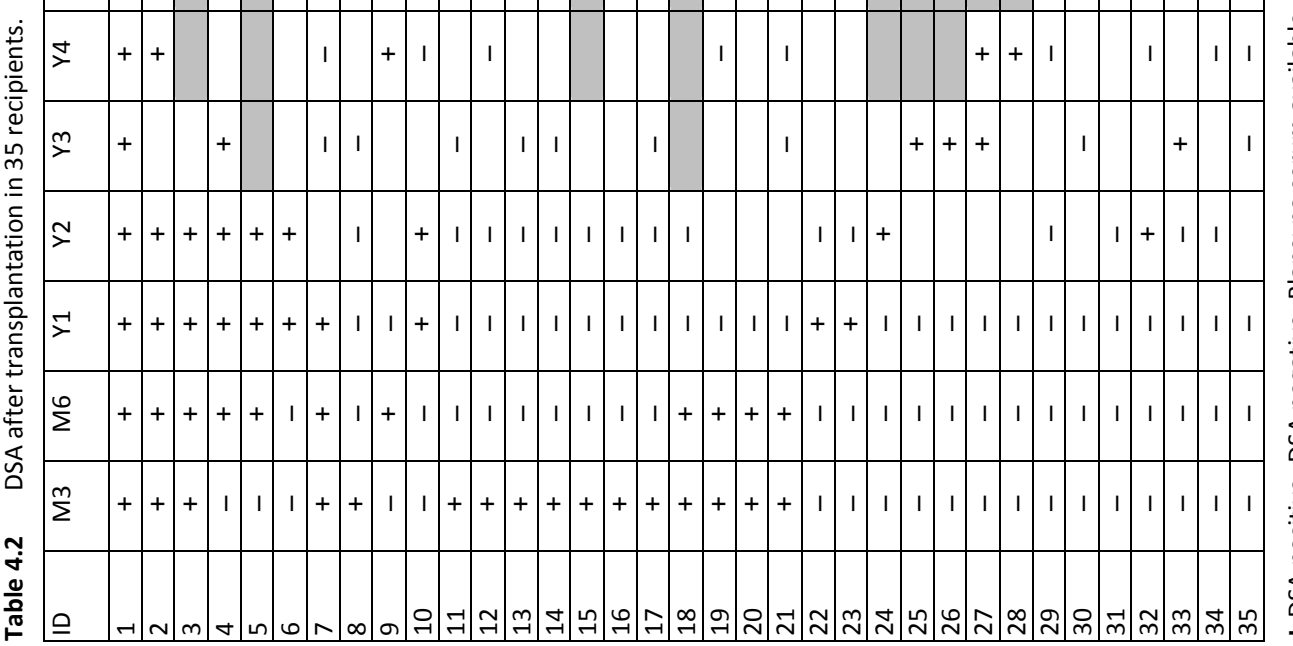




\section{Transient DSA}

A group of 17 recipients developed DSA for a short period of time but the antibodies disappeared and were not detected again during the follow up period. The time during which the DSA were present varied between 3 months and 2 years. These so-called "transient" DSA were seen both in the early ( $n=13$, ID11-23), and late ( $n=4$, ID32-35) group. Transient early DSA was class I in 8 , II in 4 and both in one recipient, transient late was class I in one and II in 3 patients.

Median Fluorescence Intensity (MFI) values obtained when testing transient DSA ranged from 2000-11500 MFI, with a median value of $3000 \mathrm{MFI}$. There was no difference between DSA class I (median 2750, range 2000-11500) and class II (median 3000, range 2000-7000). In contrast median MFI value in persistent positive patients was 12000 (range 2000-24000), while MFI values for DSA class II were considerably higher (median 14000, range 2000-24000) than those for class I (median 2400, range 2000-15500) ( $P=0.01)$.

\section{Clinical outcome}

From the 140 patients included in the study, 38 lost their graft function during the follow-up period; they were re-transplanted or returned to renal replacement therapy. Overall actuarial graft survival at the end of the follow-up period was $72.9 \%$. Of the 38 recipients who lost their graft, 16 (42\%) were DSA-positive, compared to 19 (18\%) in 102 recipients who died with functioning graft or are still functioning $(X 2=8.39$, $P=0.004)$. The grafts of the persistent positive patients had functioned in the presence of DSA from 1.3-13.5 years. From the DSA positive patients $(n=35), 17$ grafts $(49 \%)$ failed, whereas from the DSA-negative $(n=105) 21$ grafts $(20 \%)$ failed $(X 2=10.84$, $\mathrm{P}=0.001)$.

To test for donor-, recipient-, and transplant risk factors involved in death censored graft loss, multivariate analysis by Cox regression analysis was performed. First we analyzed a basic model without the inclusion of the DSA result. From the risk factors tested for in the basic model, delayed graft function (DGF) was the only significant one contributing to graft survival (Table 4.3). All other factors tested had a P-value from 0.14-0.99: $\mathrm{CIT} P=0.99$, HLA mm B $\mathrm{P}=0.96$, age recipient $\mathrm{P}=0.95$, donor type (living vs. heart-beating $(\mathrm{HB})$ vs. donation after cardiac death $(\mathrm{DCB})) \mathrm{P}=0.93$, gender recipient $P=0.91, C D C$ immunization (non-sensitized vs. sensitized) $P=0.90$, IS PRED at year one $\mathrm{P}=0.84$, age donor $\mathrm{P}=0.68$, IS CNI at year one $\mathrm{P}=0.58$, HLA mm DQ $\mathrm{P}=0.50, \mathrm{HLA} \mathrm{mm} A$ ( $0 \mathrm{~mm}$ vs. $>=1$ ) $P=0.50$, IS CNI at time of transplant (TAC vs. CSA) $p=0.47$, acute rejection (no vs. yes) $P=0.40$, first $T X$ vs. reTX $P=0.22$, serum creatinine at year one (quartiles) $\mathrm{P}=0.14$, HLA mm DR $P=0.14$. Subsequently DSA positivity was introduced as risk factor to the model. DSA class II positivity persisting or appearing after year 1 significantly improved the model that predicts long-term graft survival. Recipients with 
class II DSA after the first year post-transplant are 3.2 times $(\mathrm{Cl}$ 1.68-6.46) more at risk for graft failure, even when taking into account DGF, the other factor that influenced graft survival. DGF and DSA class II positivity were not associated ( $P=0.71)$. Class I DSA persistent or appearing after the first year post-transplant was a significant factor if introduced in the basic model ( $\mathrm{OR}=3.31, \mathrm{Cl} 1.16-1.49, \mathrm{P}=0.03)$, but did not remain significant in the multivariate analysis when introduced together with DSA class II positivity. Actuarial 5-year graft survival (Kaplan Meier) in class II DSA positive recipients after year $1(n=19)$ was $68 \%$ vs. $91 \%$ in DSA negative recipients, 10 -year graft survival was $57 \%$ vs. $80 \%$ (Figure 4.1 ).

Table 4.3 Cox regression analysis of graft survival censored for death with functioning graft: significant risk factors in basic model (chi-square $=18.58, \mathrm{df}=2 \mathrm{P}=0.000$ ) and entry of DSA results.

\begin{tabular}{lcccc}
\hline Basic model & Odds Ratio & $95 \% \mathrm{Cl}$ & $\mathrm{df}$ & $\mathrm{P}$-value \\
\hline $\begin{array}{l}\text { Delayed graft function } \\
\text { Entry of DSA results in basic model }\end{array}$ & 2.04 & $1.08-3.87$ & 1 & 0.028 \\
1 DSA class I positive before Y1 & 1.15 & $0.41-3.26$ & 1 & 0.79 \\
2 DSA class II positive before Y1 & 1.67 & $0.69-4.01$ & 1 & 0.25 \\
3 DSA class I positive after Y1 & 3.31 & $1.16-9.45$ & 1 & $0.03^{*}$ \\
4 DSA class II positivity after Y1 & 3.23 & $1.68-6.46$ & 1 & $0.001^{* *}$ \\
Interaction between DGF and 4 & 0.78 & 0.71 & & \\
\hline
\end{tabular}

* Disappears after addition of class II; ** Change from basic model chi-square=10.70 df=1 P=0.001

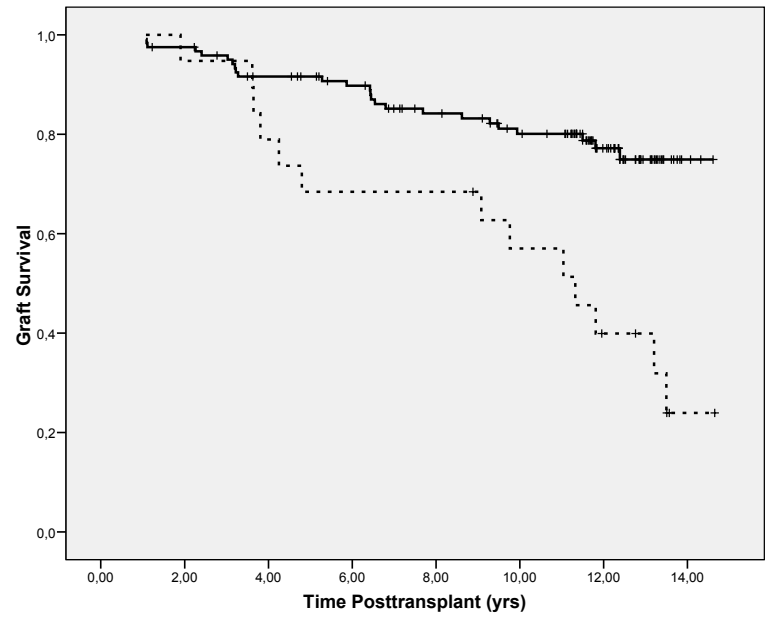

Figure 4.1 Graft survival according to DSA class II positivity after the first year post-transplant.

Kaplan-Meier curve of graft-survival for DSA class II negative (solid line, $n=121$ ) and positive (after the first year post-transplant) recipients (dotted line, $n=19$ ). 
The graft survival of patients with transient DSA class II was comparable to the graft survival of transient DSA class I positive and DSA-negative patients $(P=0.51)$. Positivity in recipients with "transient" DSA was not related to clinical parameters such as rejection episodes, rise in serum creatinine, proteinuria or change in immunosuppressive regimen (data not shown).

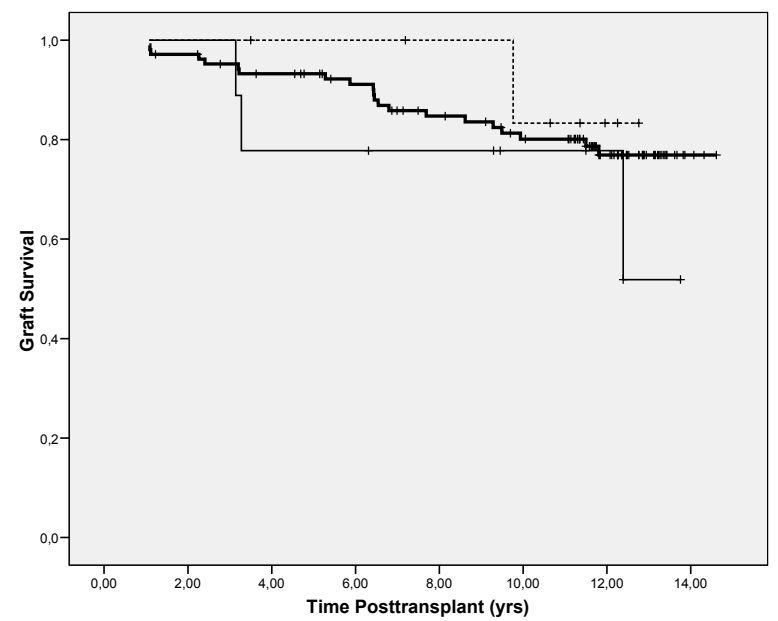

Figure 4.2 Graft survival in transient class I and class II DSA-positive patients compared to DSA-negative patients.

Kaplan-Meier curve of graft survival in DSA negative recipients (bold line), recipients with transient class I DSA (dotted line) and transient class II DSA (solid line).

\section{Discussion}

This single center study analyzed the frequency and nature of HLA DSA after kidney transplantation. The presence of DSA was monitored from the time of transplantation up to 15 years thereafter. All patients were DSA negative before transplantation, had at least 1 year of renal function and an average of 8 serum samples was tested per patient. The class and specificity of the antibodies was determined by the Single antigen assay. We concentrated on "de novo" donor specific antibody formation, nonDSA were not included in the analysis. The inclusion of as many serum samples as possible in the study enabled us to detect changes in DSA if any, over the posttransplant years. The strength of the present study is the screening for "de novo" DSA during a follow-up period of up to 15 years in a cohort of consecutive renal transplant recipients.

DSA developed after transplantation in $25 \%$ of a consecutive series of kidney transplant recipients. The DSA were more often class II (60\%) than class I, the high 
number of patients with anti-DQ antibodies was remarkable. Only few patients had both classes of antibody (10\%). From the patients who lost their graft, $42 \%$ was DSA positive compared to $18 \%$ of the remaining patients, showing that the presence of antibodies is associated with graft survival, but does not necessarily lead to an immediate deleterious effect on graft-function. The absence of graft-dysfunction in the presence of DSA is possibly the result of accommodation, a phenomenon mainly known from $A B O$ incompatible transplants ${ }^{16}$.

The DSA were detected in the majority of the patients within one year after grafting $(66 \%)$, the remaining appeared after the first year post-transplant at different time points during the follow-up period. From 18 persistent DSA positive patients, 13 lost their graft after having been DSA positive for 0.6 up to 13.5 years. In general DSA were persistent once detected, as was the specificity of the antibodies detected. Only one patient (ID 1) showed next to the persistent DQ7 antibody in his serum samples, the additional presence of 2 class I donor specific antibodies in one sample, however the class I antibodies disappeared after 6 months.

A distinct group of 17 patients presented with DSA during a short period of time only, thereafter the antibodies disappeared. We called them patients with "transient" DSA. Patients with transient DSA were found both early (ID 11-23) and late (ID 32-35) after transplantation, the DSA were more often class I than class II. Of the 17 transient DSA-positive recipients only three lost their graft during the follow-up period, patients with transient DSA seemed to have the same risk of graft failure as DSA negative recipients. Transient DSA could not be shown to have an effect on graft survival. To our knowledge transient antibodies have not been described previously in studies on chronic rejection, but studies as the present one with long-term follow-up of sera and patients, are rare. In the transient DSA patients no difference in graft survival was found between DSA class I and II, however the numbers in the analysis were small and the number of patients with DSA class II after year-1 is only 3.

The strength of the antibodies detected in the Luminex Single antigen assay is expressed as MFI. When the MFI values for the persistent and transient DSA were compared, the transient DSA proved to have significantly lower MFI values. MFI values for transient DSA had a median value of 3000, compared to $12000 \mathrm{MFI}$ for persistent DSA. For persistent DSA a difference was also shown between class I and II, median MFI for class I was 2400 and for class II 14000. This is a puzzling finding, although class II DSA are found more often than class I, the difference in MFI value is unexpected. The one patient (ID 1) who presented with persistent class II DSA and transient class I fitted the persistent/transient MFI profile.

These findings again point to the fact that defining the cut off point for positivity in the Single antigen assay is not easy. Where the blessing of the technique is the clear and 
sensitive determination of the distinct HLA antibody specificities, the question remains whether all the HLA antibodies whose presence is determined, are also clinically relevant. In a previous paper we already showed that DDA detected by SA and not by less sensitive methods may be related to acute rejection episodes, but are not detrimental to long-term graft outcome ${ }^{17}$ This is consistent with our findings in the analysis of 103 cytotoxic typing sera. All cytotoxic class I and II antibodies had MFI values $>4000$ in $99 \%$ of the class I and $92 \%$ of the class II sera (data not published). On the basis of these results, for our transplant center the decision was taken that only antibody in pre-transplant sera with an MFI value $>4000$, would be considered positive for clinical purposes. Although lower MFI values may represent harmful DSA in occasional patients, we believe this to be a small minority.

DSA was strongly associated with graft survival $(P=0.001)$ in univariate analysis. Risk factors reported to be associated with long-term graft survival were included in multivariate Cox regression analysis. DSA class II positivity persistent or appearing after year 1 proved to be significantly associated with long-term graft survival. Recipients with class II DSA after the first year post-transplant are 3.2 times more at risk for graft failure, even when taking into account other factors that influence graft survival such as DGF. Class I DSA after the first year post-transplant were not an independent significant factor in the multivariate analysis in addition to class II DSA, nor were either class I or II when only present in the first year post-transplant. From our data it is not possible to conclude whether it is the specificity or the MFI value that is more related to a worse clinical course, because the higher MFI values are predominantly found for the class II DSA.

Interesting are the nine patients, who were DSA class II positive both before and after year 1 post transplant. Although in five of them the MFI values of the positive sera in the first year post-transplant were 19.500-22.300, this was not correlated with an immediate clinical event at that time. One patient still has a functioning graft after 15 years, one died with functioning graft after 8.8 years, while the others had graft failure at 3.6, 9.0, and 11.8 years. From the seven patients, who were positive only after the first year post-transplant, one still has a functioning graft after 15 year, while the other six had graft failure at 3.6, 3.8, 4.2, 4.8, 11.0 and 11.3 year. Although these are small numbers, the results are suggestive of worse graft survival for patients with persistent DSA class II appearing after year I. This is in contrast with the findings by Lee et al., that development of HLA antibodies within the first year post-transplant markedly lowered allograft survival compared with later antibody development ${ }^{12}$.

Actuarial 5-year graft survival (Kaplan-Meier) in class II DSA positive recipients after year 1 was $68 \%$ versus $91 \%$ in DSA negative recipients, 10 -year graft survival was $57 \%$ versus $80 \%$. Actuarial 10 -year graft survival for transient DSA positive (class I and class II) and DSA negative recipients was comparable $( \pm 80 \%)$. 
The role of class II antibodies in graft survival has been described before. Lachmann et al. tested patients with a minimum of 6 months stable kidney function, at a median of 5 years post-transplant for the presence of DSA in one serum sample. The patients were antibody negative by CDC and ELISA at the time of transplant. DSA were mainly against HLA class II antigens, especially HLA-DQ. They concluded that class II DSA, even when produced late after transplantation, are detrimental to graft outcome ${ }^{18}$, which is in accordance with our present findings. Campos et al. studied recipients with a minimum of 3 years stable kidney function once for the presence of HLA antibodies at a median 4.4 years post-transplant ${ }^{19}$. The presence of HLA class II antibodies was a risk factor for graft loss even before a decline in renal function was shown; the detection technique however was ELISA. Hidalgo et al. tested for DSA in sera drawn the time of clinically indicated biopsies (7 days-31 years). De novo DSA at the time of a late biopsy is primarily against class II, and is associated with histopathological changes in the biopsy and subsequent graft failure ${ }^{13}$.

Gill et al. tested for DSA using FlowPRA in the first year post-transplant. No difference in graft loss could be shown between recipients with and without de novo HLA antibodies during the first year post-transplant. These findings support our analysis that DSA, developed in the first year post-transplantation and not persisting after the first year, have no effect on graft loss ${ }^{20}$.

In a recent case-controlled study, Lee et al. looked at DSA and non-DSA in a selected patient group. Antibodies developed within the first year after transplantation resulted in graft failure after a mean of 5 years, while $80 \%$ of the recipients who developed HLA antibodies after one year had a graft survival of 10 years. Their conclusion that HLA antibody development within the first year post-transplant decreases graft survival, compared to later antibody development, was not supported by our findings. However, this study differs essentially from the one described here, because the patients were selected and patients with pre-transplant DSA were included ${ }^{12}$.

In conclusion, our study shows that post-transplant DSA is detected in $25 \%$ of recipients, slightly more class II than I. DSA presence is associated with graft survival, but does not necessarily lead to an immediate loss of graft function. Only class II DSA, persistent or appearing more than one year after transplantation, turned out to result in worse clinical outcome. Patients with DSA had a functioning graft in the presence of DSA for 1.3 to 13.5 years. Most of the DSA found are persistent throughout the follow-up period, but in a number of patients the DSA are transient, characterized by lower MFI values than the persistent ones, and presence of transient DSA is not related to graft survival. 


\section{References}

1. Terasaki PI. Humoral theory of transplantation. Am J Transplant 2003;3:665-73.

2. Terasaki PI, Ozawa M. Predictive value of HLA antibodies and serum creatinine in chronic rejection: results of a 2-year prospective trial. Transplantation 2005;80:1194-7.

3. Christiaans M, Overhof-Roos de R, Nieman F, Hooff van JP, Berg van-den Loonen EM. Donor-specific antibodies after transplantation by flow cytometry. Transplantation 1998;65:427-33.

4. Abe M, Kawai T, Futatsuyama K, Tanabe K, Fuchinoue S, Teraoka S, Toma H, Ota K. Postoperative production of anti-donor antibody and chronic rejection in renal transplantation. Transplantation 1997;63:1616-9.

5. McKenna RM, Takemoto SK, Terasaki PI. Anti-HLA antibodies after solid organ transplantation. Transplantation 2000;69:319-26.

6. Mao Q, Terasaki PI, Cai J, Briley K, Catrou P, Haisch C, Rebellato L. Extremely high association between appearance of HLA antibodies and failure of kidney grafts in a five-year longitudinal study. Am J Transplant 2007;7:864-71.

7. Terasaki PI, Ozawa M. Predicting kidney graft failure by HLA antibodies: a prospective trial. Am J Transplant 2004;4:438-43.

8. Lee PC, Terasaki PI, Takemoto SK, Lee PH, Hung CJ, Chen YL, Tsai A, Lei HY. All chronic rejection failures of kidney transplants were preceded by the development of HLA antibodies. Transplantation 2002;74:1192-4.

9. Terasaki PI, Cai J. Humoral theory of transplantation: further evidence. Curr Op Immunol 2005;17: 541-5.

10. Berg van den-Loonen EM, Terasaki $P$, Kohanof $S$, Christiaans MHL. Chapter 22. Longitudinal testing of 76 renal allograft patients for HLA antibodies: Maastricht experience. In: P T, ed. Clinical Transplants 2006. Los Angeles: Terasaki Foundation Laboratory, 2006:305.

11. Hourmant M, Cesbron-Gautier A, Terasaki PI, Mizutani K, Moreau A, Meurette A, Dantal J, Giral M, Blancho G, Cantarovich D, Karam G, Follea G, Soulillou JP, Bignon JD. Frequency and clinical implications of development of donor-specific and non-donor-specific HLA antibodies after kidney transplantation. J Am Soc Nephrol 2005;16:2804-12.

12. Lee PC, Zhu L, Terasaki PI, Everly MJ. HLA-specific antibodies developed in the first year posttransplant are predictive of chronic rejection and renal graft loss. Transplantation 2009;88:568-74.

13. Hidalgo LG, Campbell PM, Sis B, Einecke G, Mengel M, Chang J, Sellares J, Reeve J, Halloran PF. De novo donor-specific antibody at the time of kidney transplant biopsy associates with microvascular pathology and late graft failure. Am J Transplant 2009;9:2532-41.

14. Christiaans MHL, Hooff van JP, Nieman F, Berg van den-Loonen EM. HLA-DR matched transfusions: development of donor-specific T- and B-cell antibodies and renal allograft outcome. Transplantation 1999;67:1029-35.

15. Billen EVA, Christiaans MHL, Lee J, Berg van den-Loonen EM. Donor-directed HLA antibodies before and after transplantectomy detected by the Luminex single antigen assay. Transplantation 2009;87: 563-9.

16. Higgins R, Lowe D, Hathaway M, Lam F, Kashi H, Tan LC, Imray C, Fletcher S, Chen K, Krishnan N, Hamer $R$, Zehnder D, Briggs D. Rises and falls in donor-specific and third-party HLA antibody levels after antibody incompatible transplantation. Transplantation 2009;87:882-8.

17. Berg van den-Loonen EM, Billen EVA, Voorter CEM, van Heurn LW, Claas FH, van Hooff JP, Christiaans $\mathrm{MH}$. Clinical relevance of pretransplant donor-directed antibodies detected by single antigen beads in highly sensitized renal transplant patients. Transplantation 2008;85:1086-90.

18. Lachmann N, Terasaki PI, Budde K, Liefeldt L, Kahl A, Reinke P, Pratschke J, Rudolph B, Schmidt D, Salama A, Schönemann C. Anti-human leukocyte antigen and donor-specific antibodies detected by luminex posttransplant serve as biomarkers for chronic rejection of renal allografts. Transplantation 2009;87:1505-13.

19. Campos EF, Tedesco-Silva H, Machado PG, Franco M, Medina-Pestana JO, Gerbae-DeLima M. Posttransplant anti-HLA class II antibodies as risk factor for late kidney allograft failure. Am J Transplant 2007;6:2316-20. 
20. Gill JS, Landsberg D, Johnston O, Shapiro RJ, Magil AB, Wu V, Tinckam K, Keown P. Screening for de novo anti-human leukocyte antigen antibodies in nonsensitized kidney transplant recipients does not predict acute rejection. Transplantation 2010;89:178-84. 


\section{Chapter 5}

Donor-directed HLA antibodies before and after transplantectomy detected by the Luminex Single antigen assay

EVA Billen, MHL Christiaans, JH Lee, EM van den Berg-Loonen Transplantation 2009 87: 563-569 


\section{Abstract}

\section{Background}

Donor-directed antibodies (DDA) have been shown to result in poor graft survival. This study was designed to analyze antibody appearance and patient and graft characteristics related to antibody formation in patients who lost their graft at different time points after transplantation.

\section{Methods}

Pre- and post-transplant sera of 56 DDA negative first transplant patients were screened for human leukocyte antigen (HLA) class I and II DDA by the Luminex Single antigen assay (LSA). All patients were treated with calcineurine inhibitor-based immunosuppression.

\section{Results}

Three of 56 patients proved DDA positive by LSA before transplantation. Eighty-one percent of the remaining 53 patients became DDA class I or II positive or both; $16 \%$ before and $84 \%$ after transplantectomy. Class I antibodies were produced in $84 \%$ and class II in $77 \%$ of the recipients. Based on time of transplantectomy, three groups were created as follows: less or equal to 1 month, 1 to 6 months and more than 6 months. The groups proved to be significantly different for HLA class II mismatch and acute rejection. All recipients in group 1 to 6 months proved to be DDA positive. Logistic regression analysis showed that DDA positivity for class I was related to higher donor age and donor type (non-heart-beating), class II to higher donor age and class II mismatch.

\section{Conclusions}

Donor-directed HLA antibodies after transplantation were demonstrated in $81 \%$ of first transplant recipients, all of whom were DDA negative by LSA before transplantation. The majority of the antibodies were found after transplantectomy. These findings may have to be taken into consideration in the allocation of organs of marginal donors such as older or non-heart-beating kidneys. 


\section{Introduction}

Donor-directed human leukocyte (HLA) antibodies (DDA) newly formed after transplantation have been shown to result in poor graft outcome ${ }^{1-4}$. HLA antibodies have been demonstrated even before transplant rejection ${ }^{5,6}$. The results of these studies led to the suggestion that demonstrable HLA antibodies in recipients after transplantation are predictive of graft outcome and present a useful tool in monitoring of graft function.

DDA detected by Luminex bead-based assays were demonstrated in post-transplant sera and also on transplant eluates ${ }^{7-10}$. DDA fixed to the transplant can lead to a possible underestimation of HLA antibodies in post-transplant sera of recipients with their graft in situ. The high number of recipients that remained antibody negative after transplantation, but turned positive after transplantectomy, arose our interest. We wondered whether in addition to post-transplant events, also patient and graft characteristics might be related to DDA positivity. The results on patients with a transplantectomy within 1 month after grafting were reported previously ${ }^{11}$.

In contrast to many reports in the literature, we have not been able to demonstrate HLA antibodies before graft failure in earlier studies using conventional screening methods. The present study was designed with the hypothesis that antibodies before transplant failure would be detectable when using more advanced and sensitive methods. At present, the most sensitive antibody screening technique is the Luminex Single antigen assay (LSA). Only patients with no DDA before their first transplantation were included. Production of DDA, time of appearance, and antibody class were analyzed. Antibody production was correlated with matching grade, donor and patient characteristics.

\section{Materials and Methods}

\section{Patients}

From 541 patients transplanted with a first kidney graft between January 1992 and January 2005 at the University Hospital of Maastricht, 483 were HLA antibody negative in complement-dependent cytotoxicity (CDC) and ELISA before transplantation. Ninetysix of them underwent transplantectomy before 2005 . When tested by flow cytometric (FC) screening, another 27 proved HLA antibody positive before transplantation. From 13 recipients no serum samples were available. Therefore 56 patients were included in the study. They were analyzed taking into account the time of transplantectomy and divided into groups I (transplantectomy <1 month), II (1-6 months) and III (>6 months). 
Pretransplant patient characteristics are given in Table 5.1. Clinical follow-up was continued until 6 months after transplantectomy.

Table 5.1 Patient characteristics: All patients and time of transplantectomy groups.

\begin{tabular}{|c|c|c|c|c|}
\hline Parameter & $\begin{array}{l}\text { All patients } \\
\qquad(n=53)\end{array}$ & $\begin{array}{l}\text { Group I } \\
<1 \mathrm{mo} \\
(\mathrm{n}=23)\end{array}$ & $\begin{array}{c}\text { Group II } \\
1-6 \text { mo } \\
(n=13)\end{array}$ & $\begin{array}{c}\text { Group III } \\
>6 \text { mo } \\
(n=17)\end{array}$ \\
\hline Median recipient age (years [range]) & $52(17-72)$ & $47(17-71)$ & $57(24-72)$ & $52(19-66)$ \\
\hline Male gender & $32(60 \%)$ & $14(60 \%)$ & $7(54 \%)$ & $11(65 \%)$ \\
\hline Female recipients with pregnancies & $11 / 21$ & $5 / 9$ & $4 / 6$ & $2 / 6$ \\
\hline Donor type (L/HB/non-HB \%) ${ }^{a}$ & $17 / 43 / 40 \%$ & $26 / 30 / 44 \%$ & $15 / 31 / 54 \%$ & $6 / 71 / 23 \%$ \\
\hline Median donor age (years [range]) & $52(1-90)$ & $47(1-74)$ & $60(17-90)$ & $51(2-65)$ \\
\hline HLA-A, B mismatch (mean) & 1.81 & 1.78 & 1.92 & 1.65 \\
\hline HLA-DR mismatch (mean) ${ }^{\mathrm{a}}$ & 0.77 & 0.82 & 1.07 & 0.47 \\
\hline Median day of tect & $50(2-3619)$ & $5(2-22)$ & $89(32-150)$ & $428(187-3619)$ \\
\hline Acute rejection * & $30 \%$ & $9 \%$ & $77 \%$ & $24 \%$ \\
\hline
\end{tabular}

${ }^{\mathrm{a}}$ Nonparametric test for differences between group I, II, and III $\mathrm{P}<0.05 ; \mathrm{HLA}$, human leukocyte antigen.

\section{Immunosuppression}

The immunosuppressive regimen was calcineurine inhibitor-based in all recipients; tacrolimus (TAC) in 38 recipients and cyclosporine $A(\operatorname{CsA})$ in 18. Additional immunosuppression to TAC was prednisone (PRED) in 34, mycophenolate mofetil (MMF) in 12, daclizumab in one and rapamycine (RAPA) in nine patients. In addition to CSA, PRED was added in 18 and azathioprine in two recipients. CsA levels were determined in whole blood by enzyme monoclonal immuno test (Dade Behring, Newark, DE) or high performance liquid chromotography-MS/MS. In the first 3 months after transplantation, target CSA trough-levels for CSA+PRED treated recipients were 0.15 to $0.20 \mathrm{mg} / \mathrm{l}$ and for CSA+PRED+azathioprine-treated recipients 0.10 to $0.15 \mathrm{mg} / \mathrm{l}$. TAC trough levels were measured in whole blood by Imx (Abbott, Abott Park, IL) or high performance liquid chromotography-MS/MS, target levels were 15 to $20 \mathrm{ng} / \mathrm{ml}$ for weeks 1 and 2, 10 to $15 \mathrm{ng} / \mathrm{ml}$ for weeks 3 and 4 , thereafter tapering to 5 to $7 \mathrm{ng} / \mathrm{ml}$. Immunosupression was cessated after removal of the graft.

\section{Clinical Outcome Parameters}

A biopsy was taken during surgery $1 \mathrm{hr}$ after reperfusion for every transplant. Rejection was defined as any rejection treatment within 3 months after grafting and was proven by needle core biopsy. Treatment consisted of three doses of methylprednisolone ( 0.5 to $1.0 \mathrm{~g} /$ dose) in 15 patients, two of which received additional doses of antithymocyte globulin. Sixteen of 56 recipients received rejection treatment or had a positive rejection histology in the explanted graft according to the Banff criteria. Because of the retrospective nature of the study, no material for $\mathrm{C} 4 \mathrm{~d}$ staining was available. 


\section{Serum Collection}

Non-transfused patients received one leukocyte-poor protocollary blood transfusion before being placed on the transplant waiting list. After transplantation, sera were drawn weekly during hospitalization, monthly in the first half year, and yearly thereafter. After transplantectomy, sera were collected at week 0, 2, 4 and 6 and at month $2,3,4,5$, and 6 . Sera were stored at $-30^{\circ} \mathrm{C}$ and centrifugated for $10 \mathrm{~min}$ at $10.000 \mathrm{~g}$ prior to testing. Per patient, the pre-transplant serum, a post-transplant but pre-transplantectomy serum, and two post-transplantectomy sera drawn at week 6 and at months 2 to 6 were analyzed.

\section{HLA Antibody Analysis by Luminex Single antigen assay}

Specificity of HLA class I and II IgG antibodies in recipient sera was determined using the LABScreen SA assay (One Lambda, Canoga Park, CA) according to the manufacturer's instructions. Microbeads coated with purified HLA were incubated with patient serum for $30 \mathrm{~min}$. After washing to remove unbound antibody, the beads were incubated for 30 min with anti-human IgG-conjugated phyco-erythrine. All incubations were performed on a gently rotating platform in the dark at room temperature. The LABScan 100 flow analyser (Luminex, Austin, TX) and HLA-Visual software (One Lambda) were used for data acquisition and analysis. All beads with a normalized median fluorescence intensity (MFI) value (i.e., raw MFI value of the test bead MFI value of the negative control bead) more than 2000 were defined as positive. This cutoff point was chosen because MFI more than 2000 is associated with a positive FC crossmatch $^{9,12}$.

\section{Crossmatches}

Before transplantation three complement-dependent crossmatches were performed: the standard NIH crossmatch, standard NIH with dithiothreitol to reduce IgM antibodies, and a two-color fluorescence crossmatch. Sera used for the final crossmatches were the pretransplant serum drawn at the time of transplantation, the last serum tested for anti-HLA antibodies in the quarterly screening and all relevant positive historical samples. A negative class I dithiothreitol crossmatch was mandatory for transplantation.

\section{Center Policy of Tissue Typing}

During the investigation period the patients and donors were typed for HLA-A, -B, -DR and $-\mathrm{DQ}$ by serology and polymerase chain reaction-sequence-specific primers. HLA antigens were considered unacceptable for a patient if antibodies against the specificity had ever been demonstrated, either at the time of transplantation or in the past. Mismatches from previous transplants were excluded, as were the paternally 
inherited antigens of children of female patients. All transplants were performed under the auspices of Eurotransplant, which means that only HLA-A, -B and -DR matches were included in the allocation algorithm.

\section{Statistical Analysis}

Statistical analyses were performed by using Statistical Package for the Social Sciences software (SPSS, version 15.0 for Windows).

Nonparametric tests were performed when indicated. A P-value less than 0.05 was considered to be statistically significant. The suspected risk factors for total HLA antibody positivity and for HLA class I and class II positivity separately, that were tested as independent variables in stepwise backward logistic regression were as follows: 'mismatch HLA class I ( 0 vs. $\geq 1$ )', 'mismatch HLA class II ( 0 vs. 1 vs. $\geq 2$ )', 'recipient gender (male vs. female)', 'donor age (years)', 'recipient age (years)', 'acute rejection within 3 months ( 0 vs. 1)', 'donor type (living vs. postmortal)', for 'postmortal donor (heart-beating vs. non-heart-beating)' and 'time of transplantectomy (group I-IIIII). P-value for removal in the model of the possible independent variables was set at $P=0.05$. All interaction factors were introduced separately into the final model.

\section{Results}

Transplantectomy was performed in 56 first kidney graft recipients, who were all HLA antibody negative before transplantation based on screening by CDC, ELISA and flow cytometry. Their sera were now analyzed with LSA. Three of 56 recipients proved to possess DDA in their pretransplant serum; one patient was class I and two patients were class II DDA positive. They were excluded from further analysis. The patient characteristics of the remaining 53 recipients are given in Table 5.1.

Non-DDA specificities were demonstrated in the pretransplant sera of 20 of 53 recipients (38\%). They were directed against class I in 55\%, class II in $5 \%$, and both class I+II in $40 \%$ of the recipients. Specificities of non-DDA in pretransplant sera could be explained by transfusions and pregnancies. Possession of non-DDA was not an indication for exclusion from the analysis. After transplantation, non-DDA were demonstrated in 46 of 53 recipients (87\%), class I in $65 \%$, class II in $11 \%$, and class I+II in $24 \%$ of the recipients.

After transplantation, 10 of 53 recipients (19\%) stayed DDA negative after transplantation and transplantectomy. DDA positivity was demonstrated in 43 recipients (81\%) (Table 5.2). Seven of 43 recipients (16\%) showed DDA before transplantectomy (two class I and five class II), whereas in $36(84 \%)$ they appeared thereafter. After transplantectomy, $37 \%$ of the patients turned positive in the 6 -week serum, whereas $100 \%$ were found positive in the 2 to 6 month serum. 
Table 5.2 Post-transplant DDA in patients who underwent transplantectomy.

\begin{tabular}{lcccr}
\hline DDA antibody & All patients & $\begin{array}{c}\text { Group I } \\
<1 \mathrm{mo} \\
(\mathrm{n}=23)\end{array}$ & $\begin{array}{r}\text { Group II } \\
1-6 \mathrm{mo} \\
(\mathrm{n}=13)\end{array}$ & $\begin{array}{r}\text { Group I } \\
>6 \mathrm{mo} \\
(\mathrm{n}=17)\end{array}$ \\
\hline Total negative & $(\mathrm{n}=53)$ & $5(22 \%)$ & $0(0 \%)$ & $5(29 \%)$ \\
Total positive & $10(19 \%)$ & $18(78 \%)$ & $13(100 \%)$ & $12(71 \%)$ \\
$\quad$ Class I & $43(81 \%)$ & $15(65 \%)$ & $12(92 \%)$ & $8(47 \%)$ \\
Class II & $37(70 \%)$ & $12(52 \%)$ & $12(92 \%)$ & $9(53 \%)$ \\
\hline
\end{tabular}

DDA, donor-directed antibodies

\section{HLA DDA antibodies}

HLA class I and II antibody specificities were analyzed in the 43 patients, who became positive after transplantation. DDA antibodies directed against class I were detected in $23 \%$ of the recipients, against class II in $16 \%$, and against both class I and II in $61 \%$ of the positive recipients. DDA after transplantectomy were directed against class I, II, and $\mathrm{I}+\mathrm{II}$ in $25 \%, 14 \%$, and $61 \%$, respectively. The specificities of the DDA are shown in Table 5.3.

\section{DDA and rejection}

Of the 16 recipients diagnosed with acute rejection, 15 (94\%) had post-transplant DDA versus 28 of $43(65 \%)$ patients without rejection $(P=0.12)$. In rejectors, DDA were detected before transplantectomy in four and in 11 thereafter. Three non-rejectors had DDA before and 25 after transplantectomy. This difference in DDA detection before and after transplantectomy was again not statistically significant $(P=0.09)$. The antibody class of the DDA detected in rejectors and non-rejectors is explained in Table 5.4. In rejectors, a higher incidence of combined class I+II DDA was found $(P=0.16)$.

\section{Time of transplantectomy}

Time of transplantectomy ranged from 1 day to more than 10 years after transplantation. Differences in demographic and clinical parameters depending on time of transplantectomy were explored by means of non-parametric statistical tests. Patients were divided into 3 groups: I transplantectomy less than 1 month $(n=23)$, II 1 to 6 months $(n=13)$ and III more than 6 months $(n=17)$. The patient characteristics are given in Table 5.1. Group II proved to be significantly different for HLA class II mismatch $(P=0.02)$ and occurrence of acute rejection $(P<0.001)$. There was a trend towards a difference in the number of non-heart-beating (NHB) donors ( $P=0.07)$. The number of patients becoming DDA positive in group I was $78 \%$, in group II $100 \%$, and in group III 71\% ( $\mathrm{P}=0.11$ ) (Table 5.2 ). 
Table 5.3 DDA positive recipients: HLA mismatch and DDA class I and II specificities.

\begin{tabular}{|c|c|c|c|c|c|c|}
\hline \multirow[t]{2}{*}{ Recipient } & \multicolumn{4}{|c|}{ HLA mismatch } & \multirow[t]{2}{*}{ Class I } & \multirow[t]{2}{*}{ Class II } \\
\hline & A & B & DR & $\mathrm{DQ}$ & & \\
\hline 1 & 1 & 0 & 1 & 0 & A28 & DR13 \\
\hline 2 & 0 & 1 & 1 & 1 & B51 & DR4 DQ3 \\
\hline 3 & 1 & 1 & 0 & 1 & A66 & DQ4 \\
\hline 4 & 0 & 1 & 1 & 0 & B18 & DR14 \\
\hline 5 & 1 & 1 & 0 & 1 & A31 & DQ3 \\
\hline 6 & 1 & 1 & 1 & 1 & A2 B62 & DQ3 \\
\hline 7 & 1 & 1 & 2 & 0 & A11 B8 & DR11 DR14 \\
\hline 8 & 1 & 1 & 1 & 1 & A11 B61 & DR10 DQ1 \\
\hline 9 & 0 & 1 & 1 & 1 & B7 & DR15 DQ1 \\
\hline 10 & 2 & 1 & 1 & 1 & A1 A32 B62 & DR11 DQ3 \\
\hline 11 & 0 & 1 & 1 & 0 & B44 & DR13 \\
\hline 12 & 2 & 1 & 0 & 1 & A2 A31 & DQ3 \\
\hline 13 & 1 & 0 & 1 & 0 & None & DR10 \\
\hline 14 & 2 & 2 & 1 & 1 & A3 A24 B7 B62 & DR4 DQ3 \\
\hline 15 & 1 & 0 & 0 & 1 & A28 & DQ3 \\
\hline 16 & 2 & 1 & 1 & 1 & A29 A30 & None \\
\hline 17 & 1 & 1 & 1 & 1 & A28 B13 & DQ2 \\
\hline 18 & 1 & 1 & 1 & 0 & A28 B8 & None \\
\hline 19 & 2 & 1 & 1 & 0 & A11 A23 & DR7 \\
\hline 20 & 1 & 2 & 1 & 0 & None & DR7 \\
\hline 21 & 1 & 1 & 1 & 1 & None & DR13 DQ1 \\
\hline 22 & 1 & 1 & 1 & 0 & A24 & None \\
\hline 23 & 1 & 2 & 1 & 0 & A1 B44 & DR16 \\
\hline 24 & 1 & 1 & 1 & 1 & A24 & DQ2 \\
\hline 25 & 1 & 1 & 0 & 0 & A11 B35 & None \\
\hline 26 & 1 & 1 & 1 & 1 & None & DQ1 \\
\hline 27 & 1 & 1 & 0 & 0 & A1 B38 & None \\
\hline 28 & 0 & 2 & 0 & 0 & B38 B44 & None \\
\hline 29 & 0 & 1 & 1 & 1 & B57 & DR7 DQ3 \\
\hline 30 & 1 & 1 & 1 & 0 & A24 B7 & DR15 \\
\hline 31 & 0 & 1 & 0 & 0 & B35 & None \\
\hline 32 & 1 & 1 & 0 & 2 & A23 & DQ2 DQ4 \\
\hline 33 & 1 & 1 & 1 & 0 & A24 B35 & None \\
\hline 34 & 1 & 1 & 1 & 1 & A28 B35 & None \\
\hline 35 & 0 & 2 & 1 & 1 & None & DR16 DQ1 \\
\hline 36 & 0 & 2 & 1 & 1 & A3 B7 & DR15 DR4 DR53 \\
\hline 37 & 1 & 1 & 0 & 0 & A3 & None \\
\hline 38 & 1 & 1 & 1 & 1 & None & DQ2 \\
\hline 39 & 0 & 1 & 1 & 1 & None & DQ3 \\
\hline 40 & 1 & 0 & 2 & 0 & A11 & DR14 \\
\hline 41 & 0 & 1 & 1 & 1 & B57 & DR15 DQ6 \\
\hline 42 & 1 & 1 & 1 & 1 & A3 B27 & DR1 DQ1 \\
\hline 43 & 1 & 1 & 1 & 0 & A2 B57 & DR10 \\
\hline
\end{tabular}

Recipient 1-36: DDA positive after transplantectomy; Recipient 37-43: DDA positive before transplantectomy; DDA, donor-directed antibodies; HLA, human leukocyte antigen 
Table 5.4 Acute rejection in DDA positive patients before and after transplantectomy.

\begin{tabular}{lcccc}
\hline & & $\begin{array}{c}\text { DDA } \\
\text { Class I }\end{array}$ & $\begin{array}{c}\text { DDA } \\
\text { Class II }\end{array}$ & $\begin{array}{c}\text { DDA } \\
\text { Class I + II }\end{array}$ \\
\hline $\begin{array}{l}\text { Before transplantectomy } \\
\quad \text { Rejection } \\
\quad \text { No rejection }\end{array}$ & $\mathrm{n}=7$ & 1 & 3 & 0 \\
$\begin{array}{l}\text { After transplantectomy } \\
\text { Rejection }\end{array}$ & $\mathrm{n}=3$ & 1 & 2 & 0 \\
No rejection & $\mathrm{n}=11$ & 1 & 3 & 0 \\
\hline
\end{tabular}

DDA, donor-directed antibodies

\section{Logistic regression analysis}

To investigate the relationship between DDA positivity after transplantectomy and clinical parameters, such as matching grade, donor and patient characteristics, backward logistic regression analysis was performed. Outcome parameters were total DDA (class I or II or both) positivity, DDA class I positivity, and DDA class II positivity after transplantectomy. Outcome parameters tested for included the following: recipient age, recipient gender, donor age, donor type (living vs. cadaver), HLA class I or II mismatch, acute rejection within 3 months after transplantation, time of transplantectomy group I-II-III, and immunosuppressive regimen (TAC vs. CSA).

With total DDA positivity as outcome parameter, the only risk factor included in the final model $\left(P=0.008, x^{2}=9.76, d f=1, r^{2}=0.27\right)$ was donor age (year) (Odds ratio=1.053, $\mathrm{P}=0.008$ ). This can be interpreted as follows: each 1 year increase in donor age increases the risk of DDA positivity with $5.3 \%$. The positive and negative predictive values of the model are $70 \%$.

With class I DDA positivity as outcome parameter, the risk factors included in the final model $\left(P<0.0001, x^{2}=23.05, d f=3, r^{2}=0.48\right)$ were donor age (Odds ratio=1.060, $P=0.007$ ) and donor type (NHB) (Odds ratio=32.080, $\mathrm{P}<0.0001$ ). This means that each 1 year increase in donor age increases the risk of DDA positivity with $6.0 \%$ and patients receiving a kidney from a non-heart-beating donor are 32 times more at risk for DDA positivity than patients receiving a kidney from a heart-beating donor.

With class II DDA positivity as outcome parameter, risk factors included in the final model $\left(P=0.003, x^{2}=13.91, d f=3, r^{2}=0.31\right)$ were donor age (year) (Odds ratio=1.039, $\mathrm{P}=0.03$ ), HLA mismatch class II ( $0-1$ vs. $\geq 2$ ) (Odds ratio $=5.307, \mathrm{P}=0.01$ ). Thus each 1 year increase in donor age increases the risk of DDA positivity with $3.9 \%$ and patients receiving a kidney with two or more HLA class II mismatches are 5 times more at risk for DDA positivity than patients receiving a kidney with less than two HLA class II mismatches.

The positive and negative predictive values of the models are given in Table 5.5. 
Table 5.5 Logistic regression with total DDA, DDA class I or II positivity after transplantectomy as dependent variable ${ }^{a}$.

\begin{tabular}{lllll}
\hline Independent variable & Odds ratio & $95 \% \mathrm{Cl}$ & $\mathrm{df}$ & P-value \\
\hline $\begin{array}{l}\text { Total HLA DDA positivity } \\
\quad \text { Donor age (yr) }\end{array}$ & 1.053 & $(1.01-1.10)$ & 1 & 0.008 \\
$\begin{array}{l}\text { Class I DDA positivity } \\
\quad \text { Donor age (yr) }\end{array}$ & 1.060 & $(1.01-1.12)$ & 1 & 0.007 \\
$\quad \begin{array}{l}\text { Donor type (HB vs. NHB) } \\
\text { Class II DDA positivity }\end{array}$ & 32.080 & $(3.40-571.64)$ & 2 & $<0.0001$ \\
$\quad$ Donor age (yr) & 1.039 & $(1.00-1.08)$ & 1 & 0.03 \\
$\quad$ HLA mismatch class II ( $\geq 2)$ & 5.307 & $(1.35-20.81)$ & 1 & 0.01 \\
\hline
\end{tabular}

${ }^{a}$ Multivariate backward regression analysis with suspected risk factors: recipient gender (M/F), recipient age (years), donor age (years), HLA class I mismatch ( 0 vs. $\geq 1$ ), HLA class II mismatch ( 0 vs. 1 vs. $\geq 2$ ), donor type (living vs. hb vs. nhb), tect-group (I-II-III), acute rejection, immuno-suppressive regimen (TAC vs. CsA).

${ }^{\mathrm{b}}$ Final model: $\mathrm{P}=008$, chi-square $=9.763, \mathrm{df}=1, \mathrm{r}$-square $=0.271, \mathrm{PPV}=70 \%, \mathrm{NPV}=70 \%$.

${ }^{\mathrm{c}}$ Final model: $\mathrm{P}<0.0001$, chi-square $=23.05, \mathrm{df}=3, \mathrm{r}$-square $=0.488, \mathrm{PPV}=95 \%, \mathrm{NPV}=72 \%$.

${ }^{d}$ Final model: $P=0.003$, chi-square $=13.91, \mathrm{df}=2 \mathrm{r}$-square $=0.314, \mathrm{PPV}=75 \%, \mathrm{NPV}=73 \%$.

\section{Discussion}

Definition of HLA antibody specificities has become much more accurate by the use of increasingly sensitive antibody screening methods. After CDC and ELISA, flow cytometry proved to be the more sensitive method, equalled now by the Luminex bead-based assays ${ }^{12}$, particularly the Single antigen bead assay. Although the clinical relevance of DDA detected by LSA is not yet clear ${ }^{13}$, the pressure on laboratories to use it for clinical purposes and data presentation is growing. Testing by LSA screening demonstrated de novo DDA after transplantation in $81 \%$ of first transplant recipients, who were all DDA negative by LSA before transplantation. Antibodies were detected before transplantectomy in only $13 \%$ of the recipients; the majority was detected after transplantectomy. These findings are in contrast with several reports in the literature, where HLA antibodies have been shown to be associated with acute and chronic rejection ${ }^{2,14}$ and poor graft survival ${ }^{15}$. The results of these studies led to the hypothesis that detection of HLA antibodies in patients after transplantation was a useful early predictor of graft outcome ${ }^{16}$. The present findings could not confirm this view, which might be due to the selection of the patient group (transplantectomy of first graft patients only), the pretransplant antibody status of the recipients (DDA negative before transplantation by LSA) and the immunosuppressive protocol (calcineurine inhibitor-based). From 16 patients with rejection, 11 turned antibody-positive only after transplantectomy. Because only LSA DDA negative first transplant recipients were studied, the appearance of DDA is considered to be related to the renal transplant.

DDA after transplantectomy were directed against HLA class I+II in $61 \%$, class I only in $25 \%$, and class II only in $14 \%$ of the recipients. The majority of the recipients showed the presence of combined class I and II antibodies. The subdivision in antibody class 
differed considerably between different studies; $32 \%, 21 \%$, and $47 \%$ were found in a study of chronic rejection, which was performed using flow cytometric and Luminex methods ${ }^{17}$. In 2 studies using Elisa for HLA antibody detection, $22 \%, 61 \%$, and $17 \%{ }^{5}$ and $20 \%, 38 \%$, and $43 \% 18$ were found, respectively. The inclusion criteria for the patients were different in the papers mentioned.

Of the DDA positive recipients, $98 \%$ also showed non-DDA. Non-DDA pre-transplant was shown in $38 \%, 62 \%$ demonstrated non-DDA only post-transplant. Of the recipients with non-DDA antibodies, 10 were female with a history of pregnancy. Two female recipients, who had been pregnant, showed the presence of non-DDA class I without specific DDA class I antibodies. Both women were proven DDA-negative after transplantation by LSA, the non-DDA were directed against a paternally inherited antigen from their children. Because these antigens were excluded in the kidney donor, this shows that antibody production against paternal antigens can be (re-) stimulated by a nonspecific stimulus ${ }^{19,20}$. For class $\mathrm{II}$, the same phenomenon was observed in one female recipient. In two male recipients, the non-DDA were directed against antigens from a previous blood transfusion.

Mao et al. reported that $77 \%$ of recipients with failed allografts had both DDA and nonDDA in their serum ${ }^{21}$. They concluded that the majority of these non-DDA antibodies were directed against "donor-specific epitopes". The immunogenicity of a kidney graft is related to differences in amino acid sequences of HLA molecules between donor and recipient, these differences or "epitopes" are considered to be the basic units of immunogenicity ${ }^{22}$. In the study of Piazza et al. ${ }^{23}$, only $9 \%$ of recipients developed class I alloantibodies with specificity restricted to the mismatched HLA class I antigens of the graft, in $90 \%$ of their study population a broad HLA sensitization was found, supporting the idea that non-DDA are elicited together with DDA in response to a donor-specific epitope.

The DDA appeared after transplantectomy in $84 \%$ of the positive recipients within 6 months, 37\% was demonstrable at 6 weeks. Antibody detection after approximately 4 months was previously described for patients transplantectomised within 1 month after grafting ${ }^{11}$. In the present group of recipients with a median time of transplantectomy of 50 days (range 2-3619), the findings were similar. Removal of the kidney transplant itself, probably in combination with cessation of immunosuppression after transplantectomy, is the probable event leading to antibody detection ${ }^{24}$.

Recipients were divided into three groups according to the time of transplantectomy; within 1 month after grafting, between 1 and 6 months, and after more than 6 months. The first group predominantly consists of technical failures and primary nonfunction, in the second acute rejection is the major reason for graft loss and in the third the number of acute rejections is comparable to the overall transplant group and graft loss, is mainly due to chronic allograft nephropathy. When the characteristics of the 
groups are compared, HLA-DR mismatch and acute rejection episodes proved significantly different between the groups. The highest numbers of acute rejections and NHB donors were found in patients with early graft failure (groups I and II) and as a result early transplantectomy (less than 6 months after transplantation). In recent years, more NHB donors are transplanted in the Netherlands. Recipients of NHB donors experience more primary non-function, more rejection, and more early failures $^{25-27}$. The number of class $\|$ mismatches is highest in patients with transplantectomy less than 6 months (groups I and II). It is well known that class II mismatches are associated with a worse graft survival ${ }^{28}$. The number of patients that turn DDA positive for HLA is also the highest in group II.

In an attempt to determine which factors play a role in the formation of HLA class I or II antibodies, we performed backward regression analysis. For total DDA positivity, an increase in donor age was related to an increase in DDA positivity. A higher donor age related to DDA positivity has also been shown for a group of recipients with transplantectomy within 1 month, as reported previously ${ }^{11}$. Several studies have reported on the relation between higher donor age and increase in immunogenicity ${ }^{29,30}$. A mechanism called the "injury response" was suggested as explanation by Halloran et al. ${ }^{31}$.

Factors related to DDA positivity could be different for class I and class II positivity and actual relationships might be obscured by the above analysis. Therefore the analysis was repeated for DDA class I positivity and DDA class II positivity separately.

For DDA class I positivity, donor type and donor age were statistically significant in the final model. Particularly, recipients of NHB donor grafts had a high risk for DDA positivity. The effect is most probably multifactorial, NHB grafts have a longer first warm ischemic time, and up-regulation of major histocompatibility complex and shedding of antigen might be higher in those grafts, that often show primary nonfunction. But care should be taken in drawing firm conclusions from groups with small numbers, e.g. the NHB donors were older and were transplanted into older recipients. No significant differences in DDA positivity were noticed between recipients of a heart-beating and NHB graft, who failed within 6 months. Because only very few patients without class I mismatches were included, the factor 'HLA class I mismatch' could not be analyzed. Others investigators, however, did find such a relationship with class I positivity ${ }^{32}$.

For class II positivity, the related independent factors were donorage (year) and class II mismatches (DR and DQ). In an Italian study ${ }^{2}$, no such correlation between DR mismatch and class II positivity was evidenced. The relation between class II mismatches and DDA class II positivity might be due to the fact that in our study, besides HLA-DR also DQ mismatches were included. It has been reported that HLA-DQ, 
rather than HLA-DR, is targeted by the alloantibody response, proving the importance of HLA-DQ antibodies ${ }^{28,33}$. For DDA class II positivity, matching for class II antigens might be of importance especially in high risk transplants, for example, from older donors and NHB grafts, as they have a higher failure rate.

In conclusion our hypothesis that antibodies before transplant failure, which we were unable to demonstrate in earlier studies, would be detectable when using more advanced and more sensitive methods, proved not to be valid. De novo DDA HLA antibodies after transplantation were demonstrated in $81 \%$ of first transplant recipients, who were all DDA negative by LSA before transplantation. Antibodies were detected before transplantectomy in only $16 \%$ of the recipients; most of them were detected thereafter. The frequency of class I and II antibodies was approximately the same; the majority of the antibodies were found combined. NHB donortype and higher donor age is related to DDA class I positivity, whereas worse class II match and higher donor age are related to antibody class II positivity. These findings may have to be taken into consideration in the allocation of organs of marginal donors, such as older or non-heart-beating kidneys. 


\section{References}

1. Morris PJ, Williams GM, Hume DM, Mickey MR, Terasaki PI. Serotyping for homotransplantation. Transplantation 1968;6:392-9.

2. Piazza A, Poggi E, Borrelli L, Servetti S, Monaco PI, Buonomo O, Valeri M, Torlone N, Adorno D, Casciani CU. Impact of donor-specific antibodies on chronic rejection occurrence and graft loss in renal transplantation: posttransplant analysis using flow cytometric techniques. Transplantation 2001;71:1106-12.

3. Lee P-C, Terasaki PI, Takemoto SK, Lee PH, Hung CJ, Chen YL, Tsai A, Lei HY. All chronic rejection failures of kidney transplants were preceded by the development of HLA antibodies. Transplantation 2002;74:1192-4.

4. Terasaki PI. Humoral theory of transplantation. Am J Transplant 2003;3:665-73.

5. Worthington JE, Martin S, Al-Husseini DM, Dyer PA, Johnson RWG. Posttransplantation production of donor HLA-specific antibodies as a predictor of renal transplant outcome. Transplantation 2003;75: 1034-40.

6. Terasaki PI, Ozawa M. Predictive value of HLA antibodies and serum creatinine in chronic rejection: results of a 2-year prospective trial. Transplantation 2005;80:1194-7.

7. Heinemann FM, Roth I, Rebmann V, Arnold ML, Witzke O, Wilde B, Spriewald BM, Grosse-Wilde H. Immunoglobulin isotype-specific characterization of anti-human leukocyte antigen antibodies eluted from explanted renal allografts. Hum Immunol 2007;68: 500-6.

8. Bocrie O, Hussein Aly AA, Guignier F, Funes de la Vega M, Rifle G, Mousson C, Martin L. Distribution of donor-specific antibodies in the cortex and the medulla of renal transplants with chronic allograft nephropathy. Transpl Immunol 2007;17:227-9.

9. Higgins R, Hathaway M, Lowe D, Lam F, Kashi H, Tan LC, Imray C, Fletcher S, Zehnder D, Chen K, Krishnan N, Hamer R, Briggs D. Blood levels of donor-specific human leukocyte antigen antibodies after renal transplantation: resolution of rejection in the presence of circulating donor-specific antibody. Transplantation 2007;84:876-84.

10. Hourmant M, Cesbron-Gautier A, Terasaki PI, Mizutani K, Moreau A, Meurette A, Dantal J, Giral M, Blancho G, Cantarovich D, Karam G, Follea G, Soulillou JP, Bignon JD. Frequency and clinical implications of development of donor-specific and non-donor-specific HLA antibodies after kidney transplantation. J Am Soc Nephrol 2005;16:2804-12.

11. Lenaers J, Christiaans M, Heurn van E, Hooff van J, Berg van den-Loonen EM. Frequent but late donordirected antibody formation after kidney transplantectomy within one month after grafting. Transplantation 2006;81:614-9.

12. Billen EVA, Voorter CEM, Christiaans MHL, Berg van den-Loonen EM. Luminex donor-specific crossmatches. Tissue Antigens 2008;71:507-13.

13. Berg van den-Loonen EM, Billen EVA, Voorter CEM, van Heurn LW, Claas FH, van Hooff JP, Christiaans $\mathrm{MH}$. Clinical relevance of pretransplant donor-directed antibodies detected by single antigen beads in highly sensitized renal transplant patients. Transplantation 2008;85:1086-90.

14. Scornik JC, Salomon DR, Lim PB, Howard RJ, Pfaff WW. Posttransplant antidonor antibodies and graft rejection. Transplantation 1989;47:287-90.

15. Abe M, Kawai T, Futatsuyama K, Tanabe K, Fuchinoue S, Teraoka S, Toma H, Ota K. Postoperative production of anti-donor antibody and chronic rejection in renal transplantation. Transplantation 1997;63:1616-9.

16. Mao Q, Terasaki PI, Cai J, Briley K, Catrou P, Haisch C, Rebellato L. Extremely high association between appearance of HLA antibodies and failure of kidney grafts in a five-year longitudinal study. Am J Transplant 2007;7:864-71.

17. Mizutani K, Terasaki P, Rosen A, Esquenazi V, Miller J, Shih RN, Pei R, Ozawa M, Lee J. Serial ten-year follow-up of HLA and MICA antibody production prior to kidney graft failure. Am J Transplant 2005;5: 2265-72.

18. Varnavidou-Nicolaidou A, Iniotaki-Theodoraki AG, Doxiadis II, Georgiou D, Patargias T, StavropoulosGiokas C, Kyriakides G. Expansion of humoral donor-specific alloreactivity after renal transplantation relates with impaired graft outcome. Hum Immunol 2005;66:985-8. 
19. Masson D, Bayle F, Vichier C, Zaoui P, Vialtel P, Bensa JC. Anti-HLA Class I Reiimunization After One HLA Semi-Identical Blood Transfusion in Non-Naive Patients on a Waiting List for a First Renal Allograft. Transplant Proc 1998;30:2854.

20. Rebibou J-M, Chabod J, Alcalay D, Coussediere MC, Deteix P, Touchard G, Dupont I, Thévenin C, Chalopin JM, Tiberghien P. Flow cytometric evaluation of pregnancy-induced anti-HLA immunization and blood transfusion-induced reactivation. Transplantation 2002;74:537-40.

21. Mao Q, Terasaki PI, Cai J, El-Awar J, Rebellato L. Analysis of HLA class I specific antibodies in patients with failed allografts. Transplantation 2007;83:54-61.

22. Adeyi OA, Girnita AL, Howe J, Marrari M, Awadalla Y, Askar M, Martell J, Zeevi A, Shapiro R, Nalesnik $M$, Randhawa $P$, Demetris AJ, Duquesnoy RJ. Serum analysis after transplant nephrectomy reveals restricted antibody specificity patterns against structurally defined HLA class I mismatches. Transplant Immunol 2005;14:53-62.

23. Piazza A, Poggi E, Ozzella G, Borrelli L, Monaco PI, Scornajenghi A, Tisone G, Adorno D. Public epitope specificity of HLA class I antibodies induced by a failed kidney transplant: alloantibody characterization by flow cytometric techniques. Transplantation 2006;81:1298-305.

24. Doxiadis IIN, Claas FHJ. Donor-specific antibodies arising after kidney transplantectomy: priming or memory? Transplantation 2006;81:509-10.

25. Gerstenkorn C. Non-heart-beating donors: renewed source of organs for renal transplantation during the twenty-first century. World J Surg 2003;27:489-93.

26. Brook NR, Waller MJ, Nicholson ML. Nonheart-beating kidney donation: Current practice and future developments. Kidney Int 2003;63:1516-29.

27. Keizer KM, Fijter de JW, Haase-Kromwijk BJJM, Weimar W. Non-heart-beating donor kidneys in the Netherlands: allocation and outcome of transplantation. Transplantation 2005;79:1195-9.

28. Iniotaki-Theodoraki AG, Boletis JN, Trigas GC, Kalogeropoulou HG, Kostakis AG, Stavropoulos-Giokas CG. Humoral immune reactivity against human leukocyte antigen (HLA)-DQ graft molecule in the early posttransplantation period. Transplantation 2003;75:1601-03.

29. Terasaki PI, Gjertson DW, Cecka JM, Takemoto S, Cho YW. Significance of the donor age effect on kidney transplants. Clin Transplant 1997;11:366-72.

30. de Fijter JW, Mallat MJ, Doxiadis II, Ringers J, Rosendaal FR, Claas FH, Paul LC. Increased immunogenicity and cause of graft loss of old donor kidneys. J Am Soc Nephrol 2001;12:1538-46.

31. Halloran PF, Hornik J, Goes N, Lui SL, Urmson J, Ramassar V, Cockfield SM. The "injury response": a concept linking nonspecific injury, acute rejection, and long-term transplant outcomes. Transplant Proc 1997;29:79-81.

32. Piazza A, Borrelli L, Monaco PI, Poggi E, Pisani F, Valeri M, Fraboni D, Servetti S, Casciani CU, Adorno D. Posttransplant donor-specific antibody characterization and kidney graft survival. Transpl Int 2000;13 (suppl 1):S439-43.

33. Bas le-Bernardet S, Hourmant M, Valentin N, Paitier C, Giral-Classe M, Curry S, Follea G, Soulillou JP, Bignon JD. Identification of the antibodies involved in B-cell crossmatch positivity in renal transplantation. Transplantation 2003;75:477-82. 



\section{Chapter 6}

HLA-DP antibodies before and after renal transplantation

EVA Billen, MHL Christiaans, IIN Doxiadis, CEM Voorter, EM van den Berg-Loonen Tissue Antigens 2010 75:278-285 


\section{Abstract}

Human leukocyte antigen (HLA)-DP is considered a target for humoral immune response in clinical transplantation. This study analyses the incidence of HLA-DP antibodies in renal patients. Development and epitope specificity of donor-specific antibodies (DSA) and non-DSA (NDSA) were examined.

Pre- and post-transplant sera of 338 patients were screened for HLA-DP antibodies using the Luminex Single antigen assay. Positive patients, partners and/or kidney donors were HLA-DP typed by sequence specific oligonucleotides. Potential epitopes were mapped by comparing the amino acid sequences of HLA-DP hypervariable regions (HVR) A-F of recipient, partner and/or donor. Specificities in the sera were aligned to deduce the HVR motif responsible for the antibodies.

HLA-DP antibodies were detected in $14 \%$ of the patients (48/338). Before transplantation the antibodies were shown in 23\% (10 females and 1 male) and 77\% were found after transplantation (30 in patients after the first, 7 after the second graft.) Specificities were never restricted to individual mismatched antigens; broad HLA-DP sensitization was found as a rule. A single HVR mismatch was present in $80 \%$ of the DSA and in $79 \%$ of the NDSA. No HLA-DPA specific antibodies were found.

Our findings confirm that HLA-DP antibodies are specific for epitopes shared by different HLA-DP antigens, indicating that only a restricted number of mismatched epitopes are recognized by the recipients immune system. Matching for immunogenic HLA-DP epitopes for renal transplantation seems to be functionally more relevant than classical matching at the allelic level. 


\section{Introduction}

Human leukocyte antigen (HLA)-DP is an HLA class II locus identified more than 30 years ago as a possible stimulator of the mixed lymphocyte culture response in previously primed cells. It was originally named the SB locus but was renamed DP after the 1984 workshop ${ }^{1}$. DPB1 and DPA1 are the MHC genes encoding the DP molecule. HLA-DP antigens were initially typed by cellular methods, the prevalence of antibodies against HLA-DP antigens was shown later ${ }^{2,3}$. At present 132 HLA-DP alleles are described using DNA-based typing methods, mostly sequence-based typing (SBT) ${ }^{4,5}$. The polymorphism of HLA-DP is largely concentrated in six hypervariable regions (HVRs), A-F, in exon 2 of the DPB1 gene. Most DP antigens are characterized by specific combinations of amino acid sequences (motifs) of these six HVRs. HLA-DPA is also polymorphic with 27 known alleles at present. They are divided in 4 groups: DPA1*01-*04. The DPA polymorphism is restricted and involves less amino acids sequences than that of DPB.

HLA-DP antigens expressed on peripheral blood cells and also on endothelial cells especially during rejection episodes are supposed to present a target for the humoral immune response in kidney transplantation ${ }^{6-8}$. Population analyses showed that HLA-DP mismatches between donor and recipient did not influence the outcome of first kidney transplants, but did have an impact on retransplants ${ }^{9}$. Epitope-based matching rather than allele matching should probably be the method of choice ${ }^{10}$.

The contribution of HLA class II antibodies, especially HLA-DP, to graft rejection and graft loss has long been poorly understood, because testing for their detection on B-lymphocytes was hardly satisfactory. With the introduction of the solid-phase antibody detection assays, in particular, the Luminex Single antigen (LSA) assay, where HLA-DP molecules are attached to microspheres, class II DP antibodies are now detected easily and their clinical relevance might be assessed more accurately ${ }^{11}$.

This study was designed to analyze the incidence of HLA-DP antibodies in renal patients before and after transplantation. Furthermore, the epitope specificity and the correlation between the development of donor-specific antibodies (DSA) and non-donor-specific antibodies (NDSA) were examined using LSA. HVRs of both patient and donor were determined by sequence specific oligonucleotides (SSO) to identify potential DSA epitopes. 


\section{Materials and Methods}

\section{Patients and samples}

From January 2007 until January 2009, 338 renal patients from the University Hospital of Maastricht were screened for the presence of HLA class II antibodies using the Luminex Single antigen assay (LSA). Of them, 133 are currently on the renal transplant waiting list, where 43 have never been transplanted and 90 are awaiting retransplantation. The remaining 205 were tested in the local post-transplant protocol. All patients presenting with HLA-DP antibodies were selected and investigated further. Their pre- and post-transplant sera were examined with LSA. Patient characteristics are given in Table 6.1.

Table 6.1 Characteristics of HLA-DP antibody positive and negative patients: all ( $n=338$ ), un-transplanted $(n=43)$ and transplanted $(n=295)$ patients.

\begin{tabular}{lcc}
\hline & HLA-DP ab negative patients & HLA-DP ab positive patients \\
\hline All patients & $\mathrm{n}=290$ & $\mathrm{n}=48$ \\
Male gender & $145(50 \%)$ & $19(40 \%)$ \\
Females (pregnancies) & $145(121,83 \%)$ & $29(22,76 \%)$ \\
No. of transplants0 & 32 & 11 \\
1 & 180 & 30 \\
2 & 67 & 7 \\
3 & 6 & \\
5 & 3 & \\
$\quad$ Lacked cells & 2 & $2.0 \pm 2.5$ \\
Leukocyte depleted & $4.3 \pm 10.0$ & $8.6 \pm 12.2$ \\
Nr of transfusions (mean & $1.7 \pm 3.2$ & 11 \\
Leukocyte depleted & $\mathrm{n}=32$ & $10(10,100 \%)$ \\
Un-transplanted & $8(25 \%)$ & \\
Male gender & $24(24,100 \%)$ & $2.1 \pm 3.5$ \\
Females (pregnancies) & & $12.3 \pm 21.5$ \\
Nr of transfusions (mean \pm SD) & $0.7 \pm 1.0$ & $\mathrm{n}=37$ \\
Packed cells & $1.4 \pm 2.9$ & $18(49 \%)$ \\
Transplanted & $\mathrm{n}=258$ & $19(12,63 \%)$ \\
Male gender & $137(53 \%)$ & \\
Females (pregnancies) & $121(97,80 \%)$ & $2.0 \pm 2.2$ \\
Nr of transfusions (mean \pm SD) & & $2.0 \pm 2.2$ \\
Packed cells & $1.8 \pm 3.3$ & \\
Leukocyte depleted & $4.6 \pm 10.5$ & \\
\hline
\end{tabular}

HLA, human leukocyte antigen

\section{HLA-DP antibody detection by LSA}

Antibodies against HLA-DP in recipient sera were determined using the LABScreen ${ }^{\circledR}$ SA class II assay (One Lambda, Canoga Park, CA) according to the manufacturer's instructions. Microbeads coated with purified HLA molecules were incubated with 
patient serum for $30 \mathrm{~min}$. After washing to remove unbound antibody, the beads were incubated for $30 \mathrm{~min}$ with antihuman-IgG-conjugated phyco-erythrine. All incubations were performed on a gently rotating platform in the dark at room temperature. The LSA class II lot used contained 13 micro-beads coated with single HLA-DP alleles: DPB1*0101, *0201, *0301, *0401, *0402, *0501, *0901, *1001, *1101, *1301, *1401, *1701 and *1901. The LABScan 100 flow analyser (Luminex, Austin, TX) and HLA-VISUAL software (One Lambda) were used for data acquisition and analysis. All beads with normalized median fluorescence intensity value (i.e. raw median fluorescence intensity (MFI) value of the test bead - MFI value of the negative control bead) $>2000$ were considered positive. The cut-off point was established based on the results from previous studies ${ }^{12}$.

\section{HLA-DP typing by luminex SSO assay}

DNA samples of patients with HLA-DP antibodies $(n=48)$, partners $(n=8)$ and kidney donors ( $n=31)$ were typed for HLA-DP using LABType ${ }^{\circledR S S O}$ according to the manufacturer's instructions. For two patients, no DNA from the partner was available and for six recipients DNA of the organ donor was lacking. DNA samples were isolated from either peripheral blood or spleen cells using the QIAamp DNA blood mini kit (Qiagen, Venlo, The Netherlands) and stored at $-30^{\circ} \mathrm{C}$.

In short, $2 \mu \mathrm{l}$ of purified genomic DNA (concentration $20 \mathrm{ng} / \mu \mathrm{l}$ ) is polymerase chain reaction (PCR)-amplified using $4 \mu \mathrm{l}$ of group-specific primer, $0.2 \mu \mathrm{l}$ Taq polymerase $(0.33 \mathrm{U})$ and $13.8 \mu \mathrm{l}$ amplification mix. The primer has a biotin label, which allows the PCR product to be detected using R-phycoerythrin-conjugated streptavidin (SAPE). After amplification, the PCR product is denaturated and neutralized and allowed to rehybridize $\left(15 \mathrm{~min}, 60^{\circ} \mathrm{C}\right)$ to a mixture of 43 complementary sequence-specific oligonucleotide probes conjugated to color-coded beads. The mixture is then washed three times and is incubated with $50 \mu$ of SAPE (1:50) for $5 \mathrm{~min}$ at $60^{\circ} \mathrm{C}$. Excess SAPE is washed away. The LABScan 100 flow analyser (Luminex) identifies the fluorescent intensity of the PE on each microsphere. The assessment of the HLA-DP typing is based on the reaction pattern compared to patterns associated with published HLA-DP sequences.

Twelve DNA samples previously typed for HLA-DP by the SBT method described previously ${ }^{13}$ were used to validate the SSO HLA-DP typing method, which represented the alleles: DPB1*0101, *0201, *0301, *0401,*0402, *0501, *0901,*1001, *1101, $* 1301, * 1401, * 1701$ and $* 1901$. The aim was to correctly identify the different polymorphic motifs of the six HVRs of exon 2 of all HLA-DP alleles present in the LSA class II lot used (Table 6.2). The results obtained were identical to SBT, albeit SSO included ambiguous typing results. Among those, the correct typing was always present, for all samples the six HVR polymorphisms were correctly identified. In case 
an ambiguous result was obtained for patient and partner/donor-HLA-DP typing, the allele most frequent in Caucasians was assigned ${ }^{14}$.

Table 6.2 Hypervariable regions (A-F) of exon 2 of the HLA-DPB1 alleles present in the LSA class II assay.

\begin{tabular}{lcccccc}
\hline & A & B & C & D & E & F \\
DPB1 & $8-11$ & $33-36$ & $55-57$ & $65-69$ & 76 & $84-87$ \\
\hline$* 0101$ & VYQG & EEYA & AAE & ILEEK & V & DEAV \\
$* 0201$ & LFQG & EEFV & DEE & ILEEE & $\mathrm{M}$ & GGPM \\
$* 0301$ & VYQL & EEFV & DED & LLEEK & V & DEAV \\
$* 0401$ & LFQG & EEFA & AAE & ILEEK & M & GGPM \\
$* 0402$ & LFQG & EEFV & DEE & ILEEK & M & GGPM \\
$* 0501$ & LFQG & EELV & EAE & ILEEK & M & DEAV \\
$* 0901$ & VHQL & EEFV & DED & ILEEE & M & DEAV \\
$* 1001$ & VHQL & EEFV & DEE & ILEEE & V & DEAV \\
$* 1101$ & VYQL & QEYA & AAE & LLEER & M & DEAV \\
$* 1301$ & VYQL & EEYA & AAE & ILEEE & I & DEAV \\
$* 1401$ & VHQL & EEFV & DED & LLEEK & V & DEAV \\
$* 1701$ & VHQL & EEFV & DED & ILEEE & M & DEAV \\
$* 1901$ & LFQG & EEFV & EAE & ILEEE & I & DEAV \\
\hline
\end{tabular}

HLA, human leukocyte antigen; LSA, Luminex Single antigen

\section{Donor specificity of HLA-DP antibodies}

Epitopes for possible antibody formation were mapped by comparing the HLA-DP HVR amino acid sequences of exon 2 of recipient, partner and/or donor, as defined by SSO typing. A potential mismatched epitope was defined as an amino acid sequence present in one of the six HVRs of partner or donor, but absent in the recipient. To verify the potential epitopes, LSA patterns were used (Table 6.2). The amino acid sequences of the HLA-DP-specificities recognized by the serum were aligned. They were compared in order to deduce the most likely mismatched HVR motif responsible for the antibodies. An example is given in Table 6.3.

\section{Results}

\section{HLA-DP antibody incidence in renal patients}

Screening for HLA class II antibodies by LSA before and after transplantation was performed for 338 renal patients from the University hospital of Maastricht. Class II HLA-DP antibodies were detected in 48 (14\%) of them. In 11 patients (23\%), DP antibodies were detected before transplantation, 10 females and 1 male. In 37 of the positive patients (77\%), the antibodies were shown after transplantation, in 30 
after the first and in 7 after the second graft (Table 6.1). In two patients, DP antibodies were the only ones demonstrable; HLA-DR and -DQ antibodies were present next to DP in 41 (Table 6.4). Additional class I antibodies were shown in 45 patients.

Table 6.3 Comparison of patient and donor hypervariable region (HVR) typing (SSO) to identify potential epitopes (bold) and alignment of specificities detected with LSA to verify donor-specific epitope (boxed).

\begin{tabular}{|c|c|c|c|c|c|c|c|}
\hline \multirow[t]{2}{*}{ SSO } & \multirow[t]{2}{*}{ HLA-DP } & \multicolumn{6}{|c|}{ HVR } \\
\hline & & A & B & $\mathrm{C}$ & $\mathrm{D}$ & $\mathrm{E}$ & $\mathrm{F}$ \\
\hline \multirow{2}{*}{ Patient 18876} & *0201 & LFQG & EEFV & DEE & ILEEE & M & GGPM \\
\hline & *0401 & LFQG & EEFA & AAE & ILEEK & M & GGPM \\
\hline \multirow[t]{2}{*}{ Donor } & *0101 & VYQG & EEYA & AAE & ILEEK & $\mathbf{v}$ & DEAV \\
\hline & *0401 & LFQG & EEFA & AAE & ILEEK & $\mathrm{M}$ & GGPM \\
\hline \multirow[t]{2}{*}{ LSA } & DP & \multicolumn{6}{|c|}{ HVR } \\
\hline & & $\mathrm{A}$ & B & C & $\mathrm{D}$ & $\mathrm{E}$ & $\mathrm{F}$ \\
\hline \multirow[t]{10}{*}{ positive beads } & *1901 & LFQG & EEFV & $\mathrm{EAE}$ & ILEEE & 1 & DEAV \\
\hline & *0101 & VYQG & EEYA & $\mathrm{AAE}$ & ILEEK & V & DEAV \\
\hline & *1701 & VHQL & EEFV & DED & ILEEE & M & DEAV \\
\hline & *0301 & VYQL & EEFV & DED & LLEEK & V & DEAV \\
\hline & *0501 & LFQG & EELV & $\mathrm{EAE}$ & ILEEK & M & DEAV \\
\hline & *1001 & VHQL & EEFV & DEE & ILEEE & V & DEAV \\
\hline & *1301 & VYQL & EEYA & $A A E$ & ILEEE & 1 & DEAV \\
\hline & *1401 & VHQL & EEFV & DED & LLEEK & V & DEAV \\
\hline & *0901 & VHQL & EEFV & DED & ILEEE & M & DEAV \\
\hline & *1101 & VYQL & QEYA & $\mathrm{AAE}$ & LLEER & M & DEAV \\
\hline \multirow[t]{3}{*}{ negative beads } & *0402 & LFQG & EEFV & DEE & ILEEK & $M$ & GGPM \\
\hline & *0201 & LFQG & EEFV & DEE & ILEEE & $M$ & GGPM \\
\hline & *0401 & LFQG & EEFA & $\mathrm{AAE}$ & ILEEK & $\mathrm{M}$ & GGPM \\
\hline
\end{tabular}

HLA, human leukocyte antigen; LSA, Luminex Single antigen; SSO, sequence specific oligonucleotide.

Bold: the potential mismatched epitope, defined as an amino acid sequence present in one of the six HVRs of the partner or donor, but absent in the recipient

Boxed: the mismatched DEAV motif considered to be responsible for the HLA-DP antibodies detected by LSA

Table 6.4 Class II antibodies detected by LSA in HLA DP positive and negative patients.

\begin{tabular}{lcc}
\hline & $\begin{array}{c}\text { DP ab negative patients } \\
(\mathrm{n}=290)\end{array}$ & $\begin{array}{c}\text { DP ab positive patients } \\
(\mathrm{n}=48)\end{array}$ \\
\hline DR+DQ & $74(25.5 \%)$ & $27(56 \%)$ \\
DR only & $48(16.5 \%)$ & $10(21 \%)$ \\
DQ only & $25(9 \%)$ & $4(8 \%)$ \\
DR+DQ-negative & $143(49 \%)$ & $7(15 \%)$ \\
\hline
\end{tabular}

HLA, human leukocyte antigen; LSA, Luminex Single antigen.

\section{HLA-DP typing by luminex SSO assay}

The amino acid sequences of the six HVRs of exon 2 of all HLA-DP alleles present in the LSA class II lot used (Table 6.2) were correctly identified by SSO in all samples. An 
ambiguous result in patient and partner/donor-HLA-DP typing was obtained in three individuals (ID7 DPB1*0601, ID10 DPB1*1601 and ID11 DPB1*3601) (Table 6.6).

\section{Pretransplant HLA-DP antibodies}

All female patients positive for HLA-DP antibodies before transplantation had been pregnant. For two patients, the immunization partner was unknown and no children were available for typing. For the remaining eight patients, DNA of the partner was available for retrospective DP typing to identify the potential epitopes to which the antibodies were directed. Two patients proved to be DP identical with their partner, the remaining six were mismatched for one or two DP alleles. Patient DP typing, allelic and HVR mismatches are given in Table 6.5. In 5/6 DP-mismatched patients, DSA were detected. Additional NDSA specificities directed against a single donor-specific HVR mismatch were detected in three patients and against two donor-specific HVR mismatches in one. In one patient with four HVR mismatches, no clear motif could be detected. One patient had detectable NDSA only; her DP antibodies were the result of interlocus DRB1/DPB1 crossreactivity. The same held true for the DP antibodies of the two patients, who were DP identical to their partner.

In the two females with unknown pregnancy immunization, two antibodies-causing motifs were identified. The only male patient, who presented with pretransplant DP antibodies, had received 66 transfusions with leukocyte-depleted blood. In his serum, class I antibodies were present but no additional class II DR/DQ antibodies were detected. No identification was possible for the antibody-causing motif.

\section{Post-transplant HLA-DP antibodies}

HLA-DP antibodies after transplantation were found in 37 recipients: in 30 after their first transplant and in 7 after the second. For 31 of them, donor-DNA was available for retrospective HLA-DP typing. Sixteen recipients were mismatched for two DP alleles with their donor, fifteen showed one allelic DP mismatch. Patient DP typing, allelic and HVR mismatches are given in Table 6.6.

DSA were found in 26 recipients, NDSA were shown in all. DSA and NDSA were directed against a single donor-specific HVR in 19 patients, against 2 HVRs in 2 and against 3 HVRs in 1 . The antibody-causing motif was donor-specific in 25, and non-donor-specific in 4 recipients. For eight recipients, no clear motif could be identified. 


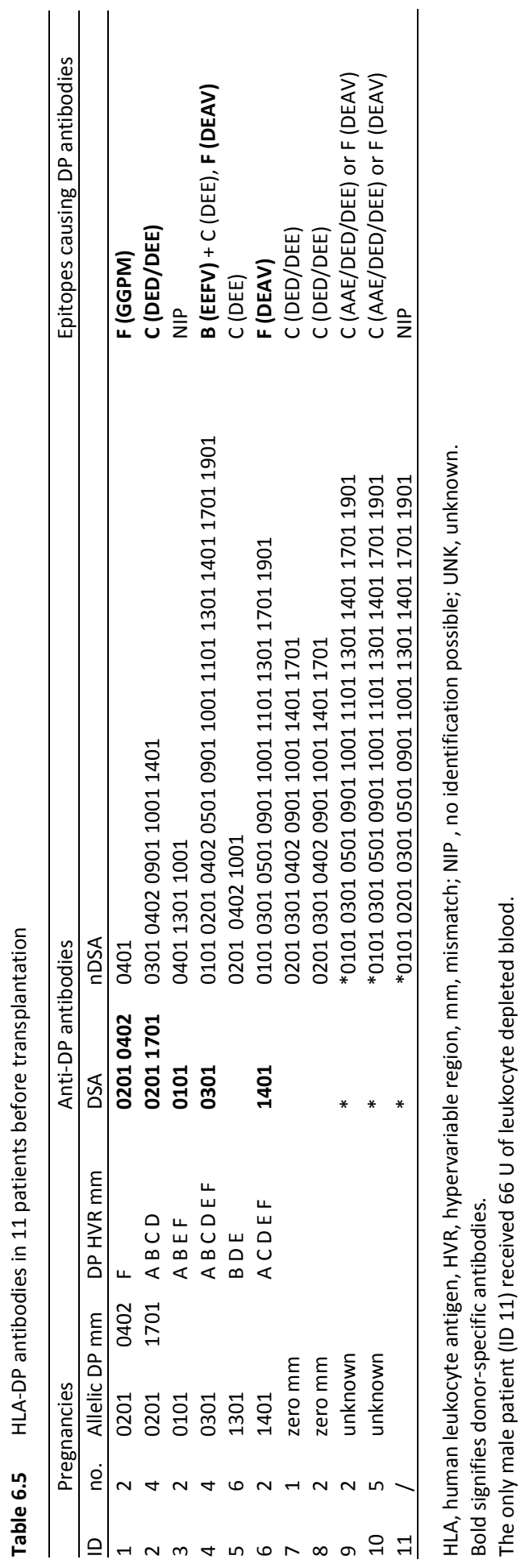




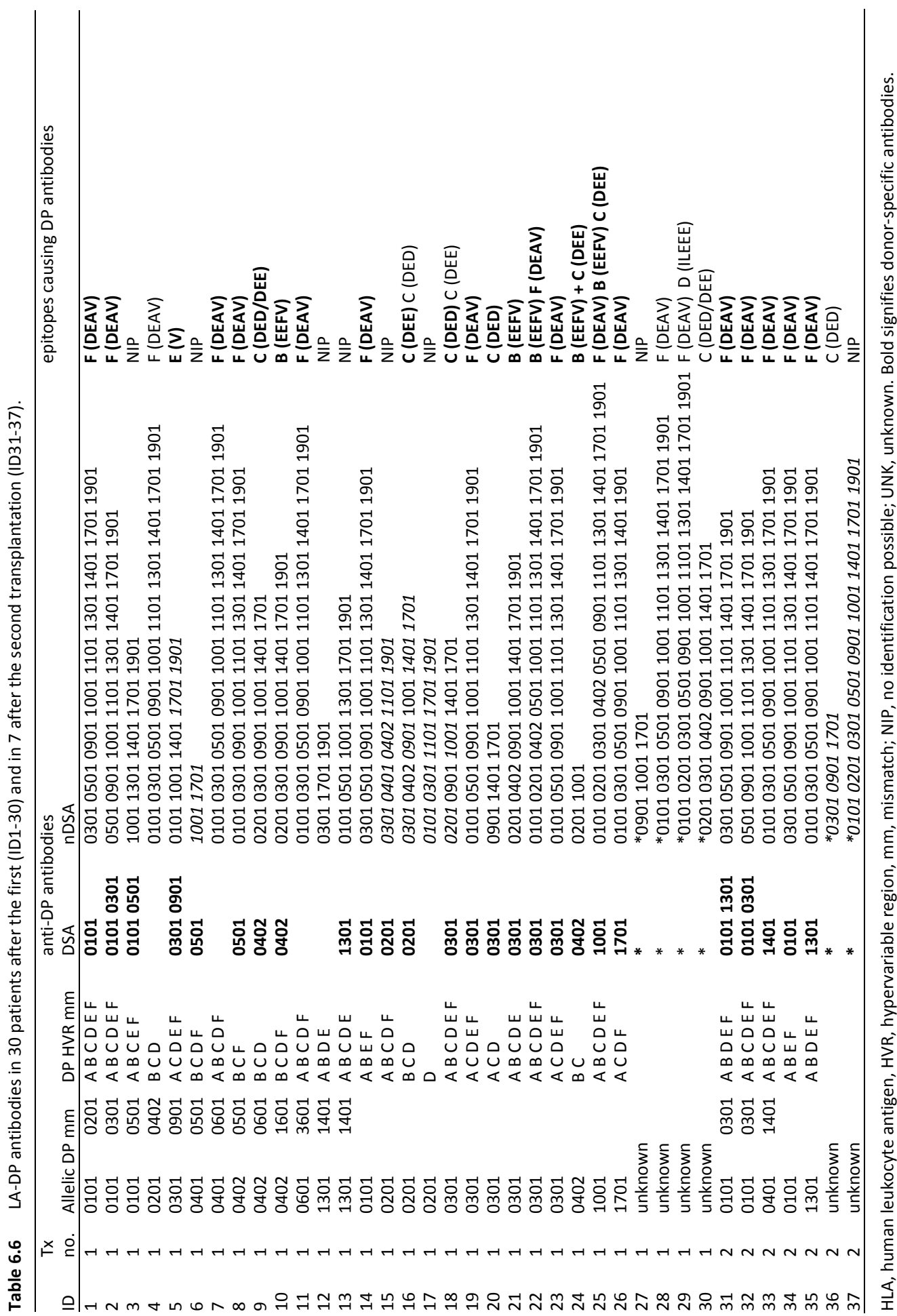




\section{Frequency of antibody-target motifs}

A total of 47 antibody-target patterns were observed. The HVR-F (DEAV) motif was detected in 23 (49\%) cases, HVR-C (DED/DEE) in 14 (30\%), HVR-B (EEFV) in 6 (13\%) and HVR-C (AAE), HVR-F (GGPM), HVR-D (ILEEE) and HVR-E (V) in 1 case each. In 70\% $(n=33)$ the antibody-target motif was donor-specific.

\section{Discussion}

Anti-HLA-DP antibodies have always been difficult to identify by complementdependent cytotoxicity (CDC). In most instances, CDC panels were not routinely typed for HLA-DP, and if typing was performed, the specificity of the antibodies was difficult to establish because they were not directed towards a single DP antigen. Furthermore, DP antibodies were often masked by the presence of other class II antibodies. Recently, microbeads coated with purified HLA-DP molecules were added to the SA class II assay, both in flow cytometry and luminex, which allows more precise identification of HLA-DP antibodies. In the present study, renal patients were screened for HLA-DP antibodies using a panel of 13 HLA-DP antigens: *0101, *0201, *0301, *0401, *0402, *0501, *0901, *1001, *1101, *1301, *1401,*1701 and *1901. Although over 130 HLA-DPB1 alleles have been described at present, the most frequent alleles in the Caucasian population are represented in this panel ${ }^{14}$. Because the polymorphism of HLA-DP is concentrated in six HVRs of exon 2 of the HLA-DPB1 gene and almost all DP antigens can be described as combinations of several different motifs at each of these HVRs (Table 6.2), the panel used covered all the important and most frequent HVRs present in the Caucasian population. The polymorphic HVR motifs of exon 2 of HLA-DP not represented in the panel were: VDQL at position 8-11 (DPB1*7001), $\operatorname{DEV}(* 3201)$ and EEE (*8401) at position 55-57, LLEEE (*0601, 2901, 4401, 9501), FLEEE $(* 4101)$, NLEEK $(* 6001)$ and FLEEK $(* 8301)$ at position $65-69$ and VGPM $(* 1501$, $* 1801,2801,3401,4001,5301,6201,7401)$ and NEAV $(* 2202)$ at position 84-87. The LLEEE motif was present in two donors typed as DPB1*0601 (ID 7 and ID 11, Table 6.6). The VGPM motif was present in one patient typed as DPB1*2801 (ID 6, Table 6.5).

The SSO assay for HLA-DP typing was validated for the alleles listed in Table 6.1. In 30\% of the validation samples, the SSO result was the same as in SBT. In 70\%, SSO resulted in ambiguous results, always including the correct SBT-DP typing. These results were because of polymorphisms outside the six HVRs, for which no DNA probes were available in the SSO assay. Nevertheless, all polymorphic motifs of the six HVRs of exon 2 could be correctly assigned using the SSO method. In only three cases we had to assign an allele that was not validated.

Before the introduction of solid-phase techniques for HLA-DP antibodies detection, DP antibodies were studied using the monoclonal antibody immobilization of 
leukocyte antigens (MAILA) technique. In 1990, Mueller-Eckhardt described DP antibodies in $9.7 \%$ of pregnancy sera using MAILA and showed a high correlation of HLA-DP immunization together with reactivity against HLA class I and II (DR/DQ) antibodies $^{15}$. Using the same technique, Pfeiffer in 1995 found the overall incidence of HLA-DP antibodies in patients awaiting renal transplantation to be $7.3 \%{ }^{16}$. Using flowcytometric beads, Youngs reported that $12 \%$ of patients on their renal transplant waiting list possessed DP antibodies. In previously transplanted patients, the percentage was even higher $(45 \%)^{17}$. With the same technique, Qiu described an increased incidence of DP antibodies after graft rejection ${ }^{11}$. In the present study, we found $12 \%$ of renal patients to have DP antibodies, $23 \%$ before and $77 \%$ after transplantation.

Although the HLA-DPA chain is also polymorphic and could potentially be the source of antibody reactivity, no HLA-DPA specific antibodies were found in this study. In a population of this size, one might expect to find DP antibodies reacting with DPA. The LSA class II kit used contained four beads carrying DPA*0103, eight beads coated with DPA $1 * 0201$ and one bead with DPA1*0401. To evaluate possible anti-DPA reactivity, DPA1 alleles have to be represented in different combinations with DPB1 alleles, even if those are not commonly encoded on the same haplotype. DPA antibodies were suspected in sera where the DPB specificities remained undetermined, especially in three patients whose sera reacted with their own DPB1 alleles (Table 6.5 ID 3, ID 12 and ID 15); however, this was not confirmed by Single antigen analysis. The role of the polymorphism of DPA1 in the intensity and specificity of antigen-antibody reactivity with the DP-heterodimer remains to be investigated further. DPA typing of patients, partners and donors was not performed because no DPA antibodies were shown.

Because of the weak linkage disequilibrium of HLA-DP with the classical HLA class I and II antigens ${ }^{18}$, even donor-recipient pairs identical for these loci have an $80 \%$ probability of being mismatched at $\mathrm{DP}^{19}$. However, because of the restricted DP polymorphism, many of these allelic mismatches will be compatible for HVR motifs and, therefore, will not result in anti-DP formation.

For most of the patients, the immunizing HLA-DP antigens and subsequent HVR mismatches could be determined. In $80 \%$ the DP antibodies were donor specific. None of the patients developed antibodies restricted to the mismatched DP antigens, and broad DP sensitization was found as a rule. This finding confirm previous observations that DP antibodies in sera of sensitized patients are specific for epitopes shared by different HLA antigens ${ }^{17,20,21}$. Even though many more potential HVR mismatches were present, almost all the DSA (80\%) and accompanying NDSA (79\%) were directed against a single donor-specific HVR mismatch: HVR-F in 16, HVR-C in 3, HVR-B in 2 and HVR-E in 1 . This indicates that only a small number of mismatched epitopes are recognized by the recipients immune system and supports the immuno- 
dominance of HVR-F and $-\mathrm{C}$ as also described by Duquesnoy et al. ${ }^{21}$. HVR-F and -C correspond to well-defined serological epitopes recognized by monoclonal antibodies $^{22,23}$. In 35 patients homozygous for GGPM (HVR-F) 69\% of the DP antibodies were directed against the DEAV motif at that same position. In 21 patients homozygous for AAE/EAE (HVR-C) $48 \%$ of the DP antibodies were directed against the DED/DEE motif at that same position. These findings support the findings by Laux et al. ${ }^{10}$ that matching for immunogenic DPB1 epitopes was functionally more relevant than classical matching at the allelic level ${ }^{9,24}$.

As first described by Bodmer et al. ${ }^{22,25}$, DR11 has the aminoacids D and E at positions 57 and 58 that correlate with the $D$ and E in HVR-C (position 56-57) of 7 of the 13 HLA-DP alleles present in the LSA assay (DPB1*0201, 0301, 0402, 0901, 1001, 1401 and 1701). In five patients with strong anti-DR11 antibodies, the DP antibodies probably resulted from this inter-locus DR11-DP epitope. In two patients, who were HLA-DP identical to their partner and had pretransplant DP antibodies, and in one patient with post-transplant DP antibodies, the DP antibodies were directed against the DED and DEE motif of HVR-C. In another patient with pretransplant DP antibodies, the specificities were explained by the DEE motif of HVR-C, because the patient possessed the DED motif herself. In another patient, the specificities were explained by the DED motif of HVR-C, while the patient himself carried the DEE motif.

HLA-DP as well as HLA-DQ are up-regulated upon inflammation as shown earlier ${ }^{8}$. This might be the reason of the clinical relevance of anti-DP antibodies in re-transplants ${ }^{9}$. The contribution of anti-HLA-DP antibodies to kidney graft rejection and failure has long been an unresolved issue. With the introduction of the SA, the presence of HLA-DP antibodies can be detected easily. Subsequently, it will become possible in the near future to assess their clinical relevance more accurately. Meanwhile, some case reports have recently shown that DP antibodies represent a possible risk factor for transplant dysfunction and failure ${ }^{25-27}$.

In summary, we have shown that HLA-DPB antibodies are found in patients before and after kidney transplantation. Before transplantation, pregnancy is the most important stimulus for antibody production but also transfusions may result in DP antibody positivity. The majority of the DP antibodies, however, are found after transplantation, usually already after the first graft. No HLA-DPA specific antibodies were found in this study. The DP antibodies detected in sera of sensitized patients are specific for a number of epitopes shared by different HLA antigens. The majority of the DSA and accompanying NDSA found are directed against a single donor-specific HVR mismatch, which indicates that only a small number of mismatched epitopes are recognized by the recipients immune system. Our findings confirm that matching for immunogenic HLA-DP epitopes seems to be functionally more relevant than classical matching at the allelic level, whether this is only true for retransplants remains to be established. 


\section{References}

1. Shaw S, Johnson AH, Shearer GM. Evidence for a new segregant series of B cell antigens that are encoded in the HLA-D region and that stimulate secondary allogenic proliferative and cytotoxic responses. J Exp Med 1980:152:565-80.

2. Shaw S, DeMars R, Schlossman SF, Smith PL, Lampson LA, Nadler LM. Serologic identification of the human secondary $B$ cell antigens. Correlations between function, genetics, and structure. J Exp Med 1982:156:731-43.

3. Tongio MM, Berg van den-Loonen EM, Bignon JD et al. in Twelfth International Histocompatibility Workshop and Conference (ed. Charron D) 135-8 (EDK, Saint Malo - Parijs, 1997).

4. Versluis LF, Rozemuller E, Tonks S, Marsh SG, Bouwens AG, Bodmer JG, Tilanus MG. High-resolution HLA-DPB typing based upon computerized analysis of data obtained by fluorescent sequencing of the amplified polymorphic exon 2. Hum Immunol 1993:38:277-83.

5. Robinson J, Waller MJ, Parham P, de Groot N, Bontrop R, Kennedy LJ, Stoehr P, Marsh SG. IMGT/HLA and IMGT/MHC: sequence databases for the study of the major histocompatibility complex. Nucl Acids Res 2003:31:311-4.

6. Müller CA, Markovic-Lipkovski J, Risler T, Bohle A, Müller GA. Expression of HLA-DQ, -DR, and -DP antigens in normal kidney and glomerulonephritis. Kidney Int 1989:35:116-24.

7. Baudeau C, Falkenrodt A, Parissiadis A,Tongio MM. A significant percentage of normal T lymphocytes express HLA-DP in the peripheral blood. Tissue Antigens 1993:42:111-7.

8. Fuggle SV, McWhinnie DL, Morris PJ. Precise Specifity of Induced Tubular HLA-class II Antigens in Renal Allografts. Transplantation 1987:22:214-20.

9. Mytilineos J, Deufel A, Opelz G. Clinical relevance of HLA-DPB locus matching for cadaver kidney retransplants. Transplantation 1997:63:1351-4.

10. Laux G, Mansmann U, Deufel A, Opelz G, Mytilineos J. A new epitope-based HLA-DPB matching approach for cadaver kidney retransplants. Transplantation 2003:75:1527-32.

11. Qiu J, Cai J, Terasaki PI, El-Awar N, Lee J-H. Detection of antibodies to HLA-DP in renal transplant recipients using single antigen beads. Transplantation 2005:80:1511-3.

12. Billen EVA, Christiaans MHL, Lee J, Berg van den-Loonen EM. Donor-directed HLA antibodies before and after transplantectomy detected by the Luminex single antigen assay. Transplantation 2009:87: 563-9.

13. Voorter C, Chatelain B, Sintnicolaas K, Tilanus M, Hidajat M, Berg van den-Loonen EM. Identification of a new DPB1 allele (DPB1*7901) by sequence-based typing. Tissue Antigens 1998:52:193-5.

14. Berg van den-Loonen van den EM, Voorter C. HLA-DPB1 and -DQB1 alleles in a population from the Netherlands. Hum Immunol 2004:65:1031-2.

15. Mueller-Eckhardt G, Kiefel V, Tlusty A, Scholten J, Schmidt A, Mueller-Eckhardt C. Incidence and specificity of HLA-DP antibodies in pregnancy sera. Hum Immunol 1990:29:166-74.

16. Pfeiffer K, Vögeler U, Albrecht KH, Eigler FW, Buchholz B, Grosse-Wilde H. HLA-DP antibodies in patients awaiting renal transplantation. Transpl Int 1995:8:180-4

17. Youngs D. HLA-DP alloantibodies. ASHI Quarterly 2004:28:60-2.

18. Baisch JM, Capra JD. Linkage disequilibrium within the HLA complex does not extend into HLA-DP. Scand J Immunol 1993:37:499-503.

19. Flomenberg N, Baxter-Lowe LA, Confer D, Fernandez-Vina M, Filipovich A, Horowitz M, Hurley C, Kollman C, Anasetti C, Noreen H, Begovich A, Hildebrand W, Petersdorf E, Schmeckpeper B, Setterholm M, Trachtenberg E, Williams T, Yunis E, Weisdorf D. Impact of HLA class I and class II highresolution matching on outcomes of unrelated donor bone marrow transplantation: HLA-C mismatching is associated with a strong adverse effect on transplantation outcome. Blood 2004:104: 1923-30.

20. Arnold M-L, Pei R, Spriewald B, Wassmuth R. Anti-HLA class II antibodies in kidney retransplant patients. Tissue Antigens 2005:65:370-8.

21. Duquesnoy RJ, Awaldalla Y, Lomago J, Jelinek L, Howe J, Zern D, Hunter B, Martell J, Girnita A, Zeevi A. Retransplant candidates have donor-specific antibodies that react with structurally defined HLA-DR, DQ, DP epitopes. Transpl Immunol 2008:18:352-60. 
22. Bodmer J, Bodmer W, Heyes J, So A, Tonks S, Trowsdale J, Young J. Identification of HLA-DP polymorphism with DP alpha and DP beta probes and monoclonal antibodies: correlation with primed lymphocyte typing. Proc Natl Acad Sci U S A 1987:84:4596-600.

23. Marshall WH, Drover S, Codner D, Gamberg J, Copp MD, Liu HW, Deng LT, Younghusband HB. HLA-DP epitope typing using monoclonal antibodies. Hum Immunol 1998:59:189-97.

24. Rosenberg WMC, Bushell A, Higgins RM, Wordsworth BP, Wood KJ, Bell JI, Morris PJ. Isolated HLA-DP mismatches between donors and recipients do not influence the function or outcome of renal transplants. Hum Immunol 1992:33:5-9.

25. Vaidya S, Hilson B, Sheldon S, Cano P, Fernandez-Vina M. DP reactive antibody in a zero mismatch renal transplant pair. Hum Immunol 2007:68:947-9.

26. Goral S, Prak EL, Kearns J, Bloom RD, Pierce E, Doyle A, Grossman R, Naji A, Kamoun M. Preformed donor-directed anti-HLA-DP antibodies may be an impediment to successful kidney transplantation. Nephrol Dial Transplant 2008:23:390-2.

27. Thaunat O, Hanf W, Dubois V, McGregor B, Perrat G, Chauvet C, Touraine JL, Morelon E. Chronic humoral rejection mediated by anti-HLA-DP alloantibodies: Insights into the role of epitope sharing in donor-specific and non-donor specific alloantibodies generation. Transpl Immunol 2009:20:209-11. 



\section{Chapter 7}

\section{Luminex donor-specific crossmatches}

EVA Billen, CEM Voorter, MHL Christiaans, EM van den Berg-Loonen Tissue Antigens 2008:71:507-513 


\section{Abstract}

In Luminex bead-based screening assays, color-coded microspheres coated with human leukocyte antigens (HLA) are used to identify both complement-binding and non-complement- binding HLA class I and II antibodies in recipient sera. Many laboratories rely on their specificity detection and use the information obtained for allocation of donor organs. A donor-specific crossmatch in the Luminex technique is for that reason desirable.

A LumXm, in which the actual donor-HLA are coated onto specific capture beads, was tested for 88 pre- and post-transplant sera of 18 recipients. The results were compared with previously published flow cytometric crossmatch $(\mathrm{FCXm})$ results for the same donor-recipient combinations. All sera were also examined by Luminex Single antigen (SA) tests.

Class I LumXm detected 24 of 27 T-cell positive FCXm (89\%) and class II 15 of 22 B-cell positive FCXm (68\%). Sensitivity of LumXm for class I and II was $89 \%$ and $68 \%$ and specificity was $98 \%$ and $97 \%$, respectively. Discrepant LumXm results were obtained in 13 sera of 9 patients (15\%). In general, based on SA testing, FCXm showed false positive results for class I, LumXm gave false-negative and positive results for class II. The LumXm test was proven not to react with recipient sera containing DQ ab only, also DP detection was insufficient.

The validity of the LumXm has been shown for class I, but its value for class II is uncertain. HLA-DR is most probably correctly identified, the validity for DQ and DP is doubtful. 


\section{Introduction}

Screening techniques of higher sensitivity than complement-dependent cytotoxicity (CDC) and enzyme-linked immunosorbent assay (ELISA), like the Luminex bead-based assays, have been introduced in the past years ${ }^{1,2}$. In these assays, color-coded microspheres coated with human leukocyte antigens (HLA) are used to identify HLA class I and II antibodies (ab) in patient sera. The tests detect both complement-binding and non-complement-binding HLA antibodies using anti-human immunoglobulin G (IgG) as second antibody. More and more laboratories rely on the detection of specificities demonstrated by these type of assays and use the information obtained for allocation of donor organs ${ }^{3-6}$.

Although the clinical relevance of antibodies detected by these bead-based techniques is still a matter of debate ${ }^{7-9}$, the availability of a prospective crossmatch in the Luminex technique is highly desirable. In the United States and United Kingdom, many laboratories are using flow cytometric crossmatches (FCXm) to make decisions on organ transplantation, although, in Europe many laboratories still rely on CDC crossmatches.

In this report, we describe a Luminex donor-specific (DS) crossmatch (LumXm), in which the actual donor-HLA are coated onto specific capture beads. The results of the LumXm were compared to flow cytometric results for the same donor-recipient combinations obtained previously ${ }^{10}$.

\section{Materials and Methods}

\section{Patients and sera}

From 18 patients transplanted at the University Hospital of Maastricht between 1997 and 1999, 88 pre- and post-transplant sera were tested with the Luminex Xm technique. The $\mathrm{Xm}$ at the time of transplantation was the CDCXm with and without dithiotreitol (DTT), as required by the organ exchange organisation. A negative class I CDCXm was mandatory for transplantation. All sera had been retrospectively tested by FCXm as described previously ${ }^{10}$. Patients and donors were typed for HLA-A/B by serology and for -DR/DQ by polymerase chain reaction sequence-specific primers (PCR-SSP). Retrospectively, all recipient and donor typings (A,B,C,DR and DQ) have been repeated with molecular techniques (sequence-specific oligonucleotide (SSO) hybridisation, Luminex) to ascertain the exact number of mismatches. If required highresolution typing (DRB3, DQA1, DPB1) was performed. Patient sera were stored at $-30^{\circ} \mathrm{C}$ and donor lymphocytes were isolated from peripheral blood or spleen cells and stored in liquid nitrogen. 


\section{Luminex donor-specific crossmatches}

\section{Crossmatch assay}

Xms were performed using Xm capture beads, consisting of microspheres coated with monoclonal antibodies against HLA class I or II, in the Luminex technology according to the manufacturer's protocol (Donor Specific Antibody beads; Tepnel Lifecodes, Stamford, CT). Per serum, $2.2 \times 10^{6}$ donor lymphocytes were treated with $8 \mu$ l of diluted (1:10) nonionic lymphocyte lysis buffer. The donor lysate was subsequently incubated for $30 \mathrm{~min}$ with $5 \mu \mathrm{l}$ of $\mathrm{Xm}$ beads to enable binding of the solubilized donorHLA molecules onto the beads. The mixture was washed three times with $250 \mu$ l wash buffer using a 96-well filter plate (Millipore, Bedford, MA) in conjunction with a vacuum manifold. Diluted recipient serum (1:4) was added and incubated for $30 \mathrm{~min}$. After another three washes, 50 $\mu$ l antihuman IgG-conjugated phycoerythrine (anti-lgGPE 1:10) was added and incubated for $30 \mathrm{~min}$. All incubations were performed on a gently rotating platform in the dark at room temperature. After addition of $130 \mu \mathrm{l}$ of wash buffer, the LABScan100 flow cytometer (Luminex ${ }^{\circledR}$, Austin, TX) was used for mean fluorescent intensity (MFI) measurement.

\section{Quality assurance}

In the $\mathrm{Xm}$ bead mixture, three negative control beads were included, whose mean MFI value was used as background signal. The test was considered failed if their mean $\mathrm{MFI}$ value was $>500$. A positive control bead (IgG) was included to check the binding of anti-IgG-PE, and the minimum requirement for the assay was $\mathrm{MFI}>10.000$. In parallel with the patient sera, the coated $\mathrm{Xm}$ beads were incubated with biotinylated monoclonal antibodies against HLA class I and II, the so-called lysate control. The lysate control was used to indicate correct attachment of donor-HLA on the beads. Instead of IgG-PE, streptavidine conjugated phycoerythrine (SAPE) is used as well as a positive control bead to check the SAPE. A minimum MFI value for both class I and II of the lysate control was set at 10.000 , otherwise the test was considered failed. For the LABScan100 flow analyser, two calibration and two control bead mixtures were run prior to data acquisition.

\section{Data analysis}

Data generated with the LABScan100 were evaluated with the LifeMatch software (Tepnel Lifecodes) to obtain MFI values of capture- and control beads. To define positivity, the median of three negative controls was subtracted from the MFI obtained for the testserum. The adjusted MFI values of class I and II Xm beads were compared with the adjusted MFI of the positive control bead. A ratio of $>5 \%$ and/or MFI value of $>1000$ were considered positive. 


\section{Flow-cytometry donor-specific crossmatches}

The FCXm was performed as described previously ${ }^{10}$. Briefly; donor lymphocytes were incubated with centrifugated, heat-inactivated recipient serum to reduce non-specific background $^{11,12}$. After three washings incubation was performed with fluorescein isothiocyanate (FITC)-conjugated anti-human IgG antibody (Tago, Burlingame, CA), PE-conjugated monoclonal mouse antihuman T-cell (CD3) and R-PE-cyanine5conjugated monoclonal mouse antihuman B-cell (CD19) (Dakopatts, Glostrup, Denmark). After washing and resuspension, lymphocytes were analyzed with a FACS Calibur system (Becton dickinson, San Jose, CA) using logarithmic amplification on a 1024 channel resolution. The linear median value of FITC fluorescence was collected for CD3- and CD19- positive cells. A FCXm was considered positive if the ratio of median value of recipient serum to negative controlserum was $>1.97$ (mean+3 standard deviation) for T cells and >2.99 (mean+3 standard deviation) for B cells, provided that the ratio of the positive control serum to negative control was greater than the cut off value. External proficiency testing for FCXm was performed in the UK NEQAS scheme (60 Xm/year) and has always proven to be adequate.

\section{Antibody specificity analysis by single antigen (SA) assay}

Specificity analysis of the IgG anti-HLA class I (A, B and C) and II (DR, DQ and DP) ab of all recipient sera was performed using the LABScreen ${ }^{\circledR} \mathrm{SA}$ assay (One Lambda ${ }^{\odot}$, Canoga Park, CA) according to the manufacturer's instructions. In short, microspheres coated with purified HLA antigens were incubated with patient serum for $30 \mathrm{~min}$. After washing to remove unbound antibody, antihuman-IgG-conjugated PE was added. The LABScan100 flow analyzer (Luminex) and HLAVisual software (One Lambda) were used for data acquisition and analysis.

The reactivity of three strong allosera (panel reactive antibody (PRA) $>90 \%$ ) was determined with the class I and II Single antigen (SA) bead assay. For each bead, the positive control value was set at the mean of the three MFI values obtained. A positive bead reaction was subsequently defined as an MFI value of at least $10 \%$ of the positive control value for that bead.

\section{Statistical analysis}

Sensitivity was defined as TP/(TP+FN), specificity as TN/(TN+FP). Predictive values were calculated as positive predictive value $=T P /(T P+F P)$ and negative predictive value $=\mathrm{TN} /(\mathrm{TN}+\mathrm{FN}) \quad$ (True Positive $(\mathrm{TP})=\mathrm{LumXm}+/ \mathrm{FCXm}+$, False Positive $(\mathrm{FP})=$ LumXm+/FCXm-, True Negative (TN)=LumXm-/FCXm- and False Negative (FN)= LumXm-/FCXm+). 


\section{Results}

Luminex bead-based crossmatches were performed for 88 longitudinal pre- and posttransplantsera of 18 patients transplanted in Maastricht between 1997-1999. All sera had been crossmatched for T- and B-cells by FCXm as described previously ${ }^{10}$. A positive LumXm was found for class I in 25 sera, for class II in 17. For 2 sera no reliable results were obtained, all other sera showed negative LumXm.

\section{LumXm versus FCXm}

Class I LumXm detected 24 of 27 T-cell positive FCXm (89\%) and class II 15 of 22 B-cell positive FCXm (68\%) (Table 7.1). LumXm MFI values showed time curves comparable to the curves obtained by FCXm ratios. In Figures 7.1 and 7.2, some examples of class I and II LumXms are shown.

Table 7.1 Comparison of donor specific LumXm with T- and B-cell FCXm.

\begin{tabular}{lccccc}
\hline & LumXm positive & LumXm negative & $\mathrm{N}^{*}$ & sens/spec & PPV/NPV \\
\hline FCXmT-cell pos & 24 & 3 & 86 & $89 \% / 98 \%$ & $96 / 95$ \\
FCXmT-cell neg & 1 & 58 & & & \\
FCXmB-cell pos & 15 & 7 & 86 & $68 \% / 97 \%$ & $88 / 90$ \\
FCXmB-cell neg & 2 & 62 & & \\
\hline
\end{tabular}

* 2 LumXm failed due to high background values. PPV = positive predictive value, NPV = negative predictive value

Results are compared to the corresponding FCXm obtained previously, for LumXm, the MFI values and for FCXm, the ratios are plotted against time. Figures 7.1A, 7.1B and 7.1C show the class I Xm results of three recipients. All have concordant negative as well as positive LumXm/FCXm results. In Figures 7.2A and 7.2B, recipients are shown with concordant positive and negative class II LumXm/FCXm results. In Figure 7.2C, a patient with discordant results is depicted, some FCXm values (indicated by ${ }^{*}$ ) are positive, while the corresponding LumXm values are negative.

Compared to FCXm, sensitivity of LumXm was $89 \%$ for class I and $68 \%$ for class II and specificity was $98 \%$ and $97 \%$ respectively. The positive predictive value of LumXm was $96 \%$ for class I and $88 \%$ for class II and the negative predictive values were 95 and $90 \%$, respectively. 

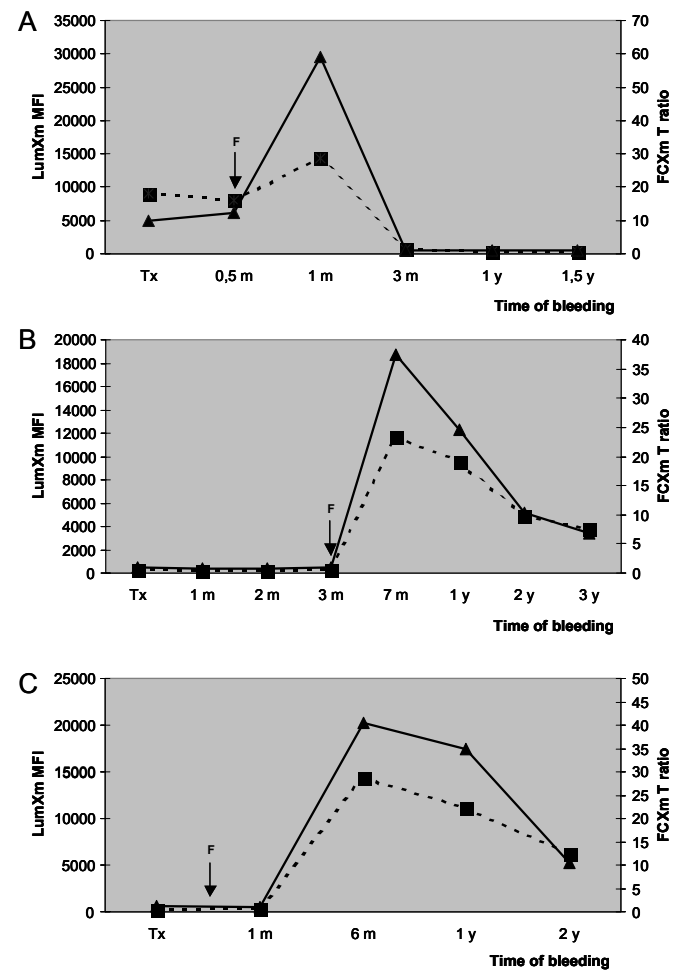

Figure 7.1 Examples of $\mathbf{3}$ donor-recipient class I LumXm compared to T-cell FCXm.

Adjusted MFI values (=MFI - median negative control) for LumXm and the ratios (=median value of recipient serum/negative control serum) for FCXm are plotted against time. The first measuring point was the time of transplantation, the others are follow-up dates.

Cut off point for positivity of T-cell FCXm was 1.97, and for LumXm $1000 \mathrm{MFI}$.

$F$ means failure of the graft.

\section{Specificity analysis}

The sera used for the crossmatches were examined for presence and specificity of HLA antibodies by the SA bead assay. For class I, all 24 LumXm+/FCXm+ sera showed class I DS ab, whereas the 58 LumXm-/FCXm- sera showed no ab ( $n=27)$, non-DS ab $(n=30)$ or a weak DS ab $(n=1)$. The weak antibody was directed against A1. For class II, all 15 LumXm+/FCXm+ sera showed class II DS ab. The 62 LumXm-/FCXm- sera showed no ab $(n=41)$, non-DS $(n=19)$ or DS $(n=2)$. The DS ab were both weak anti-DQ antibodies.

Discrepant LumXm vs FCXm results were obtained in 13 sera of nine patients. For class I, a LumXm-/FCXm+ was shown in three patients: two had non-DS ab and one had 
no ab at all. One patient presented as LumXm+/FCXm- and SA showed the presence of weak B51 DS ab.

For class II, a total of nine discrepant LumXm results was obtained in five patients: three patients with seven LumXm-/FCXm+ proved to possess DP $a b(n=2)$ or DQ $a b$ $(n=1)$. The DQ and one DP ab were DS and the other DP ab was non-DS. The other two patients with a LumXm+/FCXm- result were negative for HLA ab by the SA bead assay. With the SA bead assay as "gold standard", the sensitivity of LumXm was $96 \%$ for class I and $65 \%$ for class II, the specificity was $100 \%$ and $97 \%$, respectively.

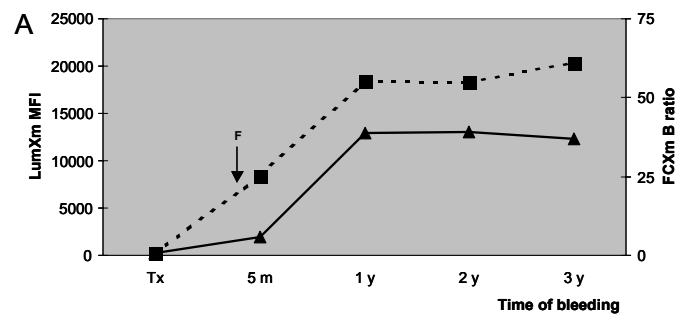

B

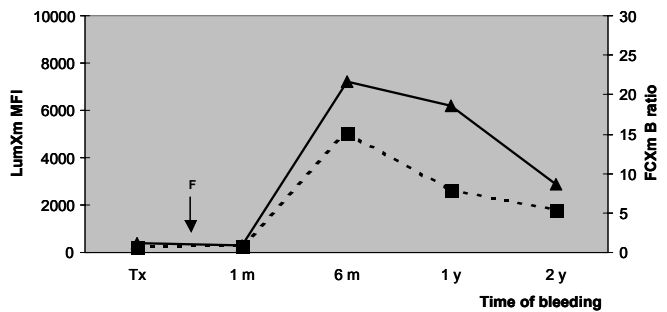

C

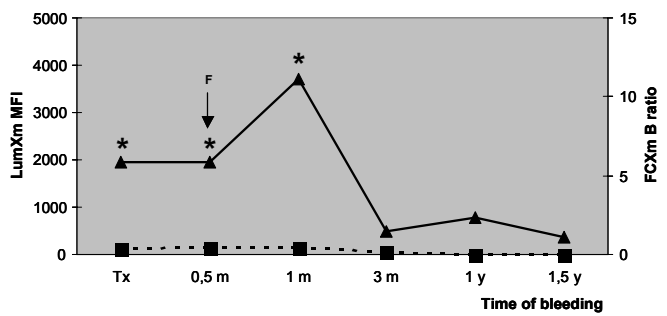

Figure 7.2 Examples of $\mathbf{3}$ donor-recipient class II LumXm compared to B-cell FCXm.

Adjusted MFI values (=MFI - median negative control) for LumXm and the ratios (=median value of recipient serum/negative control serum) for FCXm are plotted against time. The first measuring point was the time of transplantation, the others are follow-up dates.

Cut off point for positivity of B-cell FCXm was 2.99, and for LumXm $1000 \mathrm{MFI}$.

$F$ means failure of the graft.

In 2c a patient with discordant results is shown; the positive FCXm values marked * have negative corresponding LumXm values.

- FCXm T/B ratio, - - LumXm MFI, F failure, Tx transplantation, * discordant LumXm / FCXm results 


\section{Detection of HLA-DQ and -DP antibodies in selected sera}

The results obtained questioned the ability of the LumXm beads to correctly capture class II HLA-DQ and HLA-DP molecules, which might result in failure to detect class II $\mathrm{DQ}$ and DP ab. Additional tests were performed to determine whether the LumXm test detected DQ or DP ab in selected sera without other class II ab. For HLA-DQ, five sera were selected without DR or DP ab, as proven by SA testing, specificities included were HLA-DQ2,4,5,7,8 and 9. The sera were tested against eight donor cells, carrying at least one of the relevant DQ specificities. All DQ LumXm failed to react with beads prepared from the selected donors (Table 7.2).

Table 7.2 Specific HLA-DQ antibodies in the LumXm assay.

\begin{tabular}{lcccc}
\hline & $\begin{array}{c}\text { ab specificity } \\
\text { SA }\end{array}$ & DQA1 & DQB1 & LumXm \\
\hline 1 & DQ2 & 01010501 & 02010501 & neg \\
2 & DQ2 & 01010501 & 02010501 & neg \\
3 & DQ5 & 01010501 & 02010501 & neg \\
4 & DQ6+DQ9 & 01020302 & 03030602 & neg \\
5 & DQ9 & 01020302 & 03030602 & neg \\
6 & DQ5 & 01010505 & 03010501 & neg \\
7 & DQ5 & 01010201 & 02020501 & neg \\
8 & DQ4 & 050104 & 02010402 & neg \\
\hline
\end{tabular}

For HLA-DP, five sera were selected, which showed only DP ab in the SA test. DP specificities included DP1,3,4,5,13,17 and 19. The sera were tested against five different donor cells, carrying at least one of the DP specificities mentioned. Two out of five DP LumXm were positive with donors possessing the relevant DP specificity and the other three failed to react (Table 7.3).

Table 7.3 Specific HLA-DP antibodies in the LumXm assay.

\begin{tabular}{lcccc}
\hline & ab specificity & \multicolumn{2}{c}{ Panel cell } & LumXm \\
\hline 1 & SA & DPA1 & DPB1 & neg \\
2 & DP3 & 0103 & 03010401 & pos \\
3 & DP5 & 01030202 & 04010501 & pos \\
4 & DP1+DP13 & 02010401 & 01011301 & neg \\
5 & DP17 & 01030201 & 04021701 & neg \\
\hline
\end{tabular}

Specific DQ (a) and DP (b) sera were tested with selected panel cells with known high resolution HLA-DQ and DP types. 


\section{Discussion}

The aim of the present study was to compare class I and II LumXm using donor-HLA antigens coated on microparticle beads, to our standard FCXm, with donor T- and B-cells as the HLA target. The results from both tests were compared. Class I results showed good correlation with FCXm results in 18 recipient-donor combinations, the LumXm was found to have approximately the same sensitivity and specificity as the FCXm (89\%/95\%). However, for class II, the sensitivity was found to be $68 \%$, with a specificity of $97 \%$. Compared to the SA bead assay, the sensitivity of the LumXm was $96 \%$ for class I and $65 \%$ for class II and the specificity was $100 \%$ and $97 \%$, respectively. Overall there were more discrepant results found in class II, mostly negative results where positive ones were expected.

Negative LumXm for class I, discrepant with FCXm, was obtained in three recipients, two had non-DS ab and one had no HLA ab at all. In one discrepant positive LumXm, the presence of weak DS B51 ab was shown. FCXm seemed to provide false-positive Xm results, while LumXm was positive only when DS HLA ab were present.

For class II, discrepant-negative LumXm were shown for three recipients, two proved to possess DS DQ and DP ab and one had non-DS DP ab. Two recipients had discrepantpositive LumXm, they were negative for HLA ab by the SA bead assay. Thus, LumXm missed DS ab in two recipients and was false positive in two others. In general, for class I, FCXm showed false- positive results, while for class II, more false-negative and positive results were noticed for LumXm.

A closer look at the class II data suggested that test results were obtained as expected when the target molecule was DR, which was the case in most of the donor-recipient combinations used. When, however, DQ or DP was the target, the LumXm was found negative. Additional LumXm tests with specific sera that contained solely DQ or DP ab (as determined by SA analysis of the sera) yielded test results that were false negative. Five HLA-DQ-specific sera did not react in eight LumXm, with beads prepared from eight donors selected for the relevant $D Q$ antigens (Table 7.2). In the same way, five HLA-DP-specific sera gave positive results in two LumXm, but failed to react with beads prepared from three donor cells bearing the corresponding DP antigens (Table 7.3). The two positive DP sera showed high MFI values in the SA bead assay, suggesting that the ab titer might play a role in the binding as fluorescence values in the SA bead assay are correlated with ab strength and titer ${ }^{9}$. Because all DQ and most of the DP sera did not show binding of the antibody to the bead, DQ and DP antigens are most probably not captured by the LumXm beads. Another explanation could be that their molecular structure has changed in the binding process, thus preventing antibody binding. Discrepancies in the results of Luminex Xm beads and results of SA testing may also be because of the fact that the basis for attachment of the HLA molecules to the beads differs between the 2 assays. 
Both FCXm and LumXm may produce false-positive and false-negative results.

False-positive FCXm results have been described due to the presence of IgG autoab, non-HLA $a b$ or monoclonal ab, Fc-receptors, complement receptors or other immunoglobulins on the cell surface ${ }^{13,14}$. The percentage of false positive FCXm in our study is very low (3.5\% for T-cell FCXm and $2.3 \%$ for B-cell FCXm) compared with some publications $^{15}$, even though no pretreatment of lymphocytes with pronase was performed to reduce non-specific background ${ }^{16-18}$. The explanation for the low rate of false-positive FCXm in this study could be 1) the comparison of the FCXm outcome with a very sensitive technique, the SA bead assay, and 2) the specific FCXm protocol used, including centrifugation ${ }^{11}$ and heat-inactivation ${ }^{12}$ of the sera.

In bead-based immuno-assays, binding of HLA molecules to beads may modify the structure of the molecule and the accessibility of epitopes. Impaired binding of HLA antibodies may subsequently result in false positive or negative reactions ${ }^{8,19}$. It is possible that the so-called lysate control, used as a check for the correct attachment of HLA class I and II molecules, to the beads, does not reflect correctly the binding of all class I and II antigens.

An attempt to reduce the cell concentration of the lymphocyte population, necessary to provide the donor antigens for the capture beads, also revealed problems in class II binding, although class I seemed to be unaffected.

One of the major advantages of the solid-phase approach for both screening and crossmatching is that a clear distinction can be made between class I and class II ab and that no viable cells are necessary. The objective measurement of MFI values by a flow analyser in stead of subjective microscope readings is also an advantage, as is the multiplexing capacity of the LumXm, which enables performance of 96 different LumXm at the same time. The assay is performed within $3 \mathrm{~h}$, which makes it adequate for prospective crossmatching for deceased donor organ transplantation in $24 \mathrm{~h}$ services.

The LumXm assay in its present form, does not distinguish between complementbinding and non-complement-binding DS ab. The use of different types of labelled second ab as IgG subclasses or IgM might extend the test to more specific ab classes ${ }^{20}$. In this respect, the clinical relevance of complement binding ab has been described extensively, the role of non-complement-binding HLA ab in kidney transplantation is less clear ${ }^{21}$.

In conclusion, with the DS LumXm described here, a crossmatch assay is available that is performed in the same technique that many laboratories nowadays use for ab detection in transplant candidates. At this moment, the validity of the LumXm has been shown for class I, but its value for class II is uncertain. HLA DR is most probably correctly identified and the validity for DQ and DP is doubtful. 


\section{References}

1. Pei R, Lee J-H, Shih N-J, Chen M, Terasaki PI. Single human leukocyte antigen flow cytometry beads for accurate identification of human leukocyte antigen antibody specificities. Transplantation 2003:75: 43-9.

2. El-Awar N, Lee J, Terasaki PI. HLA Antibody identification with single antigen beads compared to conventional methods. Hum Immunol 2005:66:989-97.

3. Terasaki PI, Cai J. Humoral theory of transplantation: further evidence. Curr Op Immunol 2005:17: 541-5.

4. Vaidya S, Partlow D, Susskind B, Noor M, Barnes T, Gugliuzza K. Prediction of crossmatch outcome of highly sensitized patients by single and/or multiple antigen bead luminex assay. Transplantation 2006: 82:1524-8.

5. Mao Q, Terasaki PI, Cai J, Briley K, Catrou P, Haisch C, Rebellato L. Extremely high association between appearance of HLA antibodies and failure of kidney grafts in a five-year longitudinal study. Am J Transplant 2007:7:864-71.

6. Gibney EM, Cagle LR, Freed B, Warnell SE, Chan L, Wiseman AC. Detection of donor-specific antibodies using HLA-coated microspheres: another tool for kidney transplant risk stratification. Neprhol Dial Transplant 2006:21:2625-9.

7. Christiaans M, Overhof R, Haaft ten A, Nieman F, Hooff van JP, Berg van den-Loonen EM. No advantage of flow cytometry crossmatch over complement-dependent cytotoxicity in immunologically well-documented renal allograft recipients. Transplantation 1996:62:1341-7.

8. Gebel HM, Harris SB, Zibari G, Bray RA. Conundrums with flowPRA (TM) beads. Clin Transplant 2002: 16:24-9.

9. Mizutani K, Terasaki P, Hamdani E, Esquenazi V, Rosen A, Miller J, Ozawa M. The importance of antiHLA-specific antibody strength in monitoring kidney transplant patients. Am J Transplant 2007: 7: 1027-31.

10. Lenaers JIV, Christiaans MHL, Voorter CEM, Hooff van HP, Berg van den-Loonen EM. Relevance of posttransplant flow cytometric T- and B-cell crossmatches in tacrolimus-treated renal transplant patients. Transplantation 2006:82:1142-7.

11. Bray RA. Flow cytometry crossmatching for solid organ transplantation. Methods in Cell Biology 1994: 41:103-19.

12. Ta M, Scornik JC. Improved flow cytometric detection of donor-specific HLA class II antibodies by heat inactivation. Transplantation 2002:73: 1611-4.

13. Bray RA. Flow cytometry in human leukocyte antigen testing. Semin Hematol 2001:38:194-200.

14. McKenna RM, Takemoto SK, Terasaki PI. Anti-HLA antibodies after solid organ transplantation. Transplantation 2000:69:319-26.

15. Le Bas-Bernardet S, Hourmant M, Valentin N, Paitier C, Giral-Classe M, Curry S, Follea G, Soulillou JP, Bignon JD. Identification of the antibodies involved in B-cell crossmatch positivity in renal transplantation. Transplantation 2003:75:477-82.

16. Vaidya S, Cooper TY, Avandsalehi J, Barnes T, Brooks K, Hymel P, Noor M, Sellers R, Thomas A, Stewart D, Daller J, Fish JC, Gugliuzza KK, Bray RA. Improved flow cytometric detection of HLA alloantibodies using pronase. Transplantation 2001:71:422-8.

17. Bearden CM, Agarwal A, Book BK, Sidner RA, Gebel HM, Bray RA, Pescovitz MD. Pronase treatment facilitates alloantibody flow cytometric and cytotoxic crossmatching in the presence of rituximab. Hum Immunol 2004:65:803-9.

18. Lobo PI, Spencer CE, Stevenson WC, McCullough C, Pruett TL. The use of pronase-digested human leukocytes to improve specificity of the flow cytometric crossmatch. Transpl Int 1995:8:472-80.

19. Saidman SL. Histocompatibility testing for highly sensitized transplant candidates. Transpl Proc 2007: 39:673-5.

20. Arnold M-L, Zacher T, Dechant M, Kalden JR, Doxiadis IIM, Spriewald BM. Detection and specification of noncomplement binding anti-HLA alloantibodies. Hum Immunol 2004:65:1288-96.

21. Karpinski M, Rush D, Jeffery J, Exner M, Regele H, Dancea S, Pochinco D, Birk P, Nickerson P. Flow cytometric crossmatching in primary renal transplant recipients with a negative anti-human globulin enhanced cytotoxicty crossmatch. J Am Soc Nephrol 2001:12:2807-14. 


\section{Chapter 8}

Clinical relevance of Luminex donor-specific

crossmatches: data from 165 renal transplants

EVA Billen, MHL Christiaans, EM van den Berg-Loonen

Tissue Antigens 2009;74:205-212 


\section{Abstract}

The clinical significance of the presence of donor-specific anti-human leukocyte antigen (HLA) antibodies prior to renal transplantation detected solely by solid-phase techniques remains unclear.

This study was designed to determine the clinical relevance of the recently introduced bead-based Luminex donor-specific crossmatch (LumXm). A group of 165 patients transplanted between 1997 and 2001 were tested.

Out of 165 recipients transplanted with a negative complement-dependent cytotoxicity (CDC) crossmatch, 32 proved to have a positive Luminex crossmatch. Sixteen were positive for class I, 15 were positive for class II, 1 was both class I and II positive and 133 recipients were negative.

Acute rejection (AR)-free survival for all recipients was 77\%, and there was no difference in AR-free survival between LumXm-positive and LumXm-negative recipients. Overall graft survival after a median follow-up time of 8 years was $56 \%$. Recipients with a positive class I LumXm had worse long-term graft survival $(\mathrm{P}=0.006)$. In recipients with a positive class I LumXm 5 -year graft survival was $41 \%$ vs. $70 \%$ in negative patients and 10 -year graft survival was $27 \%$ vs. $56 \%$. Positivity for class II LumXm was not a significant risk factor for graft failure $(P=0.7)$.

In conclusion, pretransplant DSA detected by the LumXm had no impact on AR episodes. Class II LumXmpositivity proved no significant risk factor for graft failure, but the value of the class II LumXm is questionable. A positive class I LumXm resulted in worse long-term graft survival compared to a negative one. 


\section{Introduction}

The presence of preformed cytotoxic donor-specific anti-human leukocyte antigen (HLA) antibodies (DSA) in recipient serum prior to renal transplantation is the predominant risk factor for irreversible hyperacute allograft rejection and subsequent graft loss. For that reason, prospective complement-dependent cytotoxicity crossmatches ( $C D C X m s)$ before renal transplantation have been performed routinely for over forty years ${ }^{1}$. About 20 years ago, a more sensitive technique, the flow cytometric crossmatch (FCXm), was introduced. Many centres, mainly in the United States and the UK, strongly advocate the use of this technique ${ }^{2}$, while others regard it as a test that prevents recipients to obtain grafts that would potentially function well ${ }^{3}$.

For CDC and FC, a crossmatch is available in the same technique that laboratories use for routine antibody detection. The CDCXm and the FCXm are cell-based assays differing in sensitivity, but comparable in specificity and both methods have disadvantages. CDCXm interpretation is complicated because non-graft damaging autoreactive immunoglobuline $\mathrm{M}$ (IgM)-antibodies as well as alloantibodies are detected. CDCXm and FCXm are subject to interference by non-HLA antibodies that bind to lymphocytes and by therapeutic antibody present in the recipient. Differentiation of antibodies specific for class I and class II requires removal of class I-specific antibodies. For these reasons, many laboratories are now using solidphase techniques, in particular the recently introduced bead-based assay ${ }^{4-6}$ that offers the advantage of greater sensitivity and specificity for routine antibody screening. For the first time now, a crossmatch has become available using the same bead-based technique. In an earlier study ${ }^{7}$, we evaluated this new crossmatch technique, the Luminex donor-specific crossmatch (LumXm). LumXm results of a selected group of patients were compared with FCXm results and the outcome of Luminex Single antigen (LSA) screening. The LumXm proved to be valid for class I DSA detection but of limited value for the detection of class II DSA.

The aim of the present study was to evaluate the clinical significance of the donorspecific LumXm in a group of renal transplant recipients, who were all transplanted with a negative CDCXm over a 4-year period.

\section{Materials and Methods}

\section{Patients}

Two hundred and thirty-eight consecutive $\mathrm{ABO}$-compatible renal transplantations with a negative CDCXm were performed between January 1997 and January 2001 at the University hospital of Maastricht. Follow-up was continued up to May 2008. From 165 
of these donor-recipient pairs, sufficient donor lymphocytes were available to retrospectively perform donor-specific LumXm with the sera drawn at the time of the transplantation. Pretransplant characteristics of the patients included in the study are given in Table 8.1. The pretransplant characteristics from the 73 patients without available donor lymphocytes were comparable to those of the patients included in the study.

Table 8.1 Patient characteristics.

\begin{tabular}{lccc}
\hline Parameter & All recipients & LumXm pos & LumXm neg \\
& $\mathrm{n}=165$ & $\mathrm{n}=32$ & $\mathrm{n}=133$ \\
\hline Median recipient age, years (range) & $54(16-77)$ & $57(19-75)$ & $53(16-77)$ \\
Male gender & $103(62 \%)$ & $24(75 \%)$ & $79(59 \%)$ \\
Female recipients with pregnancies & $45 / 62$ & $6 / 8$ & $39 / 54$ \\
Donor type (L/HB/non-HB) & $23 / 85 / 57$ & $4 / 18 / 10$ & $19 / 67 / 47$ \\
Median donor age, years (range) & $49(6-74)$ & $50(11-73)$ & $49(6-74)$ \\
HLA-A mismatch 0/1/2 (\%) & $31 / 48 / 21$ & $25 / 60 / 15$ & $33 / 45 / 22$ \\
HLA-B mismatch 0/1/2 (\%) & $22 / 67 / 11$ & $22 / 66 / 12$ & $23 / 67 / 10$ \\
HLA-DR mismatch 0/1/2 (\%) & $30 / 65 / 5$ & $41 / 53 / 6$ & $28 / 68 / 4$ \\
Median day of follow-up & 2852 & 2522 & 2887 \\
Acute rejection within 6 months & $38(23 \%)$ & $6(19 \%)$ & $32(24 \%)$ \\
Delayed graft function & $61(37 \%)$ & $14(44 \%)$ & $47(35 \%)$ \\
First Tx/ReTx & $134 / 31$ & $25 / 7$ & $109 / 24$ \\
CDC PRA current $\geq 6 \%$ & $17(10 \%)$ & $8(25 \%)^{*}$ & $9(7 \%)^{*}$ \\
Cold ischemia time (h), mean \pm sd & $22.3 \pm 10.5$ & $22.7 \pm 10.1$ & $22.2 \pm 10.7$ \\
First warm ischemia time (min), mean \pm sd & $14.2 \pm 24.0$ & $9.4 \pm 17.0$ & $15.4 \pm 25.4$ \\
Nr of transfusions, mean \pm sd & $7 \pm 14$ & $12 \pm 24$ & $5 \pm 10$ \\
\hline
\end{tabular}

* Non-parametric test for differences between LumXm positive and negative recipients $(P=0.002)$

\section{Immunosuppression}

The immunosuppressive regimen was calcineurine inhibitor-based drug therapy in combination with prednisolone for all recipients. Calcineurine inhibitor was cyclosporine (CSA) in 8 and tacrolimus (TAC) in 157. Additional immunosupression consisted of azathioprine in 1 recipient, mycophenolate mofetil in 74 and rapamycine in 14. Five recipients participated in a multicenter clinical trial, and therefore, they received induction therapy with interleukine-2-receptor antagonist. CSA levels were determined in whole blood by enzyme monoclonal immuno test (Dade Behring, Newark, DE) or high-performance liquid chromatography-MS/MS. In the first 3 months after transplantation, target CsA trough levels were 0.10 to $0.15 \mathrm{mg} / \mathrm{l}$, afterwards decreasing to 0.05 to $0.10 \mathrm{mg} / \mathrm{l}$. TAC trough levels were measured in whole blood by ImX (Abbott, Abbott Park, IL) or high performance liquid chromatography-MS/MS, target levels were 15 to $20 \mathrm{ng} / \mathrm{ml}$ for weeks 1 and 2 and 10 to $15 \mathrm{ng} / \mathrm{ml}$ for weeks 3 and 4 , thereafter tapering at 5 to $7 \mathrm{ng} / \mathrm{ml}$. 


\section{Clinical outcome parameters}

A biopsy was taken during surgery $1 \mathrm{~h}$ after reperfusion for every transplant. Acute rejection (AR) was defined as any rejection treatment within 6 months after grafting. All rejection episodes were proven by needle core biopsy. No fresh-frozen material for C4d staining was available because of the retrospective design of the study. AR treatment for vascular rejection consisted of a 10-day course of rabbit antithymocyte globulin or three doses of methylprednisolone $(0.5-1.0 \mathrm{~g} / \mathrm{dose})$ in case of tubulointerstitial rejection. Delayed graft function (DGF) was defined as the need for dialysis in the first week after transplantation. Graft failure was defined as loss of kidney function (return to renal replacement therapy or retransplantation) but also included death with functioning graft. All patients were followed up until date of graft failure, date of death or May 2008.

\section{Centre policy of tissue typing}

During the investigation period all patients and donors were typed for HLA-A, -B, -DR and $-\mathrm{DQ}$ by serology and polymerase chain reaction with sequence specific primers (PCR-SSP). All recipient sera were screened before transplantation for presence of antiHLA class I and II antibodies by CDC using the two-colour fluorescence technique on unseparated peripheral blood lymphocytes (PBLs). Reading was performed with an automated Leitz inverted fluorescence microscope. HLA antigens were considered unacceptable for a patient if antibodies against the specificity had ever been demonstrated, either at the time of transplantation or in the past. Mismatches from previous transplants were excluded, as were the paternally inherited antigens of children of female patients. All transplants were performed under the auspices of Eurotransplant, which means that only HLA-A, -B and -DR matches were included in the allocation algorithm.

\section{Prospective CDC and FCXm Crossmatches}

Before transplantation, CDCXms were performed using unseparated PBLs: the standard national institute of health $(\mathrm{NIH})$ crossmatch with and without dithiothreitol (DTT) to reduce IgM antibodies. Sera used for the final crossmatch were the pretransplant serum drawn at the time of transplantation, the last serum tested for anti-HLA antibodies in the quarterly screening and all relevant positive historical samples. A negative class I DTT-Xm for current as well as historical sera was mandatory for transplantation. T- and B-cell FCXm from current and historical sera are performed for all transplantations according to the technique described by Scornik et al. ${ }^{8}$ with slight modifications, that is centrifugation ${ }^{9}$ and heat inactivation of the sera ${ }^{10}$ to reduce the number of false positive results. The result of the FCXm is not considered in the decision regarding transplantation. A positive $\mathrm{FCXm}$ result therefore is no reason for exclusion from this study. 


\section{Retrospective LumXms}

Donor-specific LumXm of 165 recipients transplanted with a negative CDCXm were performed according to the manufacturer's (DSA, Tepnel Lifecodes, Stamford, USA) recommendations as described previously ${ }^{7}$. The sera used for LumXm were the same pretransplant sera as used for the original CDCXM. In short, a lysate prepared with donor lymphocytes was incubated for $30 \mathrm{~min}$ with capture beads to enable binding of the solubilized donor-HLA molecules onto the beads. The mixture was washed three times with wash buffer using a 96-well filter plate (Millipore, Bedford, MA) in conjunction with a vacuum manifold. Diluted recipient serum was added and incubated for $30 \mathrm{~min}$. After another three washes, anti-human immunoglobulin $\mathrm{G}$ (IgG)-conjugated phycoerythrine (1:10) was added and incubated for $30 \mathrm{~min}$. All incubations were performed on a gently rotating platform in the dark at room temperature. After addition of wash buffer, the LABScan100 flow cytometer (Luminex ${ }^{(}$) was used for mean fluorescent intensity (MFI) measurement of capture and control beads. To define positivity, the median MFI value of the three negative controls was subtracted from the MFI value of the capture bead. This adjusted MFI was then compared with the adjusted MFI of the positive control bead. A ratio of $\geq 5 \%$ and/or an adjusted MFI value of $\geq 1000$ for the capture bead were considered to be positive.

For antibody specificity analysis by the LSA assay, the reactivity of three strong allosera was determined. For each bead, the positive control value was set at the mean of the three MFI values obtained. A positive bead reaction was subsequently defined as an MFI value of at least $10 \%$ of the positive control value for that bead.

\section{Statistical analysis}

All statistical analyses were performed by using Statistical Package for the Social Sciences software (SPSS, Cary, NC). Groups were compared with parametric (independent samples Student's t-test) and non-parametric tests (Pearson chi-square test, Fisher's exact test, Kruskal-Wallis test). A P-value of $\leq 0.05$ was considered to be statistically significant. Kaplan-Meier survival analysis was used to analyze differences in rejection-free survival and graft survival (log-rank statistic). Rejection-free survival and graft survival were also analyzed with the proportional hazards regression analysis (Cox regression) using stepwise backward elimination techniques for all suspected risk factors. With rejection as outcome parameter, the suspected risk factors tested for in the basic model included crossmatch outcome of current serum: "class I and II LumXm (neg vs. pos)" and "T- and B-cell FCXm (neg vs. pos)"; patient characteristics: "age of recipient (years)", "gender recipient (male vs female)", "immunosuppressive regimen (TAC vs. CSA )", "CDC PRA\% current serum (non-immunized <6\% vs immunized $\geq 6 \%$ )"; donor characteristics: "age of donor (years)", "donor type (living vs post mortal) and (heartbeating vs. non-heartbeating)" and transplant characteristics: "transplant 
number (first transplant vs re-transplantation)", "mismatch class I HLA-A, B (0 vs. $\geq 1$ )", "mismatch class II HLA-DR (0 vs. $\geq 1$ )", "cold ischemia time (hours)". With graft survival as outcome parameter "acute rejection within 6 months (no vs. yes)" and "delayed graft function (immediate graft function vs. delayed graft function)" were included as suspected risk factors to the model.

\section{Results}

\section{Luminex donor-specific crossmatches}

Donor lymphocytes and pretransplant patient sera of 165 renal transplant recipients transplanted between 1997 and 2001 with a negative CDCXm were available for retrospective LumXm. Out of 165 recipients, 32 (19\%) were found to have a positive LumXm. Sixteen recipients had a positive class I LumXm, 15 were positive for class II and 1 recipient was positive for both class I and II. The remaining 133 recipients were negative. No statistically significant differences in patient characteristics were observed between the LumXm positive and LumXm negative recipients (Table 8.1), with the exception of a higher incidence of immunization in the positive group (25\%) compared to the negative one $(7 \%)(P=0.002)$.

Comparing FCXm with LumXm results showed that the number of positive LumXm was clearly higher than the number of positive FCXm. Of 17 class I LumXm-positive recipients, 3 were T-cell FCXm positive, while 14 were T-cell FCXm negative. Three T-cell FCXm-positive recipients were class I LumXm negative. Sixteen recipients were class II LumXm positive, 2 of them had a positive B-cell FCXm, while 14 patients were B-cell FCXm negative. Four B-cell FCXm-positive recipients were class II LumXm negative (Table 8.2).

All LumXm positive sera were examined by LSA. DSA were found in 5 out of 17 class I and 5 out of 16 class II LumXm positive sera.

Table 8.2 Comparison of donor-specific class I and II LumXm and FCXm results.

\begin{tabular}{lcrrr}
\hline & \multicolumn{5}{c}{ LumXm class I } \\
& \multicolumn{5}{c}{ pos } & neg & \\
\hline T-cell FCXm & pos & 3 & 4 & $X^{2}=10.62 \quad \mathrm{P}=0.02$ \\
& neg & 14 & 145 & \\
\hline B-cell FCXm & & \multicolumn{4}{c}{ LumXm class II } \\
& pos & pos & neg & \\
& neg & 2 & 4 & $\mathrm{X}^{2}=3.98 \quad \mathrm{P}=0.11$ \\
\hline
\end{tabular}




\section{Acute rejection-free survival}

AR-free survival for all patients was $77 \%$. Kaplan-Meier and Cox-regression analyses did not reveal statistically significant differences between the LumXm-positive and the LumXm-negative recipients (Table 8.3). AR-free survival was $81 \%$ for recipients with a positive class I LumXm and $76 \%$ for class I negative patients (log-rank $\chi^{2}=0.31, \mathrm{df}=1$, $\mathrm{P}=0.6$; Figure 8.1). Eighty-two per cent of the class II-positive recipients had AR-free survival vs $76 \%$ of the negative ones (log-rank $\chi^{2}=0.20, d f=1, P=0.7$; Figure 8.2).

Table 8.3 Cox regression analysis of acute-rejection free survival: associated risk factors and effect of LumXm result ( $n=165)$.

\begin{tabular}{lcccc}
\hline Independent variable & Odds Ratio & $95 \% \mathrm{Cl}$ & $\mathrm{df}$ & P-value \\
\hline Class I & & & & \\
$\quad$ Recipient age (years) & 0.98 & $0.96-1.00$ & 1 & 0.06 \\
$\quad$ Positive class I LumXm & 0.52 & $0.15-1.80$ & 1 & 0.3 \\
Class II & & & & \\
$\quad$ FcXm B cell (pos vs neg) & 3.36 & $1.19-9.46$ & 1 & 0.05 \\
$\quad$ Positive class II LumXm & 0.71 & $0.21-2.36$ & 1 & 0.6 \\
\hline
\end{tabular}

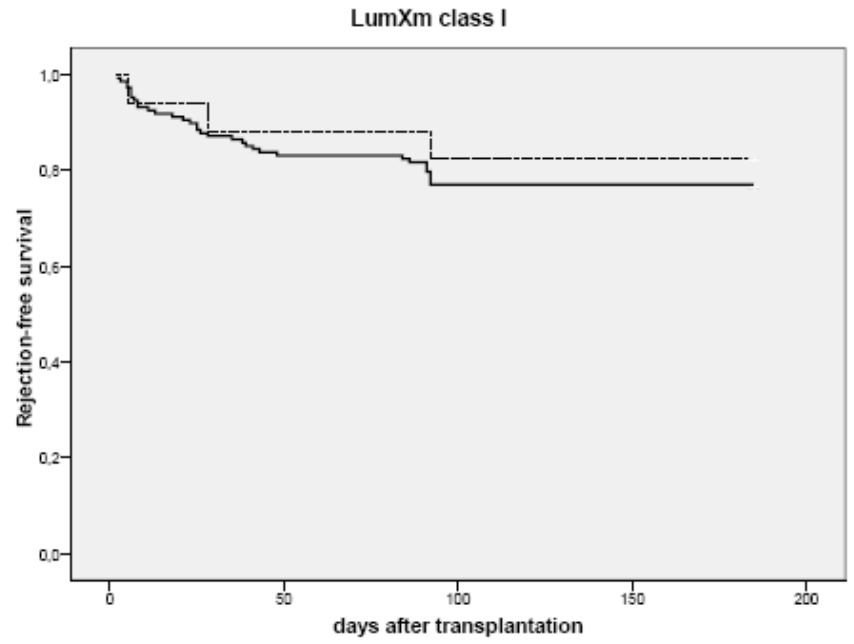

Figure 8.1 Rejection-free survival according to LumXm class I positivity of 165 recipients transplanted with a negative CDCXm between January 1997 and January 2001. Kaplan-Meier curve of acute rejection-free survival for LumXm class I negative (solid line) and LumXm class I positive (dotted line) recipients. $\log$ rank $\mathrm{x} 2=0.3 \mathrm{df}=1 \mathrm{P}=0.6$ 
None of the 165 recipients experienced hyperacute rejection. Of 17 recipients with a positive class I LumXm, 3 (18\%) were treated for biopsy proven AR within 6 months after grafting compared to 32 of $148(22 \%)$ of recipients with a negative class I LumXm $\left(\chi^{2}=0.14, P=0.7\right)$. Three of $16(19 \%)$ recipients with a positive class II LumXm had AR compared with 32 of 149 (21\%) with a negative $\operatorname{LumXm}\left(\chi^{2}=0.06, P=0.8\right.$; Table 8.4).

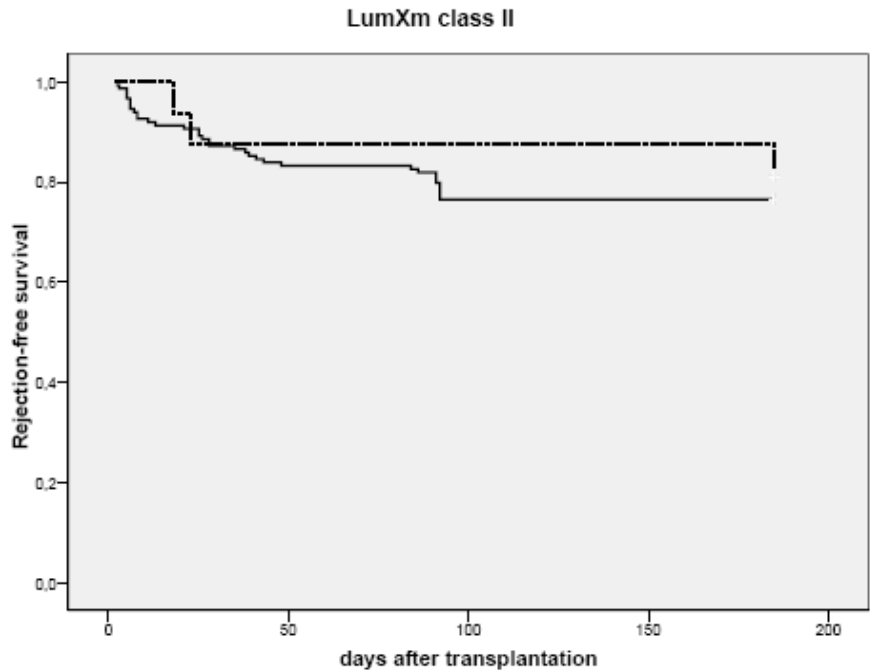

Figure 8.2 Rejection-free survival according to LumXm class II positivity of 165 recipients transplanted with a negative CDCXm between January 1997 and January 2001. Kaplan-Meier curve of acute rejection-free survival for LumXm class II negative (solid line) and LumXm class II positive (dotted line) recipients. $\log \operatorname{rank} \mathrm{x}_{2}=0.2 \mathrm{df}=1 \mathrm{P}=0.7$

Table 8.4 Biopsy proven acute rejection in LumXm positive and LumXm negative recipients.

\begin{tabular}{lcccc}
\hline & & LumXm class I & & \\
& pos $(\mathrm{n}=17)$ & neg $(\mathrm{n}=148)$ & \\
\hline Acute rejection & 3 & 32 & $\mathrm{X}^{2}=0.14 \quad \mathrm{P}=0.7$ \\
No rejection & 14 & 116 & \\
\hline & & LumXm class II & & \\
\hline Pcute rejection & 3 & neg $(\mathrm{n}=149)$ & $\mathrm{X}^{2}=0.06 \quad \mathrm{P}=0.8$ \\
No rejection & 13 & 32 & \\
\hline
\end{tabular}




\section{Graft survival}

Overall graft survival after a median follow-up period of 8 years was 56\%. KaplanMeier analysis showed a statistically significant difference in graft survival between class I LumXm- positive and class I LumXm-negative recipients (log-rank $\chi^{2}=7.43, \mathrm{df}=1$, $\mathrm{P}=0.006$; Figure 8.3). Five-year graft survival in recipients with a positive class I LumXm was $41 \%$ vs. $70 \%$ in class I-negative recipients, and 10 -year graft survival was $27 \%$ vs. $56 \%$. In multivariate Cox regression analysis, significant risk factors for graft failure were a positive class I LumXm [odds ratio $(O R)=2.47, P=0.005$ ] and HLA-B mismatch ( $\geq 1$ vs. 0 ) ( $O R=2.56, P=0.009$; Table 8.5 ). For class II LumXm positivity, there was no difference in graft survival (log-rank $\chi^{2} 0.14, \mathrm{df}=1, \mathrm{P}=0.7$; Figure 8.4). Five-year graft survival in recipients with a positive class II LumXm was $88 \%$ vs. $64 \%$ in recipients with a negative class II LumXm, and 10 -year graft survival was $50 \%$ vs. $53 \%$. LumXm class II positivity was not a significant risk factor for graft failure in multivariate Cox regression analysis ( $\mathrm{OR}=0.69, \mathrm{P}=0.6$; Table 8.5$)$.

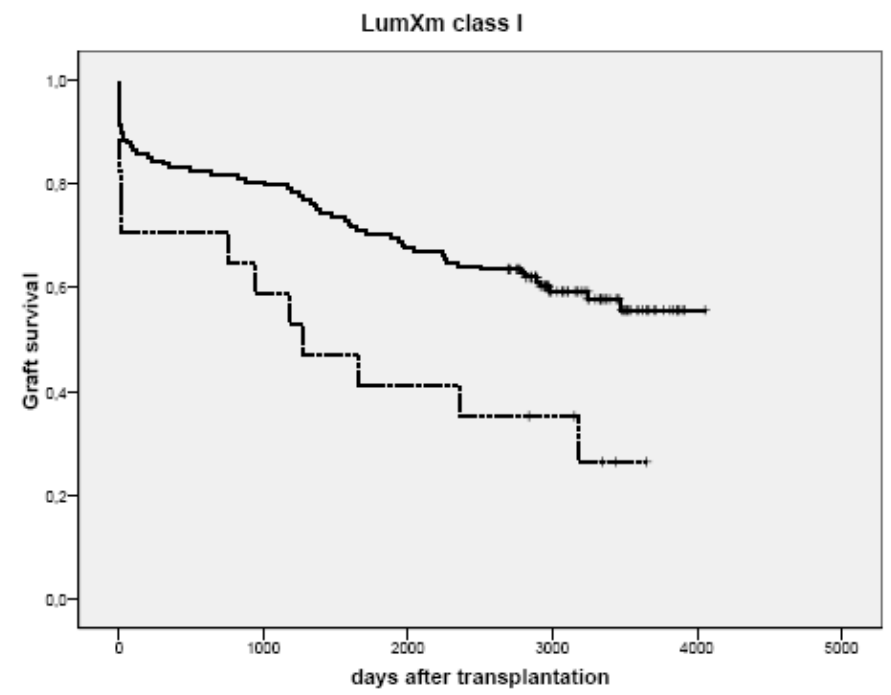

Figure 8.3 Graft survival according to LumXm class I positivity of 165 recipients transplanted with a negative CDCXm between January 1997 and January 2001. Kaplan-Meier curve of graft survival for LumXm class I negative (solid line) and LumXm class I positive (dotted line) recipients. log rank $\times 2=7.4 \mathrm{df}=1 \mathrm{P}=0.006$ 
Table 8.5 Cox regression analysis of graft survival: associated risk factors and effect of LumXm result $(n=165)$.

\begin{tabular}{lcccc}
\hline Independent variable & Odds Ratio & $95 \% \mathrm{Cl}$ & $\mathrm{df}$ & P-value \\
\hline Class I & & & & \\
$\quad$ Positive class I LumXm & 2.47 & $1.32-4.62$ & 1 & 0.005 \\
$\quad \geq 1$ HLA-B mismatch & 2.56 & $1.27-5.17$ & 1 & 0.009 \\
Class II & & & & \\
$\quad$ Positive class II LumXm & 0.69 & $0.29-1.61$ & 1 & 0.4 \\
$\quad$ Recipient age (years) & 1.02 & $1.00-1.04$ & 1 & 0.04 \\
\hline
\end{tabular}

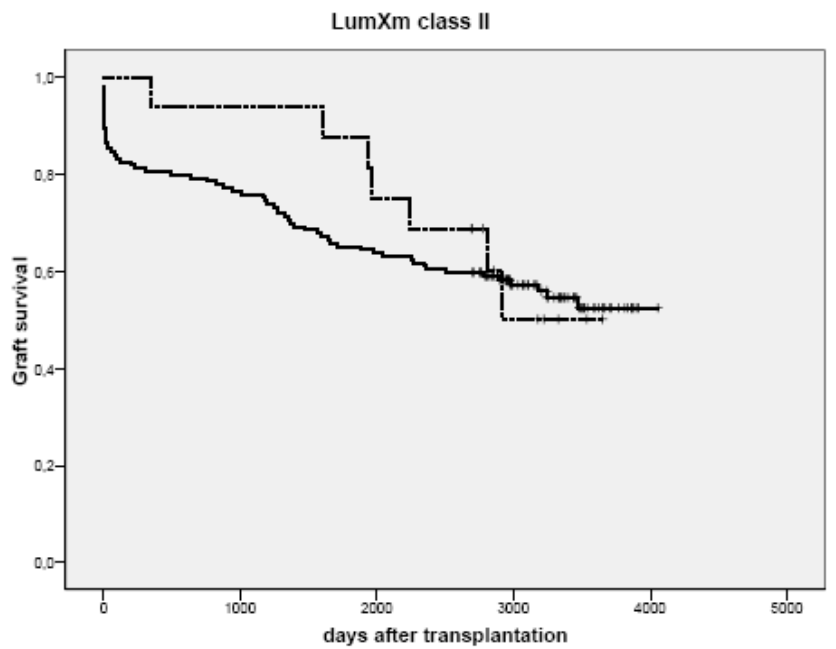

Figure 8.4 Graft survival according to LumXm class II positivity of 165 recipients transplanted with a negative CDCXm between January 1997 and January 2001. Kaplan-Meier curve of graft survival for LumXm class II negative (solid line) and LumXm class II positive (dotted line) recipients. log rank $x_{2}=0.1 \mathrm{df}=1 \mathrm{P}=0.7$

\section{Discussion}

Within Eurotransplant, the standard prospective crossmatch is the CDCXm, which detects antibodies that activate complement and are thus responsible for tissue injury. In many countries, the more sensitive FCXm is used, which detects both complementactivating and non-complement-activating antibodies. The widespread use is based on studies showing worse graft survival in T-cell FCXm-positive regraft recipients ${ }^{11,12}$. The clinical relevance of a positive B-cell FCXm ${ }^{13,14}$ is still a matter of debate ${ }^{15}$ as is the positive FCXm for primary transplant recipients ${ }^{16}$. A previous study from our centre showed T-cell FCXm not to be superior to the classical CDCXm with regard to clinical outcome in renal transplant recipients, both retransplanted as well as sensitized first 
transplants $^{3}$. These findings were considered to be the result of the specific pretransplant antibody screening protocol and the general centre policy on obtaining all relevant patient information on immunization. Nevertheless, FCXms were adopted in our centre and are performed for living-related and -unrelated transplants as well as for postmortal transplants. At this moment their results are only taken into account for living related and unrelated transplants.

Recently, we evaluated a new bead-based solid-phase crossmatch, the LumXm, in which the actual donor-HLA antigens are coated onto specific capture beads ${ }^{7}$. LumXm results of a selected group of recipients were compared with results obtained by the LSA assay. Sensitivity of the LumXm was $96 \%$ for class I and $65 \%$ for class II, and specificity was $100 \%$ and $97 \%$, respectively. The LumXm proved to be valid for class I DSA detection, and the value for class II DSA was however uncertain; HLA-DR antibodies were most probably correctly identified, and the detection of HLA-DQ and -DP was doubtful or absent. The present study was undertaken to evaluate the clinical significance of the LumXm in a group of consecutive CDCXm negative transplant recipients.

Little is known about the clinical relevance of pretransplant DSA detected by solidphase but not by cell-based techniques. Some authors claim higher AR rates and worse graft survival in recipients with DSA detected by solid-phase assays in the crossmatchnegative pre-transplant sera ${ }^{17-20}$. In a previous paper, we reported on LSA screening for HLA antibody and the effect of donor-specific antibodies found in a group of highly sensitized patients (PRA $>85 \%$ ) transplanted with a negative CDCXm within the Eurotransplant Acceptable Mismatch program ${ }^{21}$. We concluded that DSA detected by the LSA assay in the peak historical sera of this patient group may be related to a higher incidence of AR episodes. When analysis was performed on the LSA results of the current sera, however, DSA-positive and -negative recipients had comparable AR-free survival. Long-term graft survival was not affected by DSA detected by LSA in both peak and current sera.

Nineteen per cent of the recipients transplanted between 1997 and 2001 with a negative CDCXm presented with a positive LumXm. In the LumXm-positive group, more patients were sensitized than in the negative group. Neither Kaplan-Meier nor Cox regression analysis showed a statistical difference in AR-free survival between recipients with a positive and a negative LumXm. At a median follow-up time of 8 years, however, Kaplan-Meier and Cox regression analyses of graft survival showed a statistically significant difference in graft survival between class I-positive and class I-negative recipients. For class II, such a difference was not observed. These data are concordant with the findings of Gupta et al., who showed AR rates in DSA-positive recipients detected by LSA, to be similar to those in negative recipients. However, DSA positivity proved to be associated with an increased risk of long-term graft failure ${ }^{22}$. 
All LumXm-positive sera were examined by LSA. DSA were found in 5 out of 17 class I and 5 out of 16 class II LumXm positive sera. The discrepancies between LumXm and LSA can be explained by the difference in preparation of the beads used in both techniques. For the LumXm, the actual donor-HLA antigens are coated onto the crossmatch beads. The Single antigen beads are coated with purified HLA antigens cultured in cell lines. Thus, the density of antigens expressed on the respective beads may differ, resulting in a difference in sensitivity. Also, binding of HLA molecules to beads may modify the structure of the antigens, especially in the case of the LSA, where the molecules are purified and the peptide is dislodged from the groove of the molecule. This modification of structure may have an effect on epitope accessibility and subsequent on antibody binding.

From the 12 graft losses in the class I LumXm-positive group, 5 occurred within 2 months after grafting. Three of the five recipients died shortly after transplantation; one recipient died with a functioning graft due to cardiac arrest, one graft never functioned (rejection was excluded by biopsy) and the recipient died of myocardial ischemia and one died as a result of haemorrhage caused by an infection of the graft. The two remaining recipients underwent transplantectomy; one lost his graft the day after transplantation due to technical problems and the other graft never functioned and was removed two months after transplantation (repeated biopsies did not show rejection). The remaining seven graft losses in the class I LumXm positive-group occurred late after grafting. Two recipients died with functioning grafts. Five recipients lost their graft because of chronic allograft nephropathy while on immunosuppression. In the class I LumXm-negative group, 14 of 61 graft losses were because of chronic allograft nephropathy while on immunosuppression. Thus, the incidence of immunological failures in the class I LumXm-positive group (42\%) is nearly twice as high as that in the class I LumXm negative group (23\%). Because of small numbers; this difference in AR rate between the class I LumXm-positive and the class I LumXmnegative recipients did not reach statistical significance.

The class I LumXm proved to be more sensitive than the T-cell FCXm. Fourteen patients were class I LumXm positive with a negative T-cell FCXm, while only 3 class I LumXmpositive recipients had a positive T-cell FCXm. The graft survival in both groups was significantly worse compared with recipients with a negative class I LumXm. Three patients were class I LumXm negative but showed a positive T-cell FCXm; their graft survival was comparable to that of 145 class I LumXm/T-cell FCXm-negative recipients (data not shown). We assumed that the three recipients with class I LumXm neg/T-cell FCXm positive results probably possessed non-HLA antibodies.

The contribution of preformed anti-HLA class II antibodies to graft rejection and graft loss was long poorly understood. Testing against B cells for their detection was less than satisfactory. The B-cell FCXm proved to be technically difficult, and interpretation 
of the results was not easy due to lack of specificity ${ }^{23}$. A positive B-cell FCXm can result from the presence of anti-HLA class II antibodies, weak anti-HLA class I antibodies and autoreactive or non-HLA antibodies. Therapeutic antibodies, Fc-receptors and immunoglobulins on the surface of the B cell may also yield false-positive B-cell FCXm results. With the introduction of solid-phase techniques, class II antibodies are detected easily and their impact on AR and graft survival assessed more accurately. Using this Luminex technique, Eng et al. demonstrated that only one third of positive B-cell FCXm are caused by class II antibodies and were associated with late graft loss ${ }^{24}$. Class II antibodies represent a significant risk factor for transplant dysfunction and failure as described by several authors ${ }^{25-27}$. The lack of association between a positive class II LumXm and graft survival in our present study is most probably because of the fact that the LumXm in its present form only detects HLA-DR antibodies and some but not all HLA-DQ and-DP antibodies ${ }^{7}$.

In conclusion, the class I LumXm proved to be more sensitive than the FCXm, and 14 patients were LumXm positive while FCXm negative. LumXm class II positivity was no significant risk factor for graft failure, but one should bear in mind that the class II LumXm in its present form does not detect all class II anti-HLA antibodies. Pretransplant donor-specific anti-HLA class I antibodies detected by LumXm have no impact on AR episodes; however, a positive class I LumXm results in worse long-term graft survival compared to a negative one. Considering the improved patient survival after transplantation and the late occurrence of graft failure in class I LumXm-positive recipients, for every patient, the balance between transplantation with a kidney after a class I LumXm-positive result or waiting for a class I LumXm-negative donor kidney has to be determined. 


\section{References}

1. Patel R, Terasaki PI. Significance of the positive crossmatch test in kidney transplantation. N Engl J Med 1969:280:735-9.

2. Gebel HM, Bray RA, Nickerson P. Pre-transplant assessment of donor-reactive, HLA-specific antibodies in renal transplantation: contraindication vs. risk. Am J Transplant 2003:3:1488-500.

3. Christiaans M, Overhof R, Haaft ten A, Nieman F, Hooff van JP, Berg van den-Loonen EM. No advantage of flow cytometry crossmatch over complement-dependent cytotoxicity in immunologically well-documented renal allograft recipients. Transplantation 1996:62:1341-7.

4. Pei R, Lee J-H, Shih N-J, Chen M, Terasaki PI. Single human leukocyte antigen flow cytometry beads for accurate identification of human leukocyte antigen antibody specificities. Transplantation 2003:75: 43-9.

5. El-Awar N, Lee J, Terasaki PI. HLA Antibody identification with single antigen beads compared to conventional methods. Hum Immunol 2005:66:989-97.

6. Fuggle SV, Martin S. Tools for human leukocyte antigen antibody detection and their application to transplanting sensitized patients. Transplantation 2008:86:384-90.

7. Billen EVA, Voorter CEM, Christiaans MHL, Berg van den-Loonen EM. Luminex donor-specific crossmatches. Tissue Antigens 2008:71:507-13.

8. Scornik JC, Brunson ME, Schaub B, Howard RJ, Pfaff WW. The crossmatch in renal transplantation. Transplantation 1994:57:621-5.

9. Bray RA. Flow cytometry crossmatching for solid organ transplantation. Methods in Cell Biology 1994: 41:103-19.

10. Ta M, Scornik JC. Improved flow cytometric detection of donor-specific HLA class II antibodies by heat inactivation. Transplantation 2002:73:1611-4.

11. Cook DJ, Terasaki PI, Iwaki Y, Terashita GY, Lau M. An approach to reducing early kidney transplant failure by flow cytometry crossmatching. Clin Transplant 1987:1:253-6.

12. Mahoney RJ, Ault KA, Given SR, Adams RJ, Breggia AC, Paris PA, Palomaki GE, Hitchcox SA, White BW, Himmelfarb J, et al. The flow cytometric crossmatch and early renal transplant loss. Transplantation 1990:49:527-35.

13. Scornik JC, Clapp W, Patton PR, Van der Werf WJ, Hemming AW, Reed Al, Howard RJ. Outcome of kidney transplants in patients known to be flow cytometry crossmatch positive. Transplantation 2001:71:1098-102.

14. Süsal C, Opelz G. Good kidney transplant outcome in recipients with presensitization against HLA class II but not HLA class I. Hum Immunol 2004:65:810-6.

15. Karpinski $M$, Rush D, Jeffery J, Exner $M$, Regele $H$, Dancea $S$, Pochinco D, Birk $P$, Nickerson P. Flow cytometric crossmatching in primary renal transplant recipients with a negative anti-human globulin enhanced cytotoxicty crossmatch. J Am Soc Nephrol 2001:12:2807-14.

16. Ogura K, Terasaki PI, Johnson C, Mendez R, Rosenthal JT, Ettenger R, Martin DC, Dainko E, Cohen L, Mackett $T$, et al. The significance of a positive flow cytometry crossmatch test in primary kidney transplantation. Transplantation 1993:56:294-8.

17. Ishida H, Tanabe K, Furusawa M, Ishizuka T, Hayashi T, Tokumoto T, Miyamoto N, Shirakawa H, Shimmura $H$, Shimizu T, Toma $H$. Evaluation of flow cytometric panel reactive antibody in renal transplant recipients - examination of 238 cases of renal transplantation. Transpl Int 2005:18:163-8.

18. Bielmann D, Hönger G, Lutz D, Mihatsch MJ, Steiger J, Schaub S. Pretransplant risk assessment in renal allograft recipients using virtual crossmatching. Am J Transplant 2007:7:626-32.

19. Patel AM, Pancoska C, Mulgaonkar S, Weng FL. Renal transplantation in patients with pre-transplant donor-specific antibodies and negative flow cytometry crossmatches. Am J Transplant 2007:7:2371-7.

20. Lefaucheur C, Suberbielle-Boissel C, Hill GS, Nochy D, Andrade J, Antoine C, Gautreau C, Charron D, Glotz D. Clinical relevance of preformed HLA donor-specific antibodies in kidney transplantation. Am J Transplant 2008:8:324-31.

21. van den Berg-Loonen EM, Billen EV, Voorter CE, van Heurn LW, Claas FH, van Hooff JP, Christiaans MH. Clinical relevance of pretransplant donor-directed antibodies detected by single antigen beads in highly sensitized renal transplant patients. Transplantation 2008:85:1086-90. 
22. Gupta A, Iveson V, Varagunam M, Bodger S, Sinnott $P$, Thuraisingham RC. Pretransplant donor-specific antibodies in cytotoxic negative crossmatch kidney transplants: are they relevant? Transplantation 2008:85:1200-4

23. Le Bas-Bernardet S, Hourmant M, Valentin N, Paitier C, Giral-Classe M, Curry S, Follea G, Soulillou JP, Bignon JD. Identification of the antibodies involved in B-cell crossmatch positivity in renal transplantation. Transplantation 2003:75:477-82.

24. Eng HS, Bennett G, Tsiopelas E, Lake M, Humphreys I, Chang SH, Coates PT, Russ GR. Anti-HLA donorspecific antibodies detected in positive B-cell crossmatches by Luminex predict late graft loss. Am J Transplant 2008:8:2335-42.

25. Pollinger HS, Stegall MD, Gloor JM, Moore SB, Degoey SR, Ploeger NA, Park WD, Pollinger HS, Stegall MD, Gloor JM, Moore SB, Degoey SR, Ploeger NA, Park WD. Kidney transplantation in patients with antibodies against donor HLA class II. Am J Transplant 2007:7:857-63.

26. Issa N, Cosio FG, Gloor JM, Sethi S, Dean PG, Moore SB, DeGoey S, Stegall MD. Transplant glomerulopathy: risk and prognosis related to anti-human leukocyte antigen class II antibody levels. Transplantation 2008:86:681-5.

27. Duquesnoy RJ. Human leukocyte antigen class II antibodies and transplant outcome. Transplantation 2008:86:638-40. 


\section{Chapter 9}

General discussion 



\section{General discussion}

\section{Renal transplantation and histocompatibility}

Antibodies to human leukocyte antigens develop as a result of pregnancy, blood transfusion or transplantation. The presence of donor-specific anti-HLA antibodies (DSA) in a kidney transplant patient is strongly associated with acute antibodymediated rejection. Therefore pretransplant crossmatches are performed to identify patients at risk of losing their graft due to hyperacute rejection ${ }^{1}$. The method used in histocompatibility laboratories for over half a century has been the CDC crossmatch ${ }^{2}$. Transplant immunologists try to establish very precisely the pretransplant immune status of a kidney recipient in order to be able to choose the right graft for a potential transplant recipient and to avoid positive crossmatches at the time of transplant. As described in Chapters 1 and 2, screening for preformed DSA has evolved from the relatively insensitive complement-dependent cytotoxicity to more sensitive solidphase assays, where purified HLA antigens attached to beads are used as antibody detection target ${ }^{3}$. For that reason the Luminex bead based Single antigen assay is of the utmost importance in describing the HLA antibody profile of a future transplant recipient. Despite the development of increasingly effective immunosuppressive drugs chronic allograft nephropathy, presently known as chronic transplant dysfunction, remains a major barrier to long-term renal graft survival ${ }^{4}$. The identification of the factors responsible for the development of chronic allograft nephropathy is important, since this will provide a basis for the establishment of interventions that may arrest its progression. Evidence suggests that the humoral immune response plays an important role in the development of chronic transplant dysfunction, and for that reason several authors recommend antibody monitoring after transplantation ${ }^{5,6}$. The detection of HLA antibodies and especially the determination of their specificity remains an important goal of histocompatibility testing.

\section{Solid-phase antibody detection techniques: Luminex technology}

As mentioned before the solid phase techniques, in particular the Luminex Single antigen assay allows accurate identification of HLA class I and II antibodies at a much more sensitive and specific level than conventional CDC and according to some authors even FC. The main advantages are that the assay detects complement-binding as well as non-complement-binding IgG HLA antibodies and that class I and class II HLA antibodies can be clearly discriminated ${ }^{7}$. Analysis of complex antibody profiles in highly sensitized patients is made possible, thereby allowing definition of acceptable and non-acceptable mismatches. Also so-called virtual crossmatching is within reach ${ }^{8}$. However, the highest level of sensitivity in antibody detection does not necessarily translate into clinical relevance of the antibodies detected. Whether or not low antibody levels have a deleterious impact on the graft depends also on the 
immunoglobulin (sub) class, the ability to bind complement and the avidity of the antibody.

The sensitivity of the Single antigen assay depends on the cut-off point used to define positive and negative bead reactions. This cut-off point has to be defined by the user and therefore may differ considerably between laboratories. Many cut-off points have been described in the literature for the assay, ranging from 500-6000 median fluorescence intensity (MFI) value ${ }^{9-14}$. For our first study on pretransplant DSA detected by the Single antigen assay (described in Chapter 3 of this thesis), the cut-off point for positivity was established by testing three positive control sera (PRA >90\%) with Single antigen beads for both class I and II. For every single bead in the assay, the positive control value was set at the mean MFI value of these sera. A positive bead reaction was subsequently defined as an MFI value of at least $10 \%$ of the positive control value for that specific bead, which correlated with a cut-off point for positivity of approximately $1000 \mathrm{MFI}$. In our later studies on post-transplant DSA (chapters 4, 5, 6), an MFI value of 2000 was used as cut-off point for positivity, being the value corresponding most closely to a positive flow-cytometry crossmatch in our hands. This cut-off point is not necessarily the same for tests produced by different manufacturers. In a recent quality assurance-testing program by the Australian National Association of Testing Authorities, the results of Single antigen assays were compared between laboratories and different vendors. The MFI values and bead rankings sorted by MFI were reproducible between laboratories using products from the same vendor, which was not the case when using products from different vendors ${ }^{15}$.

Results of Single antigen assays may be influenced by different amounts of antigen or immunogenic epitope on the SA bead. Also the configuration may be altered and not represent the one found on intact cells. The presence of IgM antibodies in the serum may hinder the binding of IgG antibodies to the SA beads, which can be overcome by the addition of DTT to the test ${ }^{16}$. In a study by Kosmoliaptis, the addition of DTT to patient sera markedly increased (doubled) the antibody binding to HLA class I and/or class II specificities in $18 \%$ of the sera. In a cohort of highly sensitized patients, treatment of sera with DTT enhanced antibody-binding levels in $93 \%$ of the tested sera ${ }^{17}$. To reduce variation in antibody definition caused by day to day testing or measurement on different platforms, and to compare results between different laboratories, another unit of fluorescence has been introduced. The MESF (molecules of equivalent soluble fluorochrome) value, are converted from MFI values to accurately compare quantitative fluorescence intensities ${ }^{18,19}$. Another approach to overcome this problem is the expression of the MFI value as a percentage of maximum binding as determined by a monoclonal antibody for each HLA specificity ${ }^{20}$. This allows correcting for variation in antigen density on Single antigen beads between different lots of the SA assay. A variant of this approach was used for the cut-off determination in chapter 3. 
For clinical purposes, it was considered desirable to define a cut-off value for those HLA antibodies that were acceptable or not acceptable for a patient waiting for a renal transplant. This cut-off point should include all HLA antibodies that were detected in the CDC screening and were considered relevant. To clarify how the results of the regular CDC screening compared to the results obtained with the Single antigen assay, we tested well-known HLA typing sera in both techniques. As described in Chapter 2, more than 100 sera for which CDC specificity and reaction strength were well defined, have been tested with Single antigens class I and II. For each serum the main CDC specificity and extra specificities if present, were categorized according to the MFI value obtained. For class I $99 \%$ of all CDC specificities (main plus extra) had an MFI value of $>4000$, for class II this was $92 \%$. The reason for the latter lower percentage is that the Single antigen class II assay contains multiple beads coated with the same serological class II specificity, but not necessarily the same subtype specificity. For the analysis, the mean MFI value of all specific beads (regardless of subtype) was used. Based on the results of the studies previously performed and those from the typing sera, the cut-off point for positivity of the Single antigen assay was set at $4000 \mathrm{MFI}$ or higher for clinical transplant purposes in our centre. We feel confident that in this way all specificities detected by the classical CDC screening are covered and listed as non-acceptable antigens for a future transplant recipient. As a consequence of this policy, specificities with an MFI value of $>4000$, not detected in CDC, are also considered unacceptable for a patient.

\section{Clinical relevance of pre-transplant HLA antibodies}

We have shown that in patients transplanted with a negative CDC crossmatch in the Eurotransplant AM program, the presence of DSA detected only by the Single antigen assay, was associated with a higher incidence of treatable acute rejection within the first 6 months post-transplant, but was not related to poorer graft survival when compared to patients without DSA (chapter 3 ). Currently all patients transplanted in the AM program in the Netherlands have been tested by Luminex Single antigens and the preliminary data of this nationwide study, confirm our results on graft survival. About $50 \%$ of patients have DSA in their pre-transplant serum by Single antigens, but the DSA do not effect graft survival. No data on acute rejections were available for this study (personal communication Prof. I. Doxiadis, Eurotransplant)

In the past three years, several studies investigated the effect of low strength pre-transplant DSA detected by the Single antigen assay on acute rejection rate and graft survival. The study designs and the cut-off points used for determining positive bead reactions differed considerably between studies. All included large consecutive series of patients with different PRA values and different pre-transplant protocols. In some studies correlations with acute rejection were found ${ }^{21-23}$, and some showed DSA 
to be correlated to graft survival ${ }^{21,22,24}$. The different results may be explained by the fact, that in our study, only highly sensitized recipients (>85\%) were included, who had been extensively screened in CDC and ELISA. Their sensitization history was well known, as were their acceptable and non-acceptable antigens.

Increased sensitivity results in a larger number of specific HLA antibodies identified in a patient's serum. When those antibodies are listed as non-acceptable mismatches, as is customary within Eurotransplant, it prolongs the waiting time and leads to a higher percentage of sensitized recipients. This clearly has implications for organ allocation, because sensitized recipients receive extra transplant points. As long as no consensus on the cut-off point for Single antigen positivity exists, patients from different centres will be put on the waiting list with incomparable antibody statuses. The present uncertainty on the relevance of antibodies detected by the Single antigen assay influences the allocation program for the whole Eurotransplant organization. The number of highly sensitized patients will rise, which may have a clear impact on the Eurotransplant AM program. That this threat is considered real, is revealed by the recent implementation of Eurotransplant (also based on the results of our study presented in Chapter 3) that recipients with antibodies detected by Luminex Single antigen only, are not considered for the AM program ${ }^{25}$.

\section{Solid-phase crossmatch: Luminex crossmatch}

European histocompatibility standards (EFI) require the use of crossmatch methods of similar or greater sensitivity than those used in screening to define the presence of antibodies. For that reason the availability of a prospective crossmatch in the Luminex technique is highly desirable. It has the added advantages that no viable cells are needed for the crossmatch, is specific for HLA antibodies and reading is easy and automated. Chapter 7 is the first report ever on the use of a Luminex Crossmatch $\left(D S A^{\mathrm{TM}}\right.$, donor specific antibody detection, Tepnel). The results obtained were compared with results from flow cytometric crossmatches. Sensitivity and specificity of the Luminex crossmatch for class I were $89 \%$ and $98 \%$ and for class II $68 \%$ and $97 \%$. After all sera were tested with the Single antigen assay from One Lambda, to define the DSA in each serum, the sensitivity of the Luminex crossmatch proved to be higher for class I (96\%) than class II (65\%). The Luminex crossmatch did not detect any HLA-DQ antibodies, HLA-DP antibody detection was insufficient, only HLA-DR seemed to be correctly identified. Recently Caro-Oleas compared results of the Single antigen assay to the Luminex crossmatch in sera that were well defined by CDC. The sensitivity of the Single antigen assay was found to be higher than that of the Luminex crossmatch for both class I and II, regardless of the fact that crossmatch and screening assay were from the same vendor ${ }^{26}$. This study also confirmed our finding that the Luminex crossmatch does not identify HLA-DQ antibodies. We therefore feel that the test in its present form is not suitable for use in a clinical setting. 
The clinical significance of the Luminex crossmatch was evaluated over a 4-year period, as described in Chapter 8. The Luminex crossmatch was performed for consecutive renal transplant recipients, who have all been transplanted on the basis of a negative CDC crossmatch. A positive class I Luminex crossmatch with the current pre-transplant serum had no impact on acute rejection episodes, but resulted in worse long-term graft survival compared to a negative class I Luminex crossmatch. The class II Luminex crossmatch had no effect on acute rejection or graft survival, probably because the test proved not to detect HLA-DQ and -DP antibodies. Recently a second report on the clinical relevance of the Luminex crossmatch in 37 selected recipients with pre-transplant HLA antibodies, was published this year. No relationship with graft survival was shown, the maximum follow-up time was only 3 years. A clear relationship between the class I Luminex crossmatch and antibody-mediated acute rejection was established if they combined the results of the class I Luminex crossmatch with the results of the SA test. Antibody mediated acute rejection was found in $80 \%$ of the patients with a positive class I Luminex crossmatch and an MFI value $>900$ in the Single antigen test (test spec $96 \%$ ) $^{27}$. The conclusion of our studies still remains that the Luminex crossmatch for class II has to be improved, at least for DQ antibodies. Pre-transplant donor-specific anti-HLA class I antibodies detected by the Luminex crossmatch have no impact on acute rejection episodes; however, a positive class I Luminex crossmatch results in worse long-term graft survival compared to a negative one. Considering the improved patient survival after transplantation and the late occurrence of graft failure in class I Luminex crossmatch-positive recipients, for every patient, the balance between transplantation with a kidney after a class I positive crossmatch result or waiting for a class I negative crossmatch donor kidney has to be determined.

\section{Clinical relevance of post-transplant HLA antibodies}

Presence of HLA antibodies has been described before failure ${ }^{28}$, and their detection is considered to be useful in predicting graft failure ${ }^{29}$. There is however no consensus on antibody positivity shown by the Single antigen assay, the time of appearance of DSA nor the class of DSA detected.

The frequency and nature of "de novo" HLA DSA after kidney transplantation detected by Single antigen was analyzed in Chapter 4 . The presence of DSA was monitored from the time of transplantation up to 14 years thereafter. All patients were DSA negative by Single antigen before transplantation, had a negative CDC crossmatch, at least 1 year of renal function and were tested 5-12 times (average 8) during follow-up. Posttransplant DSA were detected frequently (25\%). Slightly more class II than I was detected, and class II antibodies were mainly against HLA-DQ. Only persistent class II DSA, that were present more than one year after transplantation, turned out to result in worse clinical outcome. Its presence was associated with graft survival, but did not 
necessarily lead to immediate loss of graft function. Most of the DSA found were persistent throughout the follow-up period, but a new finding was that in a number of patients the DSA were present only for a short period of time. These so-called "transient" DSA were characterized by lower MFI values than the persistent ones and were not related to graft survival. We concluded from the study that the detection of DSA posttransplant in a single serum sample, has to be interpreted with caution and may not necessarily justify the use of therapeutic interventions. Furthermore, the fact that only the presence of class II DSA was found to be predictive of graft failure after adjusting for a number of clinical variables, is concordant with recent publications on the importance and relevance of class II HLA antibodies ${ }^{30-33}$. The high number of patients with anti-DQ antibodies was remarkable. In this respect it would be desirable if within Eurotransplant, histocompatibilty laboratories would be obliged to report on HLA-DQ typing of potential donors to the transplant recipient centres.

Although this study was unique in terms of number of consecutive patients with a long follow-up and multiple sera tested, a drawback of our study is the fact that patients included in this study did not have their yearly follow-up consultation in our centre, and therefore many samples are missing. Also because of the retrospective nature of the study no biopsies from the time of failure were available. Therefore, it is difficult to identify the specific reasons for graft failure. This study allows the identification of patients with an increased risk of (immunological) graft failure for future randomized controlled trials to target immunologic failure by specific interventions.

After transplantation DSA may be undetectable in the circulation because they are absorbed by the graft. This was demonstrated by the fact that these antibodies are eluted from rejected transplants ${ }^{34,35}$ and the appearance of previously undetectable antibodies by CDC following transplantectomy ${ }^{36}$. Testing for HLA antibodies in re-transplant candidates, who still have their graft in situ, is therefore of limited value. The study in Chapter 5 was designed to test whether antibodies before transplant failure and transplantectomy would be detectable using the Single antigen assay. Time of DSA appearance was monitored in a group of 53 first renal transplant recipients, who lost their graft at different time points after transplantation (median 50 days post-transplant). $81 \%$ became DSA positive after transplantation, $16 \%$ before and $84 \%$ after transplantectomy. Logistic regression analysis showed that DSA positivity for class I was related to higher donor age and donor type (non-heart-beating), class II to higher donor age and class II mismatch. Looking at the time of transplantectomy, patients who lost their graft between 1-6 months all became DSA positive and showed a higher number of class II mismatches and acute rejections.

Remarkably, the majority of the DSA were found several months after transplantectomy. Although there still is discussion on the clinical utility of transplantectomy versus leaving the rejected graft in place ${ }^{37}$, in our centre failed grafts 
are removed and immunosuppression is cessated, because continuation of immunosuppressive drugs after return to dialysis is not tolerated due to side effects. It remains to be elucidated whether the antibodies found circulating after transplantectomy, are antibodies that were previously absorbed by the graft or were formed after the transplantectomy due to the cessation of immunosuppression and/or as a result of the fact that the vascular patch of the anastomosis was still in situ ${ }^{38}$. In general patients are tested for the presence of HLA antibodies only when they are on the ET waiting list, for transplantectomized patients this means that they are monitored only if considered for re-transplantation. Based on our results we propose that patients after transplantectomy are monitored for the presence of antibodies for at least 6 months. In our local protocol, sera are collected after a transplantectomy and monitored for antibodies at regular intervals until 6 months later. For recipients that receive a kidney donor offer before they have been monitored for half a year, prospective pretransplant crossmatches have to be performed with all historically relevant sera as well as a serum drawn at the time of the crossmatch.

In the transplantectomy study, the recipients of a NHB donor had a higher risk of DSA positivity. Combined with the fact that kidneys from non-heart-beating donors experience an increased incidence of primary non-function compared to kidney transplantation from heart-beating donor, this may point to a more stringent acceptance of NHB donors. This has to be balanced against the fact that even transplantation with NHB donors has been shown to result in increased patient survival compared to remaining on dialysis and the waiting list ${ }^{39}$.

A recent study by Marrari et al. on patients with late transplantectomy (mean 6.6 years), found a higher incidence of DSA before transplantectomy but the same overall incidence of DSA after transplantation ${ }^{40}$. They compared their results to ours and hypothesised that in their study, the transplant had been in situ for a longer period of time, thus serving as a continuous source of donor antigens, which had expanded the antibody repertoire. However in our study, late and early graft removal resulted in comparable percentages of DSA. In our study recipients with pre-transplant DSA detected by FC or SA, were excluded from the study, in contrast to the study of Marrari et al.

\section{Conclusion}

In this thesis we have mainly focussed on the detection and relevance of HLA antibodies in renal transplantation by newer antibody screening and crossmatch techniques. Throughout the literature available on Single antigen testing, there are reports of authors that support the idea that the Single antigen assay is superior to all other tests and that CDC has become obsolete. Specificity and sensitivity are usually reported, however data on clinical relevance are scarce. It has even been suggested 
that the Single antigen assay is too sensitive to use in a clinical setting. Therefore we addressed some of these items. We studied the relationship between Single antigen and CDC results and together with the results of our clinical studies we defined a cut-off point of $4000 \mathrm{MFI}$ for clinical transplant purposes. DSA by the Single antigen assay proved not to influence graft survival in highly sensitized AM patients. In post-transplant screening DSA are often seen, and unexpectedly a substantial portion of these DSA proved to be transient. Transient DSA had no effect on graft survival in contrast to persistent DSA, if they were class II and present beyond 1 year after transplantation. DSA were particularly shown to be present after failure and transplantectomy, and were related to specific donor, recipient and transplant parameters. The Single antigen assay also allows the detection of class II HLA-DP antibodies, which provides a possibility of studying their impact in renal transplantation. A positive class I Luminex crossmatch is related to graft failure, although not in the first years after transplantation. The class II Luminex crossmatch needs further development, especially for HLA-DQ and -DP, to become clinically relevant. The data presented in this thesis point to the importance of pre- end post-transplant detection of HLA antibodies and their identification in renal transplantation. 


\section{References}

1. Patel R, Terasaki PI. Significance of the positive crossmatch test in kidney transplantation. N Engl J Med 1969;280:735-9.

2. Cecka JM, Zhang Q, Reed EF. Preformed cytotoxic antibodies in potential allograft recipients: recent data. Hum Immunol 2005;66:343-9.

3. El-Awar N, Lee J,Terasaki PI. HLA Antibody identification with single antigen beads compared to conventional methods. Hum Immunol 2005;66:989-97.

4. Meier-Kriesche HU, Schold JD, Srinivas TR, Kaplan B. Lack of improvement in renal allograft survival despite a marked decrease in acute rejection rates over the most recent era. Am J Transplant 2004;4:378-83.

5. Lachmann N, Terasaki PI, Budde K, Liefeldt L, Kahl A, Reinke P, Pratschke J, Rudolph B, Schmidt D, Salama A, Schonemann C. Anti-human leukocyte antigen and donor-specific antibodies detected by luminex posttransplant serve as biomarkers for chronic rejection of renal allografts. Transplantation 2009;10:1505-13.

6. Terasaki PI, Cai J. Human leukocyte antigen antibodies and chronic rejection: from association to causation. Transplantation 2008;3:377-83.

7. Tait BD, Hudson F, Cantwell L, Brewin G, Holdsworth R, Bennett G, Jose M. Review article: Luminex technology for HLA antibody detection in organ transplantation. Nephrology 2009;14:247-54.

8. Amico P, Honger G, Steiger J, Schaub S. Utility of the virtual crossmatch in solid organ transplantation. Curr opin organ transplant 2009;14:656-61.

9. Aubert V, Venetz JP, Pantaleo G, Pascual M. Low levels of human leukocyte antigen donor-specific antibodies detected by solid phase assay before transplantation are frequently clinically irrelevant. Hum Immunol 2009;70:580-83.

10. Everly MJ, Rebellato LM, Ozawa M, Briley KP, Catrou PG, Haisch GE, Terasaki PI. Beyond histology: lowering human leukocyte antigen antibody to improve renal allograft survival in acute rejection. Transplantation 2010;89:962-67.

11. Morris GP, Phelan DL, Jendrisak MD, Mohanakumar T. Virtual crossmatch by identification of donorspecific anti-human leukocyte antigen antibodies by solidphase immunoassay: a 30-month analysis in living donor kidney transplantation. Hum Immunol 2010;71:268-73.

12. Higgins R, Hathaway M, Lowe D, Lam F, Kashi H, Tan LC, Imray C, Fletcher S, Zhender D, Chen K, Krishnan N, Hamer R, Briggs D. Blood levels of donor-specific human leukocyte antigen antibodies after renal transplantation: resolution of rejection in the presence of circulating donor-specific antibodies. Transplantation 2007;84:876-84.

13. Akalin E, Dinavati R, Friedlander R, Ames S, de Boccardo G, Sengal V, Schroppel B, Bhaskaran M, Lerner $S$, Fotino M, Murphy B, Bromberg JS. Addition of plasmapheresis decreases the incidence of acute antibody-mediated rejection in sensitized patients with strong donor-specific antibodies. Clin J Am Soc Nephrol 2008;3:1160-7.

14. Zachary A, Sholander JT, Houp JA, Leffell MS. Using real data for a virtual crossmatch. Hum Immunol 2009;70:574-9.

15. ASEATTA: HLA antibody screening and characterisation. Report of Proficiency testing 2008; October exchange: 1-4.

16. Zachary AA, Lucas DP, Detrick B, Leffell MS. Naturally occurring interference in Luminex assays for HLAspecific antibodies: characteristics and resolution. Hum Immunol 2009:70:496-501.

17. Kosmoliaptsis V, O'Rourke C, Bradley JA, Taylor CJ. Improved Luminex-based human leukocyte antigenspecific antibody screening using dithiothreitol-treated sera. Hum Immunol 2010;71:45-9.

18. Mizutani K, Terasaki PI, Hamdani E, Esquenazi V, Rosen A, Muller J, Ozawa M. The importance of antiHLA-specific antibody strength in monitoring kidney transplant patients. Am J Transpl 2007;7:1027-31.

19. Vaidya S. Clincal importance of anti-human leukocyte antigen-specific antibody concentration in performing calculated panel reactive antibody and virtual crossmatches. Transplantation 2008; 85:1046-50.

20. El-Awar N, Lee JH, Tarsitani C, Terasaki PI. HLA class I epitopes: recognition of binding sites by mAbs or eluted alloantibody confirmed by single recombinant antigens. Hum Immunol 2007;68:170-80. 
21. Ho EK, Vasilescu ER, Colovai Al, Stokes MB, Hallar M, Markowitz GS, D'Agati VD, Cohen DJ, Ratner LE, Suciu-Foca N. Sensitivity, specificity and clinical relevance of different crossmatching assays in deceased-donor renal transplantation. Transl Immunol 2008;20:61-7.

22. Amico P, Hönger G, Mayr M, Steiger J, Hopfer H, Schaub S. Clinical relevance of pretransplant donorspecific HLA antibodies detected by single-antigen flow-beads. Transplantation 2009;87:1681.

23. Vlad G, Ho EK, Vasilescu ER, Colovai Al, Stokes MB, Markowitz GS, D'Agati VD, Cohen DJ, Ratner LE, Suciu-Foca N. Relevance of different antibody detection methods for the prediction of antibodymediated rejection and deceased-donor kidney allograft survival. Hum Immunol 2009;70:589

24. Gupta A, Iveson V, Varagunam M, Bodger S, Sinnott P, Thuraisingham RC. Pretransplant donor-specific antibodies in cytotoxic negative crossmatch kidney transplants: are they relevant? Transplantation 2008;85:1200.

25. Claas FH, Doxiadis II. Human leukocyte antigen antibody detection and kidney allocation within Eurotransplant. Hum Immunol 2009;70:636-9.

26. Caro-Oleas JL, Gonzales-Escribano MF, Toro-Llamas ST, Acevedo MJ, Martinez-Bravo MJ, Aguilera I, Nunez-Roldan A. Donor-specific antibody detection: comparison of single antigen assay and luminex crossmatches. Tissue Antigens 2010;76:398-403.

27. Riethmuller S, Ferrari-Lacraz S, Muller MK, Raptis DA, Hadaya K, Rusi B, Laube G, Schneiter G, Fehr T, Villard J. Donor-specific antibody levels and three generations of crossmatches to predict antibodymediated rejection in kidney transplantation. Transplantation 2010;90:160-7.

28. Lee PC, Terasaki PI, Takemoto SK, Lee PH, Hung CJ, Chen YL, Tsai A, Lei HY. All chronic rejection failures of kidney transplants were preceded by the development of HLA antibodies. Transplantation 2002;74:1192-4.

29. Terasaki PI, Ozawa M. Predicting kidney graft failure by HLA antibodies: a prospective trial. Am J Transpl 2004;4:438-43.

30. Campos EF, Tedesco-Silva H, Machado PG, Franco M, Medina-Pestana JO, Gerbae-DeLima M. Posttransplant anti-HLA class II antibodies as risk factor for late kidney allograft failure. Am J Transplant 2007;6:2316.

31. Issa N, Cosio FG, Gloor JM, Sethi S, Dean PG, Moore SB, DeGoey S, Stegall MD. Transplant glomerulopathy: risk and prognosis related to anti-human leukocyte antigen class II antibody. Transplantation 2008;86:681-5.

32. Gerbase-DeLima M, Campos EF, Tedesco-Silva H, Machado PG, Franco M, Medina-Pestana JO. AntiHLA class II antibodies and chronic allograft nephropathy. Clin Transpl 2006:201-5.

33. Langan LL, Park LP, Hughes TL, Irish A, Luxton G, Witt CS, Christiansen FT. Post-transplant HLA class II antibodies and high soluble CD30 levels are independently associated with poor kidney graft survival. Am J Transplant 2007; 7:847-56.

34. Heinemann FM, Roth I, Rebmann V, Arnold ML, Witzke O, Wilde B, Spriewald BM, Grosse-Wilde H. Immunoglobulin isotype-specific characterization of anti-human leukocyte antigen antibodies eluted from explanted renal allografts. Hum Immunol 2007;68:500-6.

35. Bocrie O, Hussein Aly AA, Guignier F, Funes de la Vega M, Rifle G, Mousson C, Martin L. Distribution of donor-specific antibodies in the cortex and the medulla of renal transplants with chronic allograft nephropathy. Transpl Immunol 2007;17:227-9.

36. Adeyi OA, Girnita AL, Howe J, Marrari M, Awadalla Y, Askar M, Martell J, Zeevi A, Shapiro R, Nalesnik $M$, Randhawa P, Demetris AJ, Duquesnoy RJ. Serum analysis after transplant nephrectomy reveals restricted antibody specificity paterns against structurally defined HLA class I mismatches. Transpl Immunol 2005;14:53-62.

37. Ahmad N, Ahmed K, Mamode N. Does nephrectomy of failed allograft influence graft survival after retransplantation? Nephrol Dial Transplant 2009;24:639-42.

38. Doxiadis II, Claas FH. Donor-specific antibodies arising after kidney transplantectomy: priming or memory? Transplantation 2006;81:509-10.

39. Snoeijs MG, Schaubel DE, Hené R, Hoitsma AJ, Idu MM, ljzermans JN, Ploeg RJ, Ringers J, Christiaans $\mathrm{MH}$, Buurman WA, van Heurn LW. Kidneys from donors after cardiac death provide survival benefit. J Am Soc Nephrol 2010;21:1015-21.

40. Marrari M, Duquesnoy RJ. Detection of donor-specific HLA antibodies before and after removal of a rejected kidney transplant. Transpl Immunol 2010;22:105-9. 
Summary 



\section{Summary}

The immune system protects the individual against pathogens and consists of different types of cells that mediate an immune response that is either non-specific innate or antigen-specific acquired. The latter, also known as the adaptive immune response, is triggered when antigen-receptors on lymphocytes recognize antigen presented in the context of MHC molecules. HLA molecules are highly polymorphic and as a consequence, they are able to bind a variety of antigens and present them to the immune system. The response that follows is cellular or humoral. Cellular responses occur when T-cells recognize foreign antigens presented by an HLA molecule on APC's. The humoral immune response is initiated by B-cells and leads to the production of antibodies against the foreign antigen.

As discussed in Chapter 1 the recognition of donor-HLA molecules by the recipient's immune system generates an immune response that in renal transplantation, may lead to allograft rejection. The relevance of compatibility for ABO and HLA in rejection has been known for decades. Most of the immunosuppressive reagents used nowadays target the cellular rejection response; humoral rejection however is still a matter of concern. In this thesis, we focus our attention on the humoral or antibody-mediated immune response in renal transplantation. Already before transplantation contact with foreign HLA molecules through blood transfusion or pregnancy may lead to the development of HLA antibodies. It is obvious that transplantation itself is a major trigger for antibody formation. There is abundant evidence that preformed HLA antibodies have a deleterious effect on renal graft outcome as reflected by increased rejection rates and lower graft survival in sensitized recipients. Several immunological procedures in the field of histocompatibility are in use to detect the presence of HLA antibodies, thereby decreasing the rejection rate and increasing graft survival. Some of these procedures are screening for HLA antibodies before transplantation, matching the HLA antigens of recipient and final donor and performance of different cross-matches before the donor-kidney is transplanted. There is a high correlation between the degree of HLA matching and sensitization. Antibodies produced after renal transplantation constitute a risk factor for acute and chronic rejection. A poor HLA match decreases the chances of finding a second crossmatch-negative donor and prolongs the waiting time for re-transplantation. Preformed cytotoxic donor-specific HLA antibodies cause hyperacute rejection, leading to loss of graft function within minutes to hours after reperfusion. CDC-crossmatches of patient sera and donor cells to identify donor-specific antibodies, are routinely performed before transplantation and hyperacute rejection has thus become a rare event in renal transplantation. To prevent positive pretransplant crossmatches, all sera from recipients on the waiting list are tested for the presence and specificity of HLA antibodies. The specificities detected in the serum are considered non-acceptable mismatches. 
Our understanding of sensitization in renal patients, the clinical relevance of HLA antibodies and the available antibody detection and crossmatching techniques have evolved considerably during the last 40 years. In Chapter 2, the different techniques for antibody detection that have been used over the years are described, with special emphasis on the recently introduced bead-based antibody detection technology. This Luminex Single antigen technique uses beads coated with purified HLA molecules, as its target for antibody detection. It is shown to be more sensitive and specific in detecting HLA antibodies than the CDC and ELISA assays. Interpretation has become an important factor in discriminating clinically relevant from clinically nonrelevant antibodies. The cut-off point for positivity of the Luminex Single antigen assay has to be defined by its user and for that reason may differ considerably between laboratories. To clarify how the results of the assay compare to those of the CDC assay, we have tested 103 HLA typing sera with well-known CDC specificities and CDC reaction strength in the Luminex Single antigen class I and II assay. For each serum the main CDC specificity and, if present, the extra specificities, were categorized according to their MFI value. Altogether $99 \%$ of all class I CDC specificities had an MFI value of 4000 or more, as did $93 \%$ of all class II CDC specificities when tested with the Luminex Single antigen assay. Based on the results, it was decided in our centre, that the cut-off point for positivity of the Luminex Single antigen assay would be $4000 \mathrm{MFI}$ for clinical transplant purposes. With this cut-off point all specificities detected by CDC are covered and considered as non-acceptable antigens for a transplant recipient.

In Chapter 3, the clinical relevance of preformed DSA detected by the Luminex Single antigen assay, is studied in a group of highly sensitized recipients transplanted in the AM program. Recipients with a sensitization of $85 \%$ or more panelreactive antibodies (PRA) are highly sensitized (HS) and have a lower chance of receiving a kidney donor. For this type of recipients, desensitization protocols have been designed with the intention to remove their HLA antibodies in order to increase their probability of finding a crossmatch-negative donor. Within Eurotransplant (ET) a special program was developed, the Acceptable Mismatch (AM) program, to facilitate renal transplantation in HS recipients. For highly sensitized recipients (current or historical sensitization $85 \%$ PRA or more), acceptable HLA mismatches, i.e. antigens to which the recipients had never made antibodies, are determined. The patients are entered on a special waiting list that gives them priority to blood-group-compatible donors that are HLA-A, -B and -DR matched with their own HLA antigens, including the AM antigens. Up till now, the standard technique for the determination of the AM antigens was based on the CDC technique, the same assay in which the pre-transplant crossmatch was performed. From 34 AM patients, 27 were transplanted with 1-5 mismatches and 7 with 0 mismatches, for all 34 patients the pre-transplant and peak sera were retested with LSA. From the mismatched patients 13 proved to possess pre-transplant DSA detected by Luminex Single antigen assay, while 14 did not. No DSA were found in the 0 mismatched group as expected. Comparison of the DSA-positive and DSA-negative 
patients in the mismatched group revealed a trend towards earlier and more frequent rejection episodes in DSA positive patients $(P=0.08)$. No detrimental effect of DSA on graft survival was observed. This single centre study showed that in the AM program, DDA detected by LSA and not by less sensitive methods, may be related to acute rejection episodes but are not detrimental to long-term graft outcome. These findings question the indiscriminate use of more sensitive screening techniques for the allocation of organs, more specifically the interpretation of the findings.

Chapter 4 describes the prevalence, time of appearance, and HLA class of DSA in a consecutive group of patients transplanted between 1995 and 1999. All 140 renal recipients had no pre-transplant DSA, at least one year of renal function and an extensive follow-up period of up to 14 years. Multiple serum samples $(n=1107)$ of all patients were tested for "de novo" DSA with the Luminex Single antigen assay. The presence of DSA after transplantation and before graft failure was shown in 224 serum samples of 35 recipients. In 17 patients DSA were shown that were present only for a short period of time and did not reappear, so-called "transient" DSA. Median fluorescence values (MFI) in the Single antigen assay differed considerably for persistent and transient DSA, the median values being 12.000 and 3.000 respectively. In multivariate analysis the presence of class II DSA after the first year post-transplant proved to be the only independent risk factor for graft failure $(O R=3.2)$. For transient DSA patients no difference was found between class I and II positivity, both had the same risk of graft failure as DSA negative recipients. From this study, we concluded that class II DSA positivity was predictive of graft failure if appearing after the first year post-transplant. The presence of "transient" DSA did not affect graft failure. Persistent DSA was shown to have four times higher MFI values; nevertheless many DSA positive patients had grafts with stable function.

In Chapter 5 the appearance of DSA was analyzed in relation to patient and graft characteristics in a group of patients who lost their graft at different time points after transplantation. Pre- and post-transplant sera of 56 CDC-negative first transplant patients were screened for HLA class I and II DSA by the Luminex Single antigen assay. Three out of 56 patients proved DSA positive before transplantation. $81 \%$ of the remaining 53 patients became DSA class I and/or II positive; $16 \%$ before and $84 \%$ after transplantectomy. Class I antibodies were produced in $84 \%$ and class II in $77 \%$ of the recipients. Based on the time of transplantectomy the recipients were divided into 3 groups: those who lost their graft (1) within one month, (2) between one and six months and (3) after more than six months. The groups proved to be significantly different for HLA class II mismatch and acute rejection. All recipients in group 2 were DSA positive. Median time of DSA appearance was four months after transplantectomy. Logistic regression analysis showed that DSA positivity for class I was related to higher donor age and donor type (non-heart-beating), class II to higher donor age and class II mismatch. Donor-directed HLA antibodies after transplantation 
were demonstrated in $81 \%$ of first transplant recipients. The majority of the antibodies were found after transplantectomy. These findings should be taken into consideration in allocating organs of marginal donors, such as older or non-heart-beating kidneys.

The major advantage of the Luminex Single antigen assay is that it allows accurate evaluation of sera containing complex mixtures of antibodies. Class I and class II antibodies are clearly discriminated. Furthermore, antibodies directed against HLA-DRB3, 4, 5, HLA-DQ and HLA-DP are discriminated from reactivity against HLA-DR, which was difficult or even impossible using the former standard techniques. HLA-DP is considered a target for the humoral immune response in clinical transplantation. In Chapter 6, the incidence, time of development and epitope-specificity of HLA-DP antibodies in renal patients are examined, Pre- and post-transplant sera of 338 patients were screened for HLA-DP antibodies using the Luminex Single antigen assay. Patients with DP antibodies, their partners and/or kidney donors were HLA-DP typed by SSO. Potential epitopes were mapped by comparing the amino acid sequences of HLA-DP hypervariable regions (HVR) A-F of recipient, partner and/or donor. Specificities in the sera were aligned to deduce the HVR motif responsible for the antibodies. DP antibodies were detected in 48 out of 338 patients (14\%). Before transplantation, $23 \%$ (10 females and one male) was found positive, $77 \%$ after transplantation (30 after the first, 7 after the second graft). Specificities were never restricted to individual mismatched antigens; broad HLA-DP sensitization was found as a rule. A single HVR mismatch was present in $80 \%$ of the DSA and in $79 \%$ of the nonDSA. Our findings confirm that HLA-DP antibodies are specific for epitopes shared by different HLA-DP antigens, indicating that only a restricted number of mismatched epitopes are recognized by the recipient's immune system. These results suggest that matching for immunogenic HLA-DP epitopes for renal transplantation is possibly more relevant than classical matching at the allelic level.

Chapter 7 reports on the Luminex Crossmatch and compares the results obtained with those from flow-cytometric crossmatches. In Luminex bead-based screening assays, color-coded microspheres coated with HLA antigens are used to identify both complement-binding and non-complement-binding HLA class I and II antibodies in recipient sera. Many laboratories rely on all specificities detected and use that information for allocation of donor organs. A donor-specific (DS) crossmatch in the Luminex technique is therefore desirable. The Luminex DS crossmatch (LumXm), in which the actual donor-HLA antigens are coated onto specific capture beads, was tested for 88 pre- and post-transplant sera of 18 recipients. The results were compared to previously published flow cytometric crossmatch (FCXm) results for the same donorrecipient combinations. All sera were also examined by the Luminex Single antigen (SA) assays. Class I LumXm detected 24/27 T-cell positive FCXm (89\%) and class II 15/22 Bcell positive FCXm (68\%). Sensitivity of LumXm for class I and II was $89 \%$ and $68 \%$ respectively, specificity $98 \%$ and $97 \%$. Discrepant LumXm results were obtained in 13 
sera of 9 patients (15\%). In general, based on LSA testing, FCXm showed false positive results for class I, LumXm gave false negative and positive results for class II. The LumXm test was proven not to react with recipient sera containing DQ antibodies only, also DP detection was insufficient. The validity of the LumXm has been shown for class I, but its value for class II is uncertain. HLA-DR is most probably correctly identified, $-D Q$ and -DP are not.

In Chapter 8, the clinical significance of the Luminex Crossmatch is evaluated over a 4-year period in a group of renal recipients, transplanted on the basis of a negative CDC crossmatch. The clinical significance of the presence of donor-specific anti-HLA antibodies prior to renal transplantation detected solely by solid-phase techniques remains unclear. A group of 165 patients transplanted between 1997 and 2001, with a negative CDC crossmatch, was tested. 32/165 recipients proved to have a positive LumXm. Sixteen were positive for class I, 15 for class II, one was both class I and II positive and 133 recipients were negative. Acute rejection-free survival for all recipients was $77 \%$, there was no difference in acute rejection-free survival between LumXm-positive and -negative recipients. Overall graft survival after a median followup time of 8 years was $56 \%$. Recipients with a positive class I LumXm had worse longterm graft survival ( $\mathrm{P}=0.006$ ), 5 -year graft survival was $41 \%$ vs. $70 \%$ in negative patients, and 10 -year graft survival was $27 \%$ vs. $56 \%$. Positivity for class II LumXm was not a significant risk factor for graft failure $(P=0.7)$, however, as stated in chapter 7 , the value of the class II crossmatch is questionable. In conclusion pre-transplant donorspecific anti-HLA antibodies detected by the LumXm, had no impact on acute rejection episodes. A positive class I LumXm resulted in worse long-term graft survival. 

157

Samenvatting 



\section{Samenvatting}

Het immuunsysteem beschermt ons tegen pathogenen en is opgebouwd uit een netwerk van cellen, die betrokken zijn bij de niet-specifieke of bij de antigeenspecifieke immuunrespons. De eerste is aangeboren, de tweede verworven. Deze laatste ook wel adaptieve immuunrespons genoemd, wordt geactiveerd als antigenen in combinatie met MHC moleculen herkend worden door antigeen-receptoren op lymfocyten. HLA moleculen zijn buitengewoon polymorf en daardoor in staat een grote verscheidenheid aan antigenen aan zich te binden en aldus te presenteren aan het immuunsysteem. De immuunrespons die daarop volgt, kan cellulair of humoraal zijn. Een cellulaire respons treedt op als lichaamsvreemde antigenen gepresenteerd worden aan T-cellen door HLA moleculen, die aanwezig zijn op APC's. De humorale respons wordt geïnitieerd door B-cellen en leidt tot de productie van antistoffen tegen het lichaamsvreemde antigeen.

In Hoofdstuk 1 wordt besproken hoe, bij niertransplantatie, de herkenning van lichaamsvreemde donor-HLA moleculen door het immuunsysteem van de ontvanger een immuunrespons opwekt, die kan leiden tot afstoting van de transplantaatnier. Het is al geruime tijd bekend dat compatibiliteit voor zowel ABO als voor HLA een belangrijke rol speelt bij het afstotingsproces na niertransplantatie. Het merendeel van de anti-afstotingsmedicatie na transplantatie is bedoeld om cellulaire afstoting te voorkomen, tegen humorale afstoting bestaat geen afdoende medicatie. Dit proefschrift gaat over de humorale of antistof-gemedieerde, immuunrespons na niertransplantatie. Contact met lichaamsvreemde HLA moleculen, door bloedtransfusie of zwangerschap, kan leiden tot de ontwikkeling van HLA antilichamen. Maar met name transplantatie brengt vaak antistofvorming op gang. $\mathrm{Er}$ is een overvloed aan bewijs voorhanden, dat laat zien dat HLA antistoffen die al aanwezig zijn vóór de transplantatie, een negatief effect hebben op de overleving van het transplantaat; ontvangers met antistoffen hebben vaker afstotingsverschijnselen en hebben een lagere transplantaatoverleving. Weefseltyperingslaboratoria gebruiken een aantal immunologische procedures om HLA antistoffen vóór en na transplantatie op te sporen, en zo de kans op afstoting te voorkomen en de transplantaatoverleving te vergroten. Zulke procedures zijn bijvoorbeeld het onderzoeken van patiëntensera op HLA antistoffen vóór transplantatie, het matchen van de HLA antigenen van donor en ontvanger en het uitvoeren van verschillende kruisproeven tussen donor en ontvanger voordat de uiteindelijke transplantatie plaatsvindt. Er bestaat een duidelijke correlatie tussen de mate van HLA match van donor en ontvanger en de kans op vorming van HLA antistoffen na transplantatie. HLA antistoffen die gevormd worden na transplantatie, vormen een risico voor het optreden van acute en chronische afstoting. Een initiële geringe HLA match verhoogt de kans op de vorming van HLA antistoffen en verlaagt daarmee de kans op het vinden van een geschikte volgende donor. Het wordt moeilijker een kruisproef-negatieve donor te vinden en dat verlengd de wachttijd voor 
retransplantatie. Cytotoxische donorspecifieke HLA antistoffen aanwezig vóór transplantatie kunnen leiden tot hyperacute afstoting en daaropvolgend verlies van transplantaatfunctie. Daarom worden CDC kruisproeven met patiëntensera en donorcellen uitgevoerd, voordat de transplantatie doorgang kan vinden. Om positieve kruisproeven te voorkomen, worden alle ontvangers op de wachtlijst getest op de aanwezigheid van HLA antistoffen. De HLA antigenen waartegen eventuele antistoffen zijn gericht worden geregistreerd als niet-acceptabele mismatches voor de patiënt.

Onze kennis over de klinische relevantie van HLA antistoffen bij nierpatiënten en de methodes voor het opsporen ervan, hebben de laatste 40 jaar een duidelijke evolutie doorgemaakt. In Hoofdstuk $\mathbf{2}$ worden de verschillende technieken, die gebruikt zijn of nog steeds gebruikt worden, beschreven. Speciale aandacht wordt besteed aan de recent geïntroduceerde Luminex techniek, waarbij beads met daaraan HLA moleculen gekoppeld, worden gebruikt om antistoffen aan te tonen. Deze techniek is gevoeliger en specifieker dan de al langer in gebruik zijnde CDC en ELISA testen. De interpretatie van de Luminex resultaten is een belangrijke factor geworden bij het onderscheid tussen klinisch relevante en irrelevante antistoffen. Een probleem is het cut-off point voor positiviteit dat gedefinieerd moet worden door de gebruiker zelf, daardoor kan variëren van het ene laboratorium tot de andere. Om de resultaten verkregen met deze techniek te vergelijken met de resultaten verkregen met de CDC techniek, werden 103 cytotoxische HLA typeersera (uitvoerig bekend in CDC), getest door middel van Luminex SA. Voor elke serum werden de belangrijkste CDC specificiteiten gerangschikt op MFI waarde verkregen met SA. De MFI waarde van $99 \%$ van alle klasse I en 93\% van de klasse II CDC specificiteiten was groter dan 4000. Daarom werd in ons transplantatiecentrum de cut-off voor positiviteit vastgelegd op $4000 \mathrm{MFI}$.

In Hoofdstuk 3 wordt de klinische relevantie van donorspecifieke antistoffen voor transplantatie, die alleen aantoonbaar zijn met Luminex SA, onderzocht bij patiënten getransplanteerd in het AM programma. Binnen Eurotransplant werd het AM programma ontwikkeld om de transplantatiekans van deze hooggeïmmuniseerde patiënten te vergroten. Ontvangers met een huidige of historische PRA hoger dan 85\% worden met hun zogenoemde acceptabele mismatches, dit zijn HLA antigenen waartegen de ontvanger nooit antistoffen heeft gevormd, op een speciale wachtlijst gezet. Wanneer een ABO compatibele donor, waarvan de HLA-A, -B en -DR antigenen overeenkomen met hun eigen en/of $A M$ antigenen, beschikbaar is, krijgen de $A M$ patienten voorrang bij de allocatie van die donor. Tot nu toe was de CDC, die ook gebruikt wordt voor de pretransplantatie kruisproeven, de standaard techniek voor het bepalen van AM antigenen. Van de in totaal 34 patiënten getransplanteerd binnen het AM programma in Maastricht, werden er 27 getransplanteerd met 1 tot 5 en 7 met 0 mismatches. Het pretransplantatie serum en historisch piekserum van deze patiënten werden hertest met Luminex SA. Van de 27 patiënten die getransplanteerd werden met 1-5 mismatches, werden bij 13 patienten DSA gevonden en bij 14 niet. 
Zoals verwacht werden er geen DSA gevonden bij de patiënten die getransplanteerd waren zonder mismatch. In de gemismatchte groep hadden de patiënten met DSA een trend tot vroegere en frequentere afstotingsverschijnselen ( $P=0.08)$. DSA bleek echter geen nadelig effect te hebben op transplantaatoverleving. Uit deze studie blijkt dat bij patienten in het AM programma, DSA gedetecteerd met Luminex SA en niet met minder gevoelige technieken, gerelateerd zouden kunnen zijn aan afstotingsverschijnselen, maar dat zij de lange termijn transplantaatoverleving niet beïnvloeden. Deze bevindingen stellen vraagtekens bij onbedachtzaam gebruik van gevoelige screeningsmethodes en de interpretatie ervan bij orgaanallocatie.

Hoofdstuk 4 beschrijft het vóórkomen van DSA, het tijdstip van verschijnen en de HLA klasse ervan in een groep van 140 patiënten getransplanteerd in Maastricht tussen 1995 en 1999. De 140 ontvangers hadden geen HLA antistoffen vóór transplantatie, hun nier functioneerde tenminste 1 jaar en de follow-up tijd bedroeg tot 14 jaar. Meerdere sera ( $n=1107$ ) van de patiënten werden getest op de ontwikkeling van "de novo" (nieuwgevormde) DSA met behulp van Luminex SA. De aanwezigheid van DSA na transplantatie en voor transplantaatfalen werd aangetoond in 224 sera van 35 patiënten. In 17 van deze patiënten was het DSA slechts korte tijd aantoonbaar ("transient" DSA). De MFI values van transient DSA waren aanzienlijk lager (3000 MFI) dan die van persisterende DSA (12000 MFI). Multivariaat analyse toonde aan dat de aanwezigheid van klasse II DSA na het eerste jaar posttransplantatie, de enige onafhankelijke risicofactor was voor falen van het transplantaat $(O R=3.2)$. Patiënten met transient klasse I of klasse II DSA hadden een risico op transplantaatfalen vergelijkbaar met dat van patiënten zonder DSA. Uit deze studie concludeerden wij, dat klasse II DSA, ontstaan of reeds aanwezig na het eerste jaar posttransplantatie, voorspellend zijn voor transplantaatfalen. De aanwezigheid van transient DSA had geen invloed op falen. De MFI waardes van persisterend DSA waren 4 maal hoger dan die van transient DSA, maar desondanks hadden veel patiënten een stabiele transplantaatfunctie in aanwezigheid van DSA.

In Hoofdstuk $\mathbf{5}$ wordt het verschijnen van DSA geanalyseerd aan de hand van patiënten transplantaatkenmerken in een groep patiënten, die een transplantectomie ondergingen. Pre- en posttransplantatie sera van 56 patiënten, die een eerste nier ontvingen en geen CDC detecteerbare antistoffen hadden, werden opnieuw getest met Luminex SA. Drie van hen toonden DSA voor transplantatie, 43 patiënten ontwikkelden DSA na transplantatie. Van de 43 DSA positieve patiënten werden de DSA in $16 \%$ voor en in $84 \%$ na transplantectomie gevonden. Klasse I HLA antistoffen waren aanwezig in $84 \%$ en klasse II HLA antistoffen in $77 \%$. De ontvangers werden onderverdeeld in 3 groepen op basis van het tijdstip waarop ze hun transplantectomie ondergingen: binnen 1 maand na transplantatie (1), tussen 1 en 6 maanden (2) en na meer dan 6 maanden (3). De 3 groepen verschilden significant wat betreft HLA klasse II mismatch en acute afstoting. Bij alle ontvangers in groep 2 werden DSA gevonden. DSA 
verschenen gemiddeld vier maanden na transplantectomie. Uit logistische regressie analyse bleek dat positiviteit voor klasse I gerelateerd was aan hogere donorleeftijd en donortype (NHB), en positiviteit voor klasse II aan hogere donorleeftijd en klasse II mismatch. DSA na transplantatie werden gedetecteerd bij $81 \%$ van de ontvangers van een eerste nier. Het merendeel van de antistoffen werd pas aangetoond na transplantectomie. Met deze bevindingen zou rekening gehouden moeten worden bij de allocatie van nieren van marginale donoren, zoals oudere donoren en NHB donoren.

Het belangrijkste voordeel van Luminex SA is, dat het een nauwkeurige evaluatie toelaat van sera, die een complex mengsel van antistoffen bevatten. Klasse I en klasse II antistoffen kunnen duidelijk van elkaar onderscheiden worden. Zelfs antistoffen gericht tegen HLA-DRB3,4,5, HLA-DQ en HLA-DP kunnen onderscheiden worden van antistoffen gericht tegen HLA-DR, iets wat voorheen met de standaard technieken op zijn minst moeilijk zoniet onmogelijk was. Ook HLA-DP is een mogelijk doelwit voor de humorale immuunrespons bij klinische transplantatie. In Hoofdstuk 6 worden de incidentie, het tijdstip van verschijnen en de epitoop-specificiteit van HLA-DP antistoffen bij nierpatiënten onderzocht. Pre- en posttransplantatie sera van 338 patiënten werden getest op de aanwezigheid van antistoffen gericht tegen HLA-DP met behulp van SA. Patiënten met DP antistoffen werden getypeerd voor HLA-DP met behulp van SSO, evenals hun partners en/of nierdonoren. De aminozuursequenties van de HVR A-F van HLA-DP van patiënt, partner en/of donor werden met elkaar vergeleken om potentiële epitopen voor antistofvorming te bepalen. De in sera gevonden HLA-DP specificiteiten werden vergeleken om de HVR verantwoordelijk voor de antistofvorming af te leiden. 48 van de 338 (14\%) patiënten hadden DP antistoffen, $23 \%$ van de antistoffen werd gevonden voor transplantatie, $77 \%$ erna. De gevonden specificiteiten waren nooit uitsluitend gericht tegen de gemismatchte DP antigenen. $80 \%$ van de DSA en $79 \%$ van de NDSA werden veroorzaakt door 1 enkele HVR mismatch. Dit lijkt erop te wijzen dat slechts een beperkt aantal van de gemismatchte epitopen herkend worden door het immuunsysteem van de ontvanger. Deze resultaten tonen aan dat bij niertransplantatie, matchen voor immunogene HLA-DP epitopen, mogelijk relevanter is dan klassiek matchen op allel niveau.

Hoofdstuk 7 beschrijft de Luminex kruisproef en de resultaten ervan worden vergeleken met die verkregen met behulp van flow cytometrische kruisproeven. De Luminex techniek maakt gebruik van kleurgecodeerde microbeads met daarop HLA antigenen gehecht, om complement-bindende en niet-complement-bindende HLA klasse I en II antistoffen aan te tonen in patiëntensera. Veel laboratoria gebruiken deze techniek om sera te screenen en houden rekening met de verkregen informatie bij de allocatie van donornieren. Een kruisproef in dezelfde techniek is daarom wenselijk. De LumXm, waarbij de HLA antigenen van de donor aan beads gekoppeld worden, werd getest met behulp van 88 pre- en posttransplantatiesera van 18 patiënten. De 
resultaten werden vergeleken met resultaten van flow cytometrische kruisproeven uitgevoerd met dezelfde patiëntensera en donorcellen. De sera werden eveneens getest met SA. Een positieve klasse I LumXm werd gevonden bij 24 van de 27 (89\%) T-cel positieve FCXm en een positieve klasse II LumXm bij 15 van de 22 (68\%) B-cel positieve FcXm. De sensitiviteit van de LumXm bedroeg $89 \%$ voor klasse I en $68 \%$ voor klasse II, de specificiteit voor klasse I was 98\% en voor klasse II 97\%. In 13 sera (15\%) van 9 patiënten werd een discrepantie tussen de FCXm en LumXm resultaten gevonden. Wanneer de SA screeningsresultaten van de sera erbij betrokken werden, kon geconcludeerd worden dat de FcXm vals positieve resultaten opleverde voor klasse I en de LumXm vals negatieve en vals positieve resultaten voor klasse II. De LumXm toonde geen HLA-DQ antistoffen aan en ook de detectie van HLA-DP antistoffen was onvoldoende. Samenvattend waren de resultaten van de klasse I LumXm bevredigend, maar die van de klasse II LumXm twijfelachtig; antistoffen tegen HLA-DR werden aangetoond, antistoffen tegen HLA-DQ en -DP niet.

In Hoofdstuk 8 wordt de klinische relevantie van de LumXm geëvalueerd in een groep nierpatiënten getransplanteerd met een negatieve CDC kruisproef over een periode van 4 jaar. De klinische betekenis van pretransplantatie DSA, die alleen aantoonbaar is met behulp van gevoelige solid-phase technieken is nog steeds onduidelijk. De pretransplantatiesera van 165 patiënten getransplanteerd op basis van een negatieve CDC kruisproef tussen 1997 en 2001, werden getest met de LumXm. 32 van de 165 patiënten hadden een positive LumXm; 16 klasse I, 15 klasse II en een klasse I en II. 133 patienten hadden een negatieve LumXm. Acute rejectie-vrije overleving in de hele groep was $77 \%$, er was geen verschil tussen patiënten met een positieve of negatieve LumXm. De transplantaatoverleving bedroeg 56\% na 8 jaar (mediaan). Patiënten met een positieve klasse I LumXm hadden een slechtere transplantaatoverleving $(P=0.006)$; de 5-jaars transplantaatoverleving in patiënten met een positive klasse I LumXm bedroeg $41 \%$, die in patiënten met een negatieve klasse II LumXm 70\%. De 10-jaars transplantaatoverleving bedroeg 27 versus 56\%. Een positieve klasse II LumXm leek geen risicofactor voor transplantaatfalen $(P=0.7)$, hierbij dient echter rekening gehouden te worden met het feit dat de waarde van de klasse II LumXm twijfelachtig is. DSA aanwezig voor transplantatie, en alleen aantoonbaar met LumXm, hebben geen invloed op afstoting. Een positieve klasse I LumXm resulteert in een slechtere lange termijn transplantaatoverleving. 

Abbreviations 



\section{Abbreviations}

\begin{tabular}{|c|c|}
\hline AHG & anti-human globulin \\
\hline AM & acceptable mismatch (es) \\
\hline APC & antigen-presenting cell \\
\hline AR & acute rejection \\
\hline ATG & anti-thymocyte globulin \\
\hline AZA & azathioprine \\
\hline B1 & immature B-cell \\
\hline B2 & mature B-cell \\
\hline $\mathrm{B}_{2} \mathrm{~m}$ & $\mathrm{~B}_{2}$ microglobulin \\
\hline BCR & B-cell receptor \\
\hline$C D$ & cluster of differentiation \\
\hline $\mathrm{CDC}$ & complement-dependent cytotoxicity \\
\hline $\mathrm{Cl}$ & confidence interval \\
\hline CIT & cold ischemia time \\
\hline $\mathrm{CNI}$ & calcineurine inhibitors \\
\hline DCB & donation after cardiac death \\
\hline DDA & donor-directed antibody \\
\hline DGF & delayed graft function \\
\hline DNA & deoxyribonucleic acid \\
\hline DSA & donor-specific antibody \\
\hline DTT & dithiotreitol \\
\hline EBV & Epstein-Barr virus \\
\hline $\mathrm{EFI}$ & European Federation for Immunogenetics \\
\hline ELISA & enzyme-linked immunosorbent assay \\
\hline ESDP & Eurotransplant Senior DR-compatible program \\
\hline ESP & Eurotransplant Senior program \\
\hline ET & Eurotransplant \\
\hline FITC & fluorescein isothiocyanate \\
\hline HB & heart-beating \\
\hline HLA & human leukocyte antigen \\
\hline HS & highly sensitized \\
\hline HVR & hypervariable region \\
\hline $\lg$ & immunoglobulin \\
\hline IL2 & interleukine-2 \\
\hline LSA & Luminex Single antigen assay \\
\hline MESF & molecules of equivalent soluble fluorophores \\
\hline MFI & median fluorescence intensity \\
\hline $\mathrm{MHC}$ & major histocompatibility complex \\
\hline MICA & MHC class I chain-related molecules \\
\hline MMF & mycophenolate mofetil \\
\hline
\end{tabular}




$\begin{array}{ll}\text { NAM } & \text { non-acceptable mismatch (es) } \\ \text { NDSA } & \text { non-DSA } \\ \text { NHB } & \text { non-heart-beating } \\ \text { NIH } & \text { National Institute of Health } \\ \text { NK } & \text { natural killer } \\ \text { OR } & \text { odds ratio } \\ \text { PBL } & \text { peripheral blood lymphocyte } \\ \text { PCR } & \text { polymerase chain reaction } \\ \text { PE } & \text { phyco-erythrin } \\ \text { PRA } & \text { panel reactive antibody } \\ \text { PRED } & \text { prednisone } \\ \text { RAPA } & \text { rapamycine } \\ \text { RT } & \text { room temperature } \\ \text { SAPE } & \text { phyco-erythrin-conjugated streptavidin } \\ \text { SBT } & \text { sequence based typing } \\ \text { SSOP } & \text { sequence specific oligonucleotide probes } \\ \text { SSP } & \text { sequence specific primers } \\ \text { TCR } & \text { T-cell receptor } \\ \text { TX } & \text { renal transplantation } \\ \text { Xm } & \text { crossmatch }\end{array}$


Dankwoord 



\section{Dankwoord}

Promoveren doe je niet alleen. Vele mensen hebben me bij mij promotieonderzoek met raad en daad bijgestaan. Op deze plaats wil ik iedereen die direct of indirect zijn steentje heeft bijgedragen aan de totstandkoming van dit boekje bedanken, een aantal mensen in het bijzonder.

Allereerst mijn promotor, Prof. dr. Ella van den Berg-Loonen. Beste Ella, jij hebt een nieuwe wending aan mijn loopbaan en leven gegeven door me in 2007 voor te stellen samen een promotieonderzoek te starten. Het is bewonderenswaardig dat je dit project hebt aangevat na je carrière bij de afdeling Weefseltypering. Bedankt voor de vele uren die we bij jou thuis, met vers gebak binnen handbereik, samen met Maarten hebben doorgebracht. Ik apprecieer je efficiënte manier van werken enorm en na onze overlegmomenten had ik telkens weer frisse moed om er tegen aan te gaan. Ik sta nog steeds versteld van hoe snel je mijn versie van een manuscript leesbaarder en helderder wist te maken. Jouw toewijding voor en kennis van de transplantatieimmunologie waren een bron van motivatie en inspiratie voor mij. Ik zal je nooit genoeg kunnen bedanken voor alles wat je voor me gedaan hebt.

Mijn co-promotor, Dr. Maarten Christiaans. Maarten, steeds weer vond je ondanks je overvolle agenda tijd voor me. Al had je honderd en één andere dingen aan je hoofd, steeds gaf je me het gevoel dat mijn onderzoek het belangrijkste was. Je schijnbaar onuitputtelijk bron van enthousiasme en energie werkte aanstekelijk. Je bent niet alleen een goede nefroloog maar hebt ook nog eens een bewonderenswaardige kennis van statistiek en weefseltypering. Zonder jouw inzet, oog voor detail en onvoorwaardelijke steun was dit proefschrift er niet geweest. Hartelijk dank voor alles.

Vervolgens gaat mijn dank uit naar de leden van de beoordelingscommissie, Prof. dr. J.P. van Hooff (voorzitter), Prof. dr. C.A. Bruggeman, Prof. dr. I.I.N. Doxiadis, Dr. M. Emonds en Prof. dr. L.W.E. van Heurn, voor hun bereidwilligheid mijn manuscript te beoordelen.

Van de afdeling weefseltypering (transplantatie-immunologie) wil ik het secretariaat bedanken. Diana, voor alle hulp bij de lay-out en inzending van manuscripten, en Mieke, voor het nauwkeurig voorbereiden van afspraken en congressen, het inschrijven van literatuur in endnote en het opzoeken van patiëntenstatussen. Het afdelingshoofd, Prof. dr. Marcel Tilanus, die in de afrondingsfase mijn tweede promotor is geworden, wil ik bedanken voor zijn bijdrage aan de voorbereiding op de verdediging. Alle (oud-)collega's wil ik bedanken voor de gezellige momenten en prettige samenwerking. In het bijzonder Christel, die in de loop der jaren een vriendin geworden is en me door heel wat moeilijke momenten geholpen heeft. 
Van de afdeling Nefrologie, wil ik de secretaresses Anke en Etienne, en Monique, de onderzoeksassistente, bedanken voor het zoeken en doornemen van groene lijsten en het uiterst nauwkeurig vervolledigen van patiëntengegevens. En uiteraard Tiny, voor het verzorgen van de lay-out van dit boekje. Zonder jouw toewijding, oog voor detail en goede raad was dit boekje nooit zo mooi geworden.

Mijn familie, vrienden en kennissen, bedankt voor jullie belangstelling de afgelopen jaren. In het bijzonder mijn zus Pascale, die mij op mijn grote dag bijstaat als paranimf. En mijn ouders, aan wie ik dit proefschrift opdraag. Zonder jullie betrokkenheid, steun, vertrouwen en liefde zou ik mijn ambities niet hebben kunnen waarmaken. 
Curriculum Vitae 



\section{Curriculum Vitae}

Evy Veronicque Anne-Marie Billen was born on January 7, 1980 in Hasselt. After she finished secondary school (Humaniora Virga Jesse, Hasselt) in 1998, she studied Biology at the University of Hasselt for one year. Subsequently, she continued with biomedical sciences at the faculty of Medicine of the Universities of Hasselt and Leuven and graduated in 2003 . Her study was completed with a training period at the Centre of Fertility of the University hospital in Leuven, where she investigated prostate-specific antigen in sperm. After graduation she worked as a senior research technician at the Tissue Typing Laboratory of the University Hospital Maastricht. In October 2007 she started her PhD project under the supervision of Prof. dr. P.M. van den Berg-Loonen and Dr. M.H.L. Christiaans, later joined by Prof. dr. M. Tilanus. The study focused on the presence and detection of HLA antibodies and their relevance for patients undergoing kidney transplantation. The results are described in this thesis. 